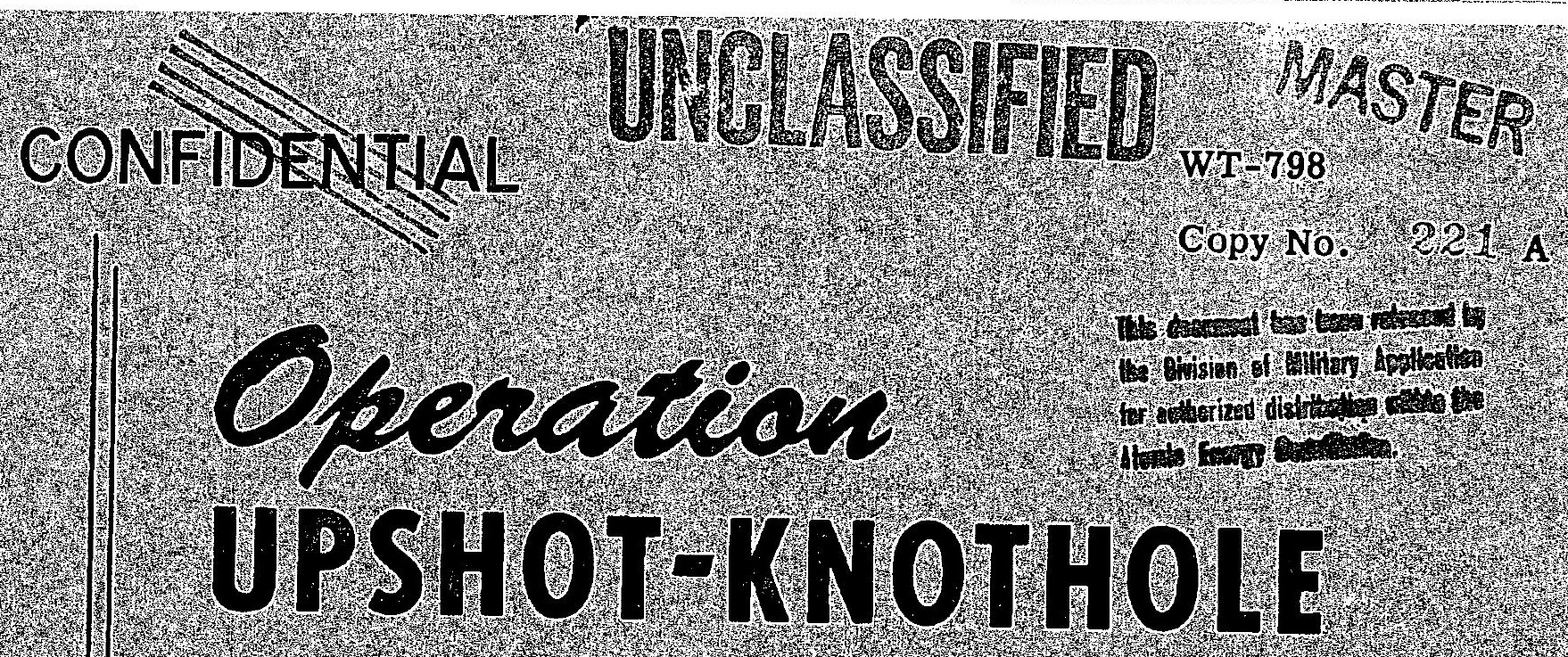

NEVADA PROVING GROUNDS

March - une 1953

Project 23.15

Part $I$

EFFECTS OF OVERPRESSURES IN GROUP SHEUTERS ON ANMAIS AND DUMMMES

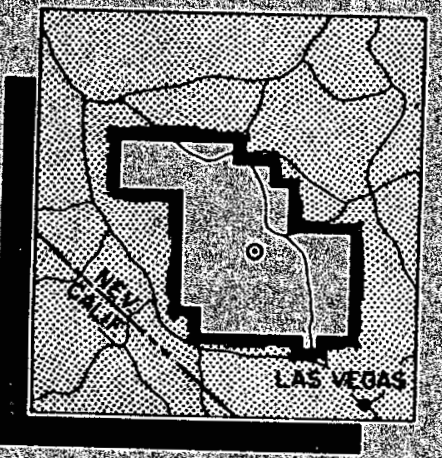

RESTRICTED DATA

Thisdocument $\mathrm{s}$, 1 h restricted data as defined in the Atom thergy Act of 1946 .

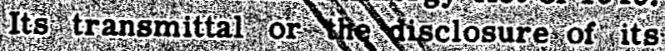

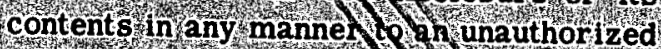
person is prohibited

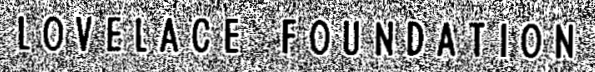

ALBUOUEROUE NEWM EXYGO

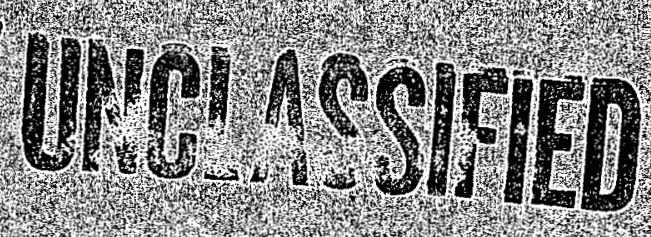




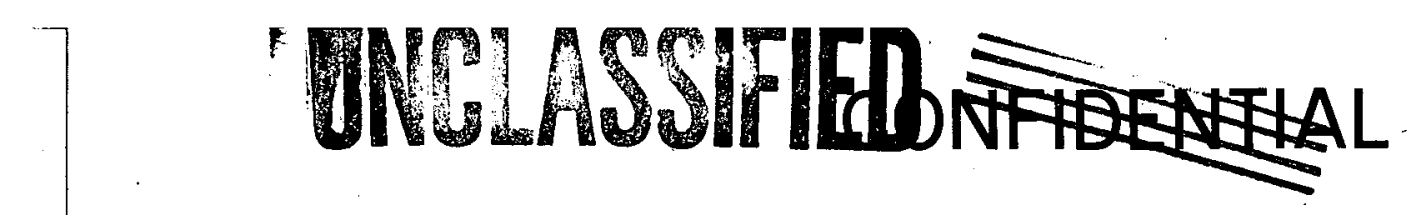

WT-798

t.

Report to the Test Director
This document consists of 70 pages

No. 221 of 305 copies, Series A

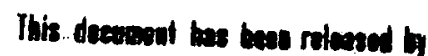
the Oivision of Iilition Inthation in autherized distrilution witum in

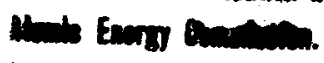

\section{EFFECTS OF OVERPRESSURES IN GROUP SHELTERS ON ANIMALS AND DUMMIES}

By

J. E. Roberts, C. S. White, and T. L. Chiffelle

Mo. 4030

Technical Associates

W. H. Lockyear, J. P. Henry, M. A. Palmer; J. Clark, and W. A. Russell

Approved by: E. P. CRONKITE, CDR (MC) USN Director, Program 23
Approved by: ROBERT L. CORSBIE

Director

Civil Effects Test Group

Lovelace Foundation Albuquerque, New Mexico September 1953
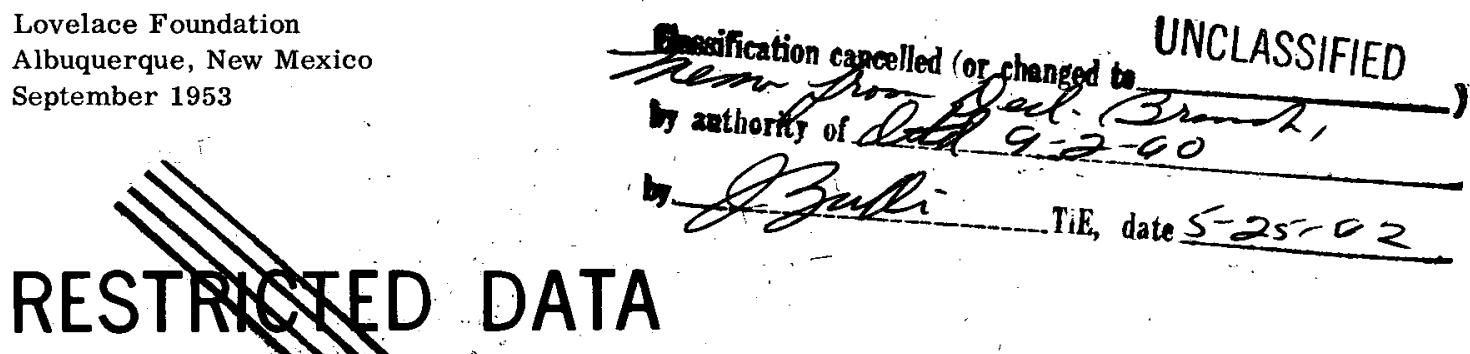

This document contain.

fined in the Atomic Energx Act of 1946. Its transmittal or the disclosure of its contents in any manner to an unauthorized person is prot.
hibited.

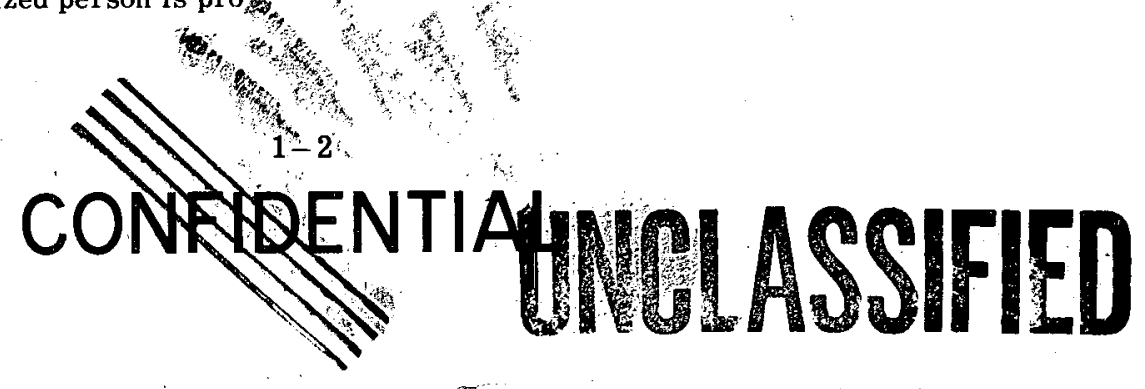




\section{DISCLAIMER}

This report was prepared as an account of work sponsored by an agency of the United States Government. Neither the United States Government nor any agency Thereof, nor any of their employees, makes any warranty, express or implied, or assumes any legal liability or responsibility for the accuracy, completeness, or usefulness of any information, apparatus, product, or process disclosed, or represents that its use would not infringe privately owned rights. Reference herein to any specific commercial product, process, or service by trade name, trademark, manufacturer, or otherwise does not necessarily constitute or imply its endorsement, recommendation, or favoring by the United States Government or any agency thereof. The views and opinions of authors expressed herein do not necessarily state or reflect those of the United States Government or any agency thereof. 


\section{DISCLAIMER}

Portions of this document may be illegible in electronic image products. Images are produced from the best available original document. 


\section{ABSTRACT}

Relative biological hazards of blast were studied in two types of communal air-raid shelters during Shots 1 and 8 (Nevada Proving Grounds, 1953). Dogs, restrained within the shelters during detonation, were studied pathologically and clinically for blast injuries. Two anthropometric dummies were test objects for displacement studies utilizing high-speed photography. Physical data included pressure vs time and air-drag determinations.

During Shot 1 animals sustained marked blast damages (hemorrhages in lungs and abdominal organs), three dogs were ataxic, and the dummies were rather violently displaced. In Shot 8 , however, no significant injuries were found in the animals, and the dummies were minimally displaced.

Analysis of the physical data indicated that blast injuries and violent displacements may occur at much lower static overpressures than previously assumed from conventional explosion data. Furthermore, biological damage appeared to be related to the rate of rise of the overpressure and air drag, as well as the maximum overpressure values. These phases of the problem should be defined by further investigation.

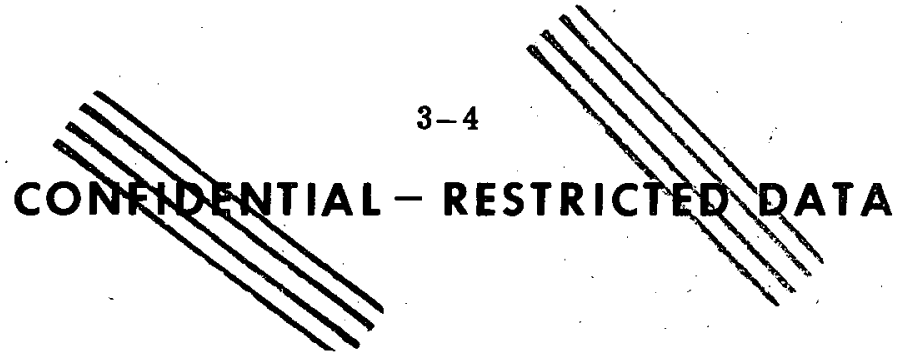




\section{ACKNOWLEDGMENTS}

The authors wish to express sincere appreciation to the following individuals for their exceptional cooperation in behalf of the prosecution of this project:

CDR E. P. Cronkite, Naval Medical Research Institute, Director of Program 23

R. L. Corsbie, Atomic Energy Commission, Director of Civil Effects Test Group Lt Col J. W. Bailey, Sandia Base

R. W. Newman, Los Alamos Scientific Laboratory

Dr. B. F. Murphey, Sandia Corporation

Dr. W. T. S. Thorp, National Institutes of Health

Dr. P. G. LeFevre, Atomic Energy Commission

Dr. F. G. Hirsch, Sandia Corporation

W. A. Osburn, Lovelace Foundation

Dr. L. M. Overton, Lovelace Clinic

Dr. J. G. Riley, Lovelace Clinic

Miss F. Sherping, Lovelace Foundation 



\section{CONTENTS}

ABSTRACT

ACKNOWLEDGMENTS

CHAPTER 1 INTRODUCTION

1.1 Background of Shelter Design . . . . . . . . . . . 11

1.2 Objectives of This Project.

1.3 Summary of the Experimental Design

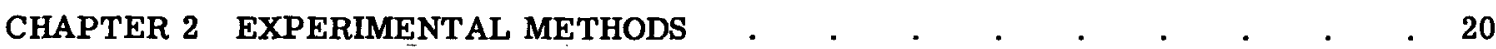

2.1 Methods and Instrumentation for Physical Data . . . . . . . . . . $\quad$. 20

2.1.1 Pressure Vs Time Measurements (Shots 1 and 8) . . . . . 20

2.1.2. Instrumentation for Drag, Accelerations of Dummy and

Photography During Shot 1

2.1.4 Instrumentation for Shot 8

2.1.5 General Operation of the System During Shot $8 \quad \cdots$

2.2 Animal Positioning and Restraining Techniques. $\quad . \quad$. $\quad . \quad$. $\quad . \quad$. $\quad .23$

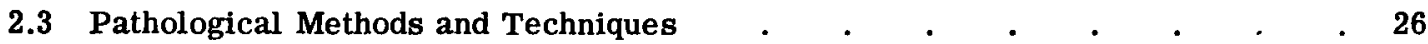

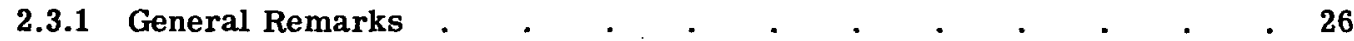

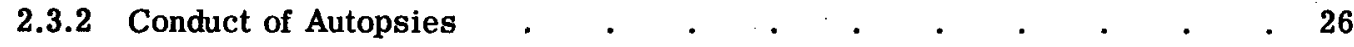

2.3.3 Photography and Pathological Specimens _ . . . . . . . . . 27

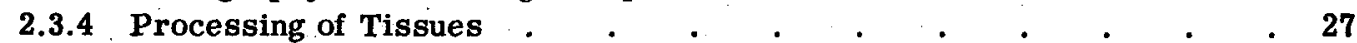

2.3.5 Selection of Tissues and Principal Stains Used _. . . . . . $\quad$ - 28

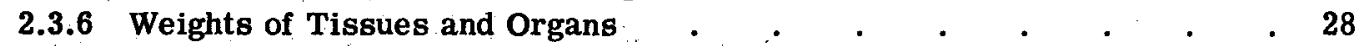

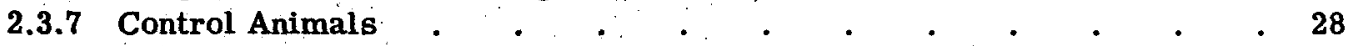

2.4 Clinical Methods (Shot 8) . . . . . . . . . . . . . . . . . . . $\quad . \quad 28$

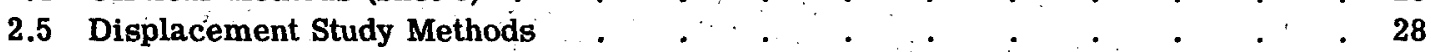

2.6 Plan and Methods for Supplementary Experiment (Shot 11) . . . . . . $\quad$. 31

CHAPTER 3 RESULTS

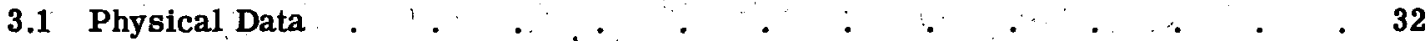

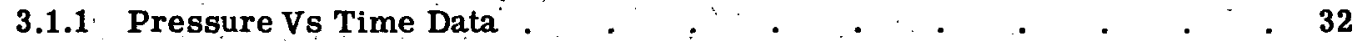

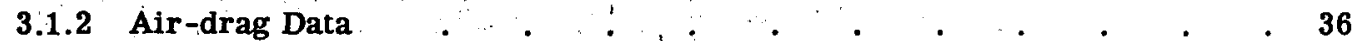

3.1.3 Peak Pressures and Pressure Vs Time for Shot $11 \quad$. . . . . $\quad 36$

3.2 Clinical Data

3.2.1 Clinical Data from Shot 1 Animals . . . . . . . . . . 38

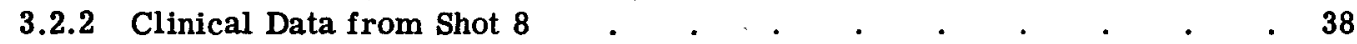

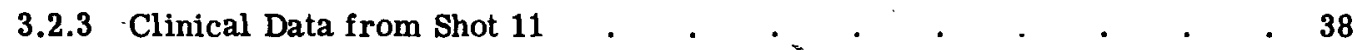

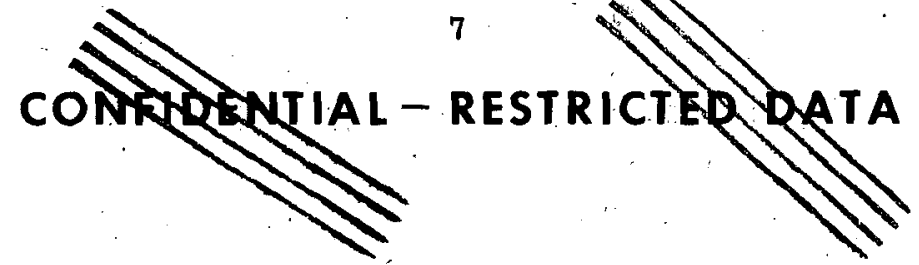


3.3 Pathological Data _. . . . . . . . 40

3.3.1 Control Animals, Findings . . . . . . . . . . . . . 40

3.3.2 Experimental Animals from Shot 1 . . . . . . . . . . . 40

3.3.3 Experimental Animals from Shot 8 . . . . . . . . . . . . 43

3.3.4 Experimental Animals from Shot $11 \quad$. . . . . . . . . . . 43

3.4 Displacement Data . . . . . . . . . . . . 52

3.4.1 Displacement Data for Dummies, Shot 1 . . . . . . . . 52

3.4.2 Displacement Data for Dummies, Shot 8 . . . . . . . $\quad$. 52

3.4.3 Displacement of Suspended Dog (Shelter 602, Shot 8) . . . . . 53

3.4.4 Accelerometer Data . . . . . . . . . . . . . $\quad$. 54

CHAPTER 4 ANALYSIS AND DISCUSSION OF RESULTS $\quad$ • $\quad$ • . . . . $\quad$ • 55

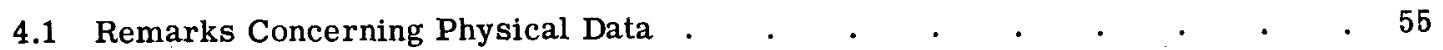

4.1.1 Pressure Vs Time Phenomena . . . . . . . . . . . 55

4.1.2 Remarks Concerning Drag Data . • . . . . . . . . 55

4.2 Correlation of Biological Findings with Physical Data . . . . . . $\quad$. 56

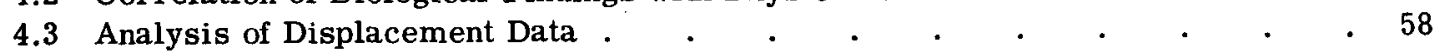

CHAPTER 5 CONCLUSIONS

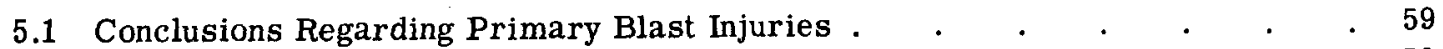

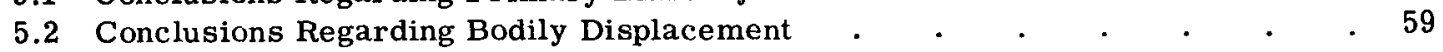

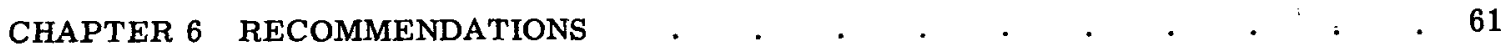

APPENDIX A LIST OF STRUCTURES EXAMINED AT AUTOPSY . . . . . $\quad$. 63

APPENDIX B CALCULATION SCHEME FOR GAMMA ATTENUATION . . . . $\quad 64$

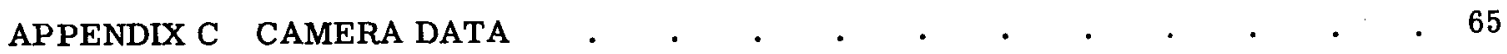

\section{ILLUSTRATIONS}

\section{CHAPTER 1 INTRODUCTION}

1.1 Plan View of Objects Used in Shelter 601 During Shot 1 (Mar. 17, 1953) $\quad$. 12

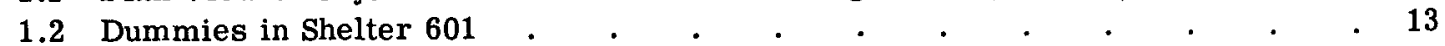

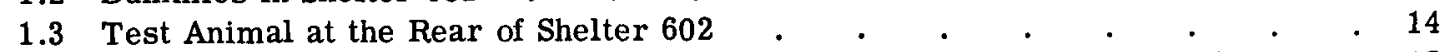

1.4 Plan View of Objects Used in Shelter 602 During Shot 1 (Mar. 17, 1953) . $\quad 15$

1.5 Plan View of Objects Used in Shelter 601 During Shot 8 (May 19, 1953) . $\quad$. 17

1.6 Plan View of Objects Used in Shelter 602 During Shot 8 (May 19, 1953) $\quad . \quad$. 18

\section{CHAPTER 2 EXPERIMENTAL METHODS}

2.1 General Structure and Dimensions of the Drag Gauges (Sandia Corporation)

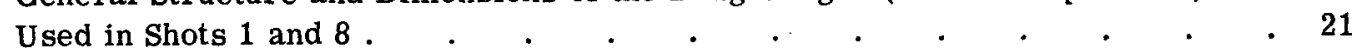

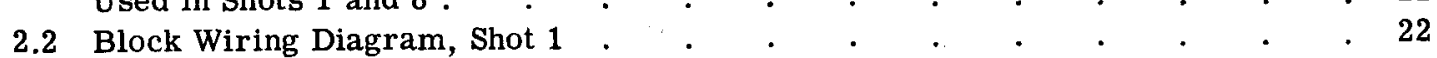

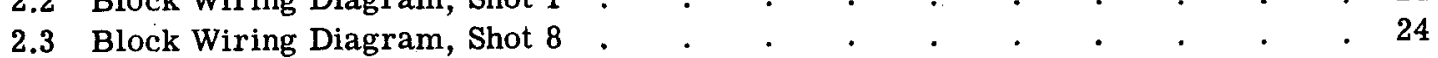
2.4 Harness Used to Restrain Dogs, Showing General Design and
Construction Method . . . . . . . . . . .

8

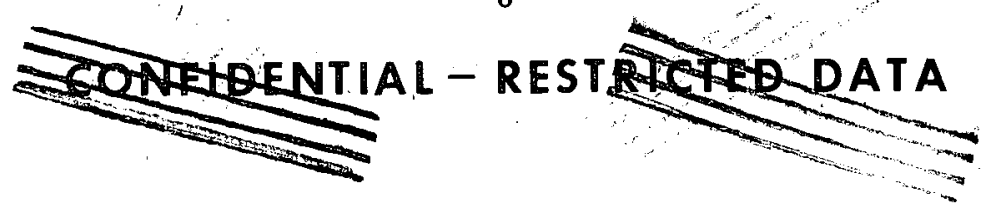




\section{ILLUSTRATIONS (Continued)}

2.5 Animals Shown in Position Prior to Shot 11 (C-1, C-2, C-3, and C-4 from Left to Right)

\section{CHAPTER 3 RESULTS}

3.1 Pressure Vs Time Curves, Shots 1 and 8, Gauge P-3, Entrance 601 Shelter Proper . . . . . . . . . . . . . 33

3.2 Pressure Vs Time Curves, Shots 1 and 8, Gauge P-11, Entrance 602 Shelter Proper . . . . . . . . . . . . . 33

3.3 Air Drag Vs Time Curves for Shelter 601, Shot 1 (Mar. 17, 1953), and for Shelters 601 and 602, Shot 8 (May 19, 1953) . . . . . . . 37

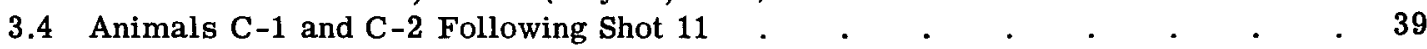

3.5 Anterior View of Lungs and Heart of Animal D-10 (Position 602-7). . . 44

3.6 Posterior View of Lungs and Heart of Animal D-10 (Position 602-7) . . . . 45

3.7 Cross Section of Fixed Right Lung of Animal D-14 . . . . . . . . . . $\quad . \quad 46$

3.8 Lung (Microscopic), Hemorrhagíc Areas . . . . . . . . . . . . $\quad .47$

3.9 Lung (Microscopic), Bronchial Blood _. . . . . . . . . . . $\quad .48$

3.10 Mesentery (Gross), Showing Hemorrhages (Animal D-4, Position 601-7) . . 49

3.11 Spleen (Gross and Microscopic), Hemorrhages at Poles (Animal D-5, Position 602-2). . . . . . . . . . . . . 50

3.12 Bladder Lesion (Gross and Microscopic) (Animal D-11, Position 601-6) . . 51

3.13 Displacement Vs Time Graph of Standing Dummy (Structure 601, Shot 1) . $\quad$. 52

3.14 Displacement Vs Time Graph of Suspended Dog and Tag (Structure 602, Shot 8)

\section{TABLES}

\section{CHAPTER 3 RESULTS}

3.1 Analysis of Pressure Vs Time Data for Shot 1 . . . . . . . . . . . . 34

3.2 Analysis of Pressure Vs Time Data for Shot 8 . . . . . . . . . . . 35

3.3 Analysis of Pressure Vs Time Data for Shot 11. . . . . . . . . . . . 36

3.4 Time and Order of Autopsies Following Shot 1 . . . . . . . . . . . 38

3.5 Distribution of Lesions in Various Organs (Gross and Microscopic) . . . . . 41

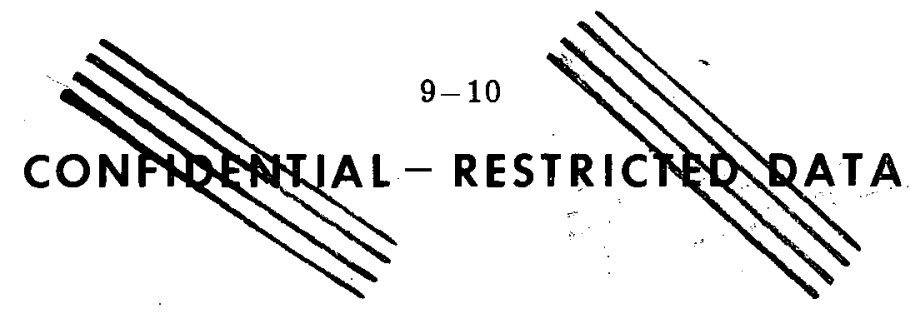




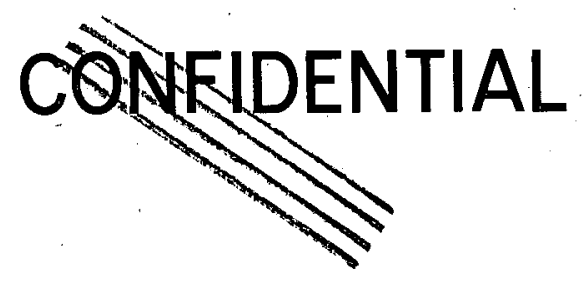

CHAPTER 1

\section{INTRODUCTION}

\subsection{BACKGROUND OF SHELTER DESIGN}

An orientation to the work reported herein may be facilitated by indicating briefly the background of design used for the two communal air-raid shelters tested at the Nevada Proving Grounds (NPG) during the 1953 series. Robert L. Corsbie, Director of Civil Effects Test Group, executed the design for such structures which would fulfill the following criteria: (1) a relatively high degree of safety afforded shelter occupants, with respect to effects from nuclear weapons, (2) the construction requirements should be simple as well as feasible, (3) materials used should be readily available and transportable, and (4) the total cost should be kept as low as possible.

The basic design was resolved into a structure which is shown in plan view in Fig. 1.1 (hereafter referred to as Structure or Shelter 601). An open ramp leads downward into a roofed entraniceway, which in turn opens at a right angle into a blast trap. These components of the structure were poured concrete. Opening at a right angle to the blast trap is the shelter proper, which was constructed or prefabricated reinforced concrete culvert pipe sections, 90 in. I. D., with poured concrete floor. This shelter design made it possible to locate seating benches along either side of the shelter proper (see Fig. 1.2). An emergency escape hatch and ventilation duct were provided in the rear of the shelter (background of Fig. 1.3). This is shown as the rectangular projection in Fig. 1.1 containing the air inlet valve.

In anticipation of possible blast hazards, a second structure was devised in an attempt to reduce the peak overpressure attained within the shelter and to reduce the rate of rise of the overpressure. This shelter is shown in plan view in Fig. 1.4 (denoted Structure 602). It will be noted that a double (through and through) ramp was used and the blast trap was revised to contain a baffle. The basic construction remained the same as that of Shelter 601 except that three sections of steel culvert were installed and tested in place of the first three reinforced conrete sections. A detailed description of both structures may be found in the Report to the Test Director by Corsbie. ${ }^{1}$

\subsection{OBJECTIVES OF THIS PROJECT}

Recognition of possible or potential blast hazards within the shelters became apparent when it was considered that shock waves associated with overpressures of several hundred milliseconds' duration would be imposed upon structures with open entrances of rather large areas. In addition, it appeared that the volume of the structure with respect to the entrance areas was such that little or no reduction in peak overpressure would occur. Therefore prior

11

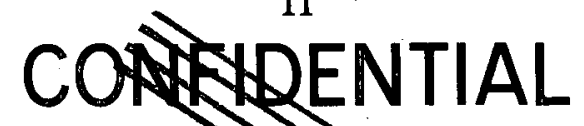

- RESTRTER PATA 

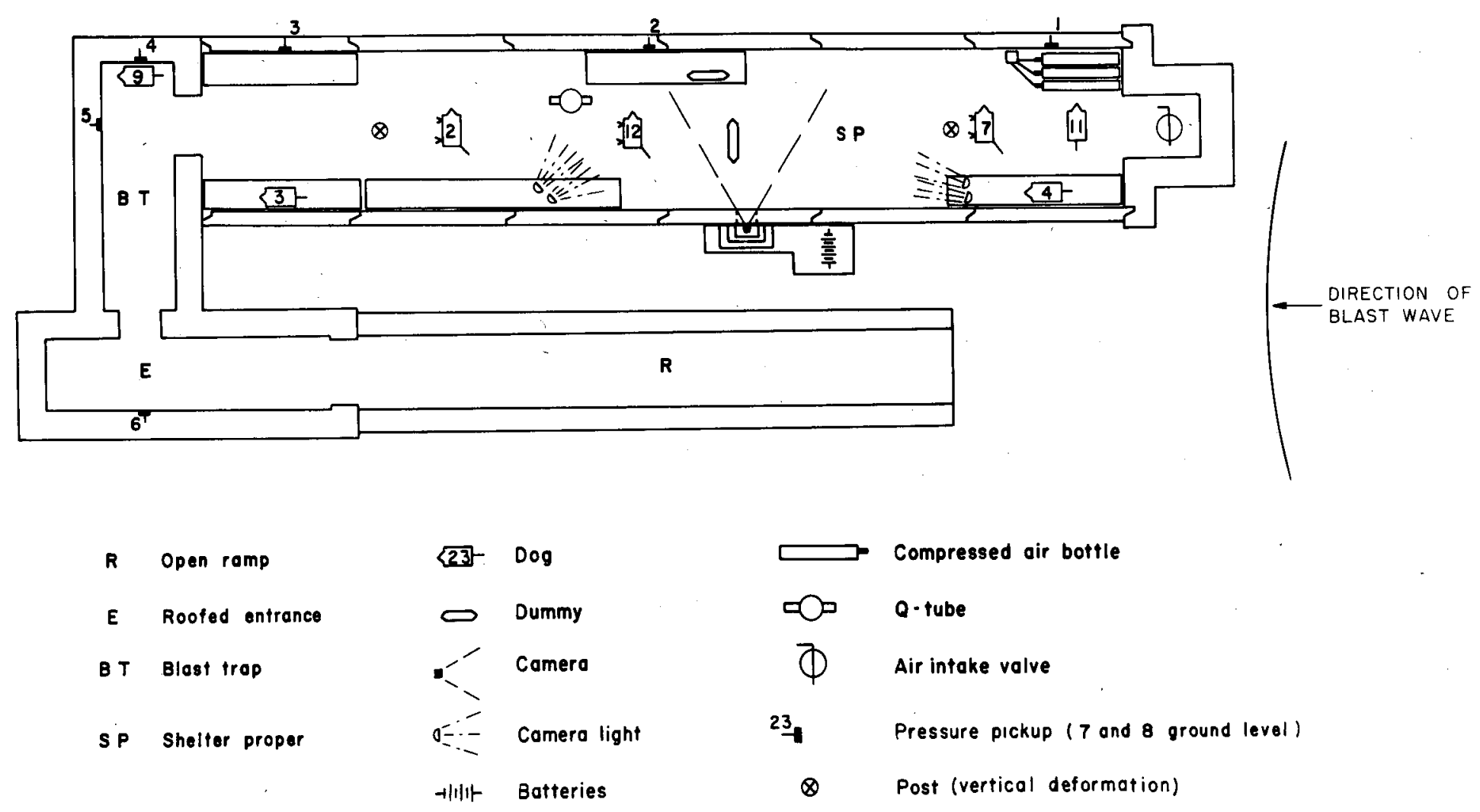

Fig. 1.1-Plan view of objects used in Shelter 601 during Shot 1 (Mar. 17, 1953). Only objects of relative importance to this project are indicated. 


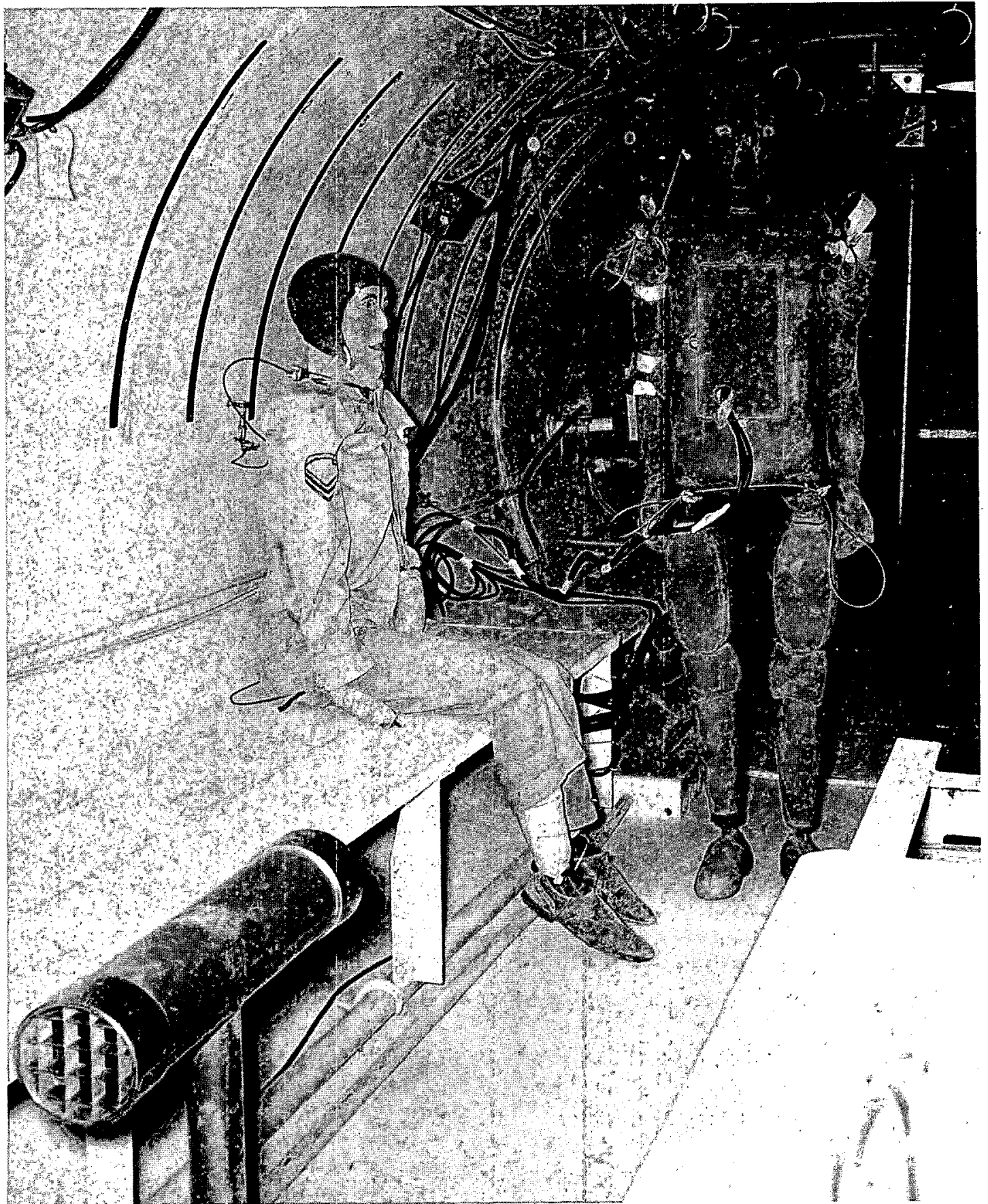

Fig. 1.2-Dummies in Shelter 601. In the foreground of this photograph the drag gauge may be observed. The dummy positioning and restraining method is shown. Accelerometer leads extend from cavity in standing dummy. 


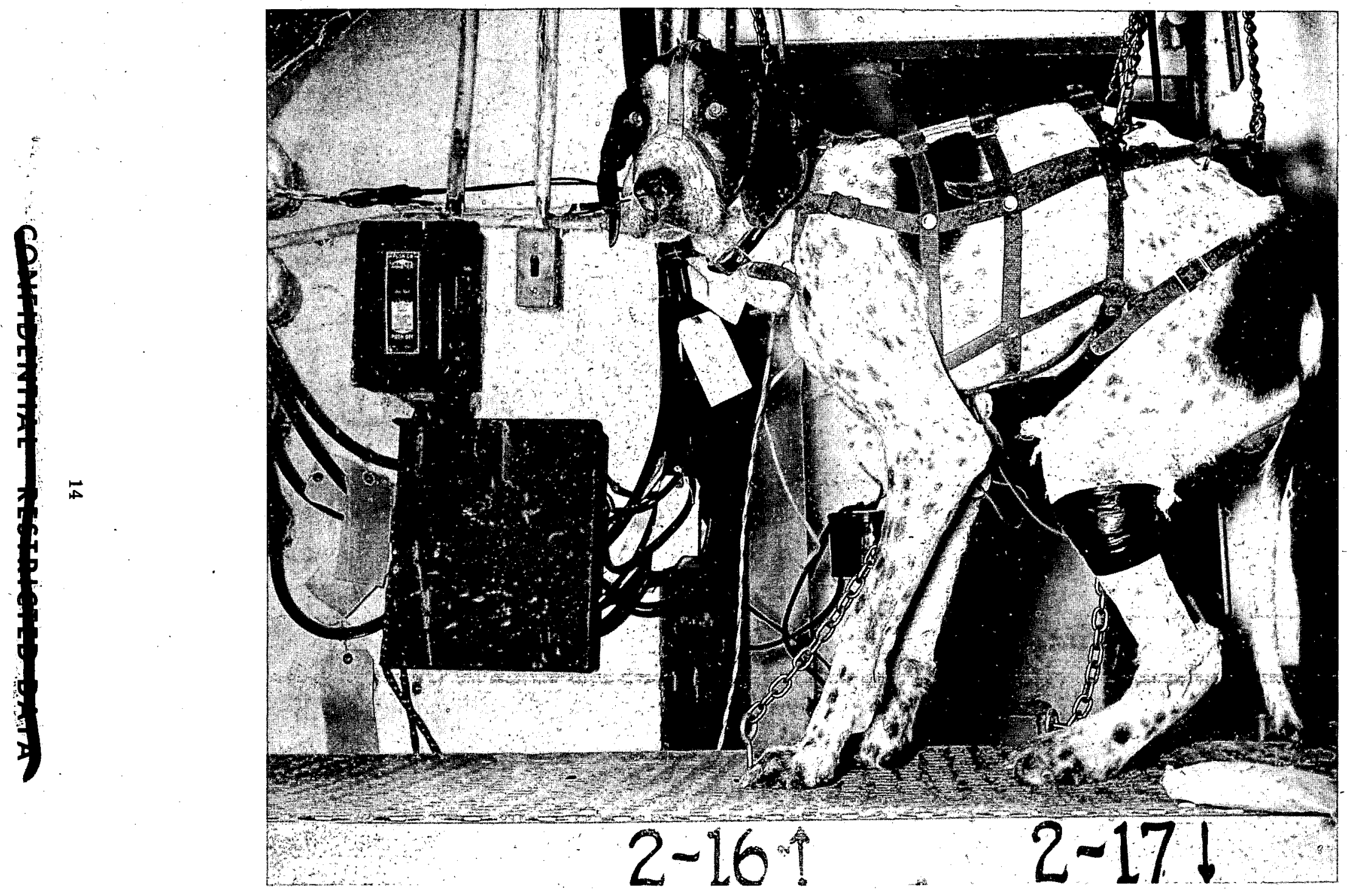

Fig. 1.3-Test animal at the rear of Shelter 602. This animal was restrained in the typical fashion. The plaster cast on the left leg illustrates the technique used to maintain the electrocardiographic electrodes in place. 

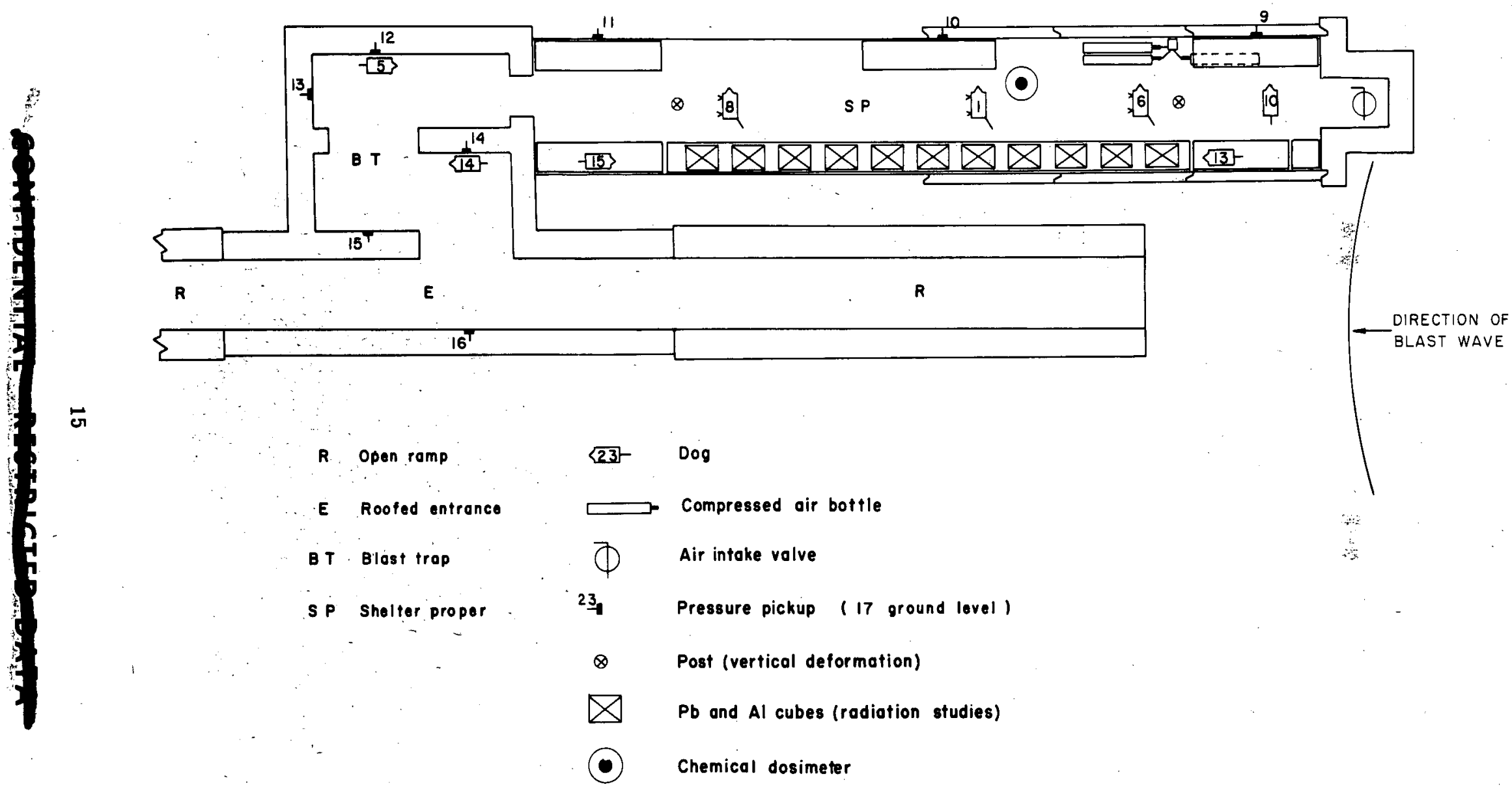

Fig. 1.4-Plan view of objects used in Shelter 602 during Shot 1 (Mar. 17, 1953). Only objects pertinent to this project are included in the drawing. 
to the field tests an assumption was made that a considerable portion of the imposed overpressure might be transmitted into the shelter proper. This contention was supported by model tests of Structure 601 executed by the Ballistic Research Laboratories (BRL) in the 24-in. shock tube at Aberdeen, $\mathrm{Md}^{2}{ }^{2}$

The incident overpressure originally anticipated at the sheiters in Yucca Flat on Shot 1 (17 March 1953) was approximately $18 \mathrm{psi}$. According to the BRL model test data, initial pressure rises during the first few milliseconds after arrival of the wave within Shelter 601 were expected to vary from about 3 to 15 psi. The pressure was then expected to rise to a "filled" value in the neighborhood of the incident pressure and to exhibit a duration essentially as long as the incident wave.

The question arose whether the above-mentioned conditions were sufficient to justify a field experiment on biological blast damage. Evidence from work and experience with conventional explosives (waves of a few milliseconds' duration) indicated that a much higher overpressure was required to produce damage in larger mammals or man. ${ }^{3,4}$ It was decided, however, that one could not assume, a priori, from this or other available data, that the loading pattern expected would not produce blast injuries.

The data of De Saga, ${ }^{5}$ relevant to the fatal effects of high-explosive blast on dogs, showed that the duration of the overpressure, as well as the peak overpressure, were both significant parameters. The work of Clemedson ${ }^{6}$ on rabbits confirms the findings of De Saga. Thus there was room to suspect from this data and other reasoning that damage might occur when the duration of static overpressure was long even though the peak overpressure proved to be relatively low.

An important secondary aspect of the blast hazard also became obvious; namely, that there was a decided likelihood that the material velocity or drag component of the entering overpressure would be of such magnitude as to cause rapid or violent displacements of shelter occupants. It was deemed necessary to investigate this possible displacement hazard.

The objectives of the project were thus defined in terms of studying both the aspect of primary blast damage and the aspect of bodily displacement within Shelters 601 and 602 .

It seems well to mention at this point that the shelters were so situated in Yucca Flat that two bursts of the 1953 series could be utilized. Furthermore, the first blast wave (Shot 1, 17 March 1953) entered the shelters in a direction paralleling the ramps (see Figs. 1.1 and 1.4), whereas, in the second test of these structures (Shot 8, 19 May 1953), the blast wave traveled in a direction perpendicular to the ramps (see Figs. 1.5 and 1.6). The project reporting herein participated in both of these operations.

\subsection{SUMMARY OF THE EXPERIMENTAL DESIGN}

Establishment of a scheme for pressure vs time determinations in Structures 601 and 602 was dictated by the requirement for following the pattern which had been applied to the model studies by BRL and Robert L. Corsbie. This, it was hoped, would allow a confirmation of the validity of the model data by actual field test, and the established scheme was deemed quite appropriate for the study of biological blast effects. Figures 1.1 and 1.4 show the positioning of P-T gauges; the positions numbered 4,12, and 14 were added to the original scheme so that supplemental and more adequate data would be available for animals placed in the corresponding locations.

In the study of primary blast effects, an ideal animal is not available with respect to anatomical characteristics closely analogous to those of man and with respect to facility of handling and restraint required in the shelter tests. The dog was chosen as the most appropriate biological test object, it being understood that data relative to this animal cannot, at this time, be explicitly extrapolated in terms of man's response to the same conditions. In addition to a designated location for each animal as to anticipated and measured pressure regions within Structures 601 and 602, their orientation relative to the direction of blast-wave propagation was considered. Final arrangement of test animals was frequently dictated by the expediency of coordination with other projects in the field. Suffice it to be stated here, however, that an at-

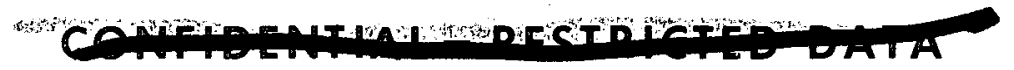



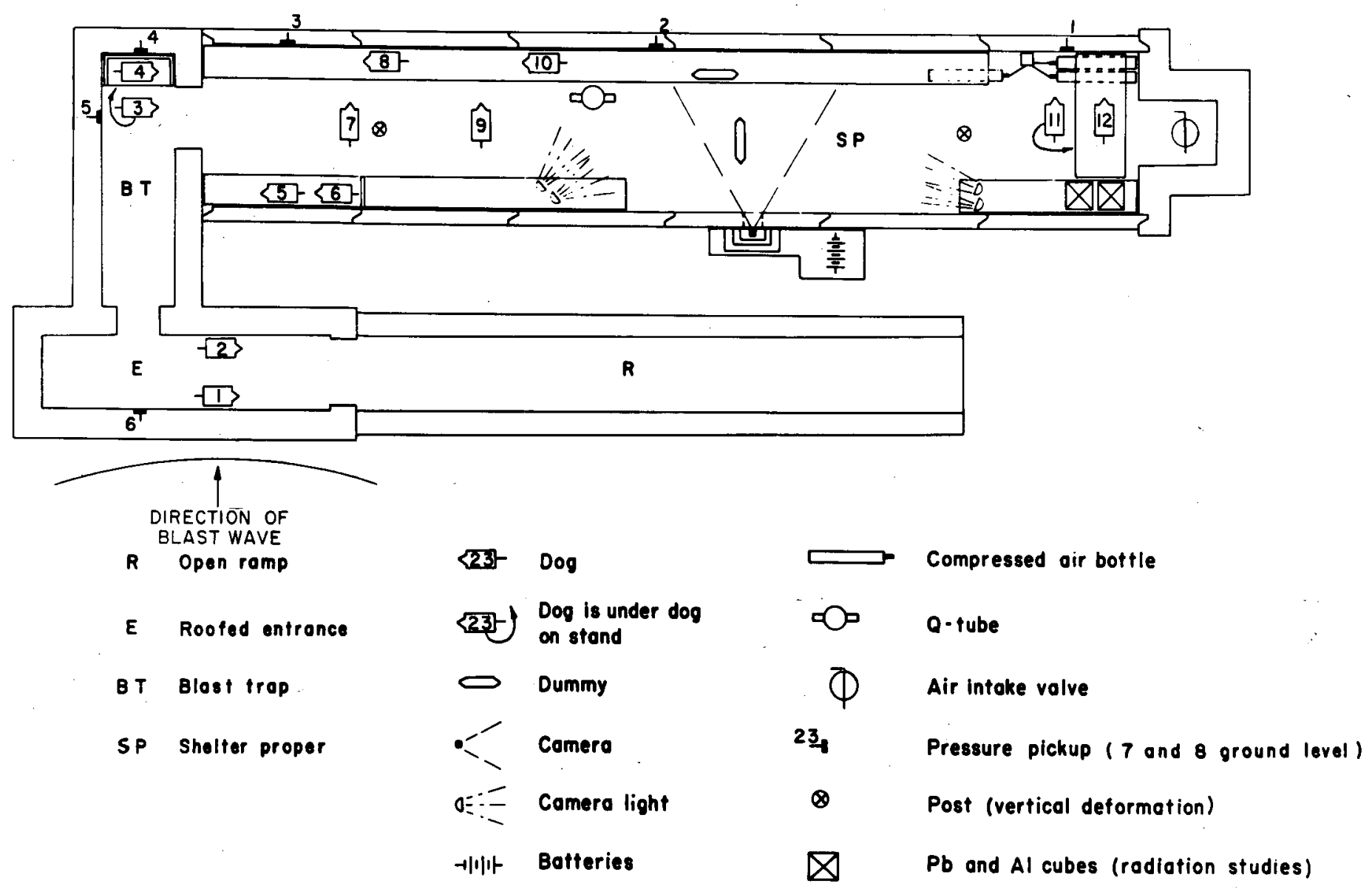

Fig. 1.5-Plan view of objects used in Shelter 601 during Shot 8 (May 19, 1953). Only pertinent objects are included in the drawing. 


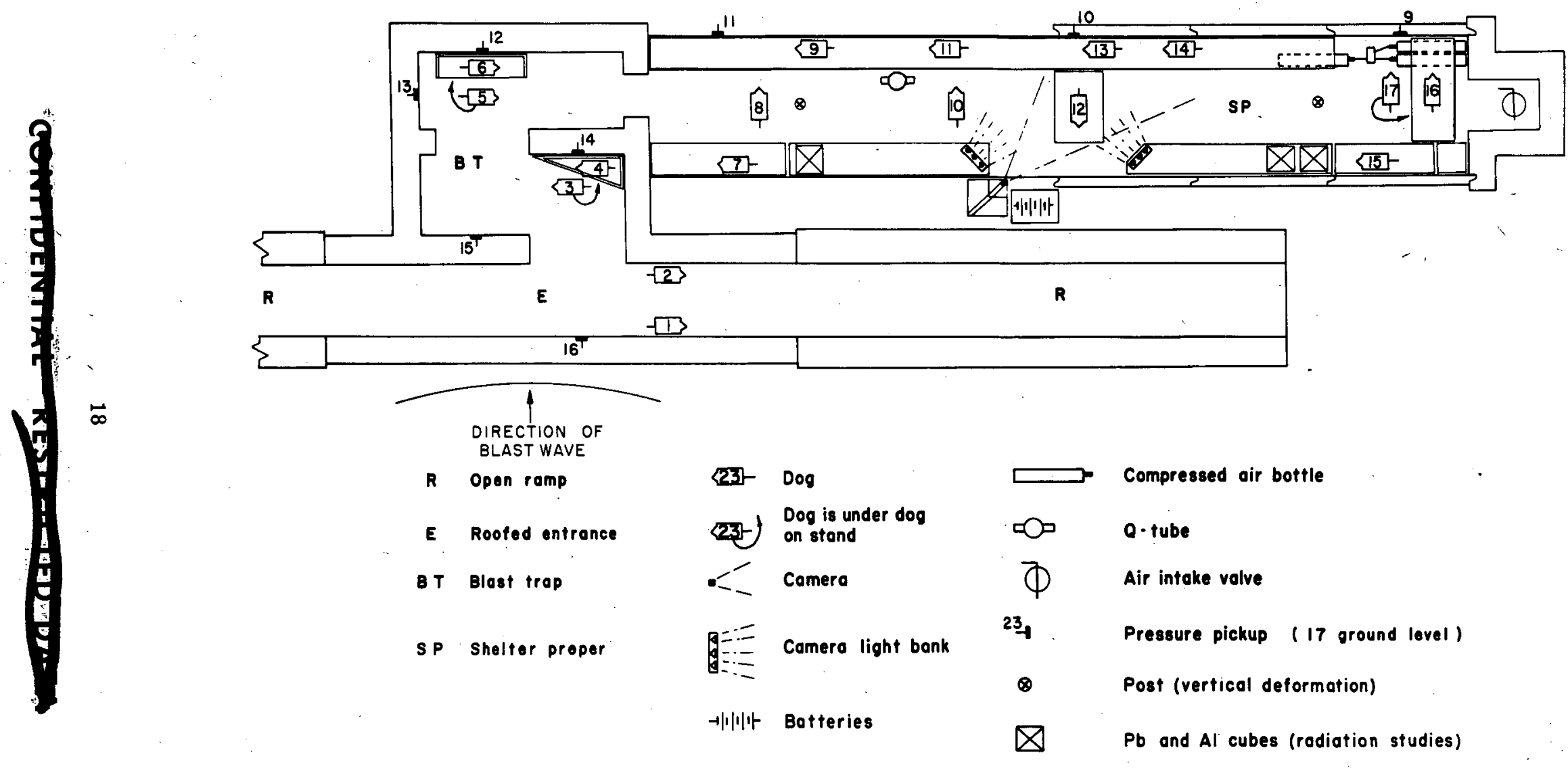

Fig. 1.6-Plan view of objects used in Shelter 602 during Shot 8 (May 19, 1953). Only pertinent objects are included in the drawing. 
tempt was consistently made to so station and position the animals during Shots 1 and 8 that $\mathbf{a}$ maximum of pertinent data might be obtained.

The extent of blast injuries following Shot 1 was appraised primarily by careful and detailed pathological examination since detailed clinical evaluation did not seem justifiable or feasible. The nature and extent of damage determined in dogs exposed in Shot 1, however, expressly prompted clinical studies to be made during Shot 8 . Thus in Shot 8 animals were " paired" as well as possible to similar blast conditions so that one might be studied and followed clinically and the alternate animal was posted for complete pathological study. Electrocardiographic facilities were also set up for Shot 8 in such a way that records might be obtained from animals within the shelters during, and just following, the detonation.

In the investigation of bodily displacement, two anthropometric dummies were situated in the central region of Shelter 601 (Fig. 1.1). One of these dummies was seated and the other was standing, but each was essentially free to move from these initial positions a distance of several feet in the direction of the entering drag pressure. A drag gauge was located just "upstream" from the dummies (Figs. 1.1 and 1.2). For an appraisal of the magnitudes of displacement, the decision was made to place three orthoginally mounted accelerometers in the chest region of the standing dummy and to orient a high-speed camera so that pictorial data of the motion could be obtained (Fig. 1.1).

Opportunity was afforded this project to obtain supplementary data on biological blast effects during Shot 11. The plan and methods used in this experiment are discussed in Sec. 2.6.

\section{REFERENCES}

1. R. L. Corsbie, AEC Shelter Evaluation, Upshot-Knothole Project 24.1 Report, 1953.

2. W. J. Taylor and R. O. Clark, Shock Tube Studies on Models of AEC Shelters, Ballistic Research Laboratories, Aberdeen; Md., July 1953.

3. R. B. Fisher, P. L. Krohn, and S. Zuckerman, The Relationship Between Body Size and the Lethal Effects of Blast, Ministry of Home Security of Great Britain, Report R. C. 284.

4. H. De Saga, Blast Injuries, Chapter XIV-D, German Aviation Medicine, World War II, Department of the Air Force, U. S. Government Printing Office, Washington, 1950.

5. H. De Saga, Experimental Investigation of the Blast Effect, edited and published by the Inspector General of the German Reich Air Force, Research Report No. 15, 1943.

6. C. J. Clemedson, An Experimental Study on Air Blast Injuries, Acta Physiol. Scand., Vol. 18, Suppl. LXI, 1949. 


\section{CHAPTER 2}

\section{EXPERIMENTAL METHODS}

\subsection{METHODS AND INSTRUMENTATION FOR PHYSICAL DATA}

\subsubsection{Pressure Vs Time Measurements (Shots 1 and 8)}

The recording of pressure vs time phenomena was undertaken by Project 24.3 (Vitro Corporation of America), using Wiancko type 3 PAD pressure transducers, which were flush mounted in the walls of the structure as indicated in Figs. 1.1 and 1.4. Gauges 7 and 8 were flush mounted at ground level outside Structure 601, and gauges 17 and 18 were similarly mounted outside Structure 602. The recording system utilized Consolidated galvanometers, types 7-223 and 7-219. Details of this instrumentation and its response characteristics may be found in the Vitro Report to the Test Director.1

\subsubsection{Instrumentation for Drag, Accelerations of Dummy, and Photography During Shot 1}

The standing dummy located in Structure 601 (Fig. 1.1) was instrumented by installing three Gulton type A 302 barium-titanate accelerometers within a cavity located in the chest region (Fig. 1.2). The accelerometers were mounted at right angles to each other, and the mounting included a cathode follower for each unit. This allowed for minimum lead length between the accelerometers and the matching cathode-follower circuit. The accelerometer-cathode-follower circuits furnished signals to the Consolidated type 1-112B linear amplifiers (located in an underground concrete instrument vault, Structure 610). Consolidated type 7-226 galvanometer strings operating in the Consolidated type 5-114 oscillograph were operated by power from these amplifiers.

An air-drag gauge or $Q$ tube $\left(q=1 / 2 \rho V^{2}\right)$ was obtained from the Sandia Corporation (Fig. 2.1). The sensing element of this gauge consisted of a conventional bridge type resistance-strain gauge affixed to a strain element (Figs. 1.5 and 1.6). This gauge was operated from a Consolidated 3-kc carrier amplifier, type 1-113B, the output of which was used to operate a Consolidated type 7-223 galvanometer. These data were also recorded by the same oscillograph as used for the accelerometer data.

In the high-speed photography used to trace the displacement path of the two dummies, time marks were placed on the film from the time-mark generator located in Structure 610. The necessary lighting was obtained from four General Electric airplane landing lamps (type 4-4560) placed in banks of two as noted in Sec. 2.5. Twenty-four hundred watts of battery power was furnished from a bank of five heavy-duty batteries mounted in a special housing adjoining the test shelter (Fig. 1.1).

\subsubsection{General Operation of the System During Shot 1}

Commercial power at 110 volts was fed into the master control unit [located in an underground concrete power vault, Structure 611 (see Fig. 2.2)]. At -30 min an Edgerton, Germes-

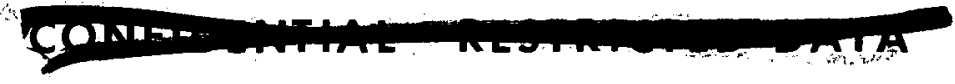




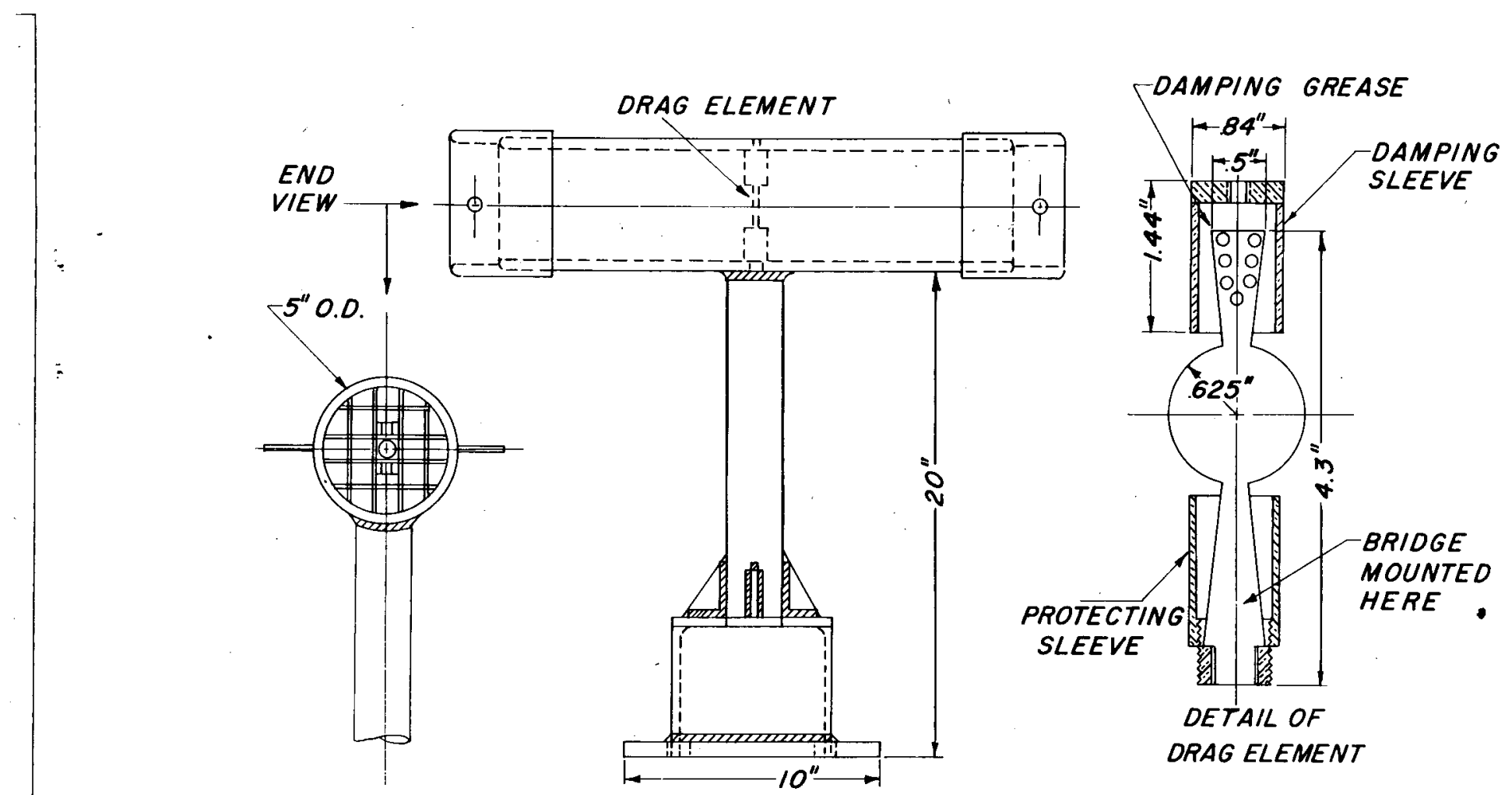

Fig. 2.1-General structure and dimensions of the drag gauges (Sandia Corporation) used in Shots 1 and 8.

hausen \& Grier (EG\&G) time signal caused relays in the unit to operate and apply this commercial power to the Consolidated oscillograph, associated amplifiers, and the timing oscillator located in Structure 610 for warm-up purposes.

A second EG\&G time signal arrived at the master control unit at -5 min. This caused a sequence of relays to operate with the following results: Both 24K50 inverters located in Shelter 611 were started and brought up to speed. The load of the equipment located in Structure 610 was removed from commercial power and transferred to the output of the inverters, the proper separation of the loads to prevent inverter overload being made at this time. Filament and plate supply voltages were applied to the accelerometer cathode followers. The ventilator valves were closed in both Shelter 601 and 602 , and the air bottles were turned on. The electronic timer circuit was placed in warm-up position.

A third EG\&G time signal arrived at the master control unit at -1 sec. This impulse caused another sequence of relays to operate with the following results: The photography lighting system located in Shelter 601 was turned on, and the Fastax camera, located in a special housing adjacent to Shelter 601, was started. The oscillograph paper drive was started so that the type 1127 linograph paper moved through the oscillograph at approximately $115 \mathrm{in} . / \mathrm{sec}$, recording accelerometer and drag-gauge data. The electronic timer commenced to count time from this -1 sec point.

At the conclusion of $13 \mathrm{sec}$ the electronic timer caused relays in the master control to operate, shutting off all equipment in all structures except the air-bottle valves. These remained on to bleed the bottles to near zero or ambient pressure, thereby providing for a known quantity of air to the animals.

\subsubsection{Instrumentation for Shot 8}

The same instrumentation used during Shot 1 (noted in Sec. 2.1.2) was operative during Shot 8 . Three primary additions were made for Shot 8 , and these are noted in the following paragraphs. 


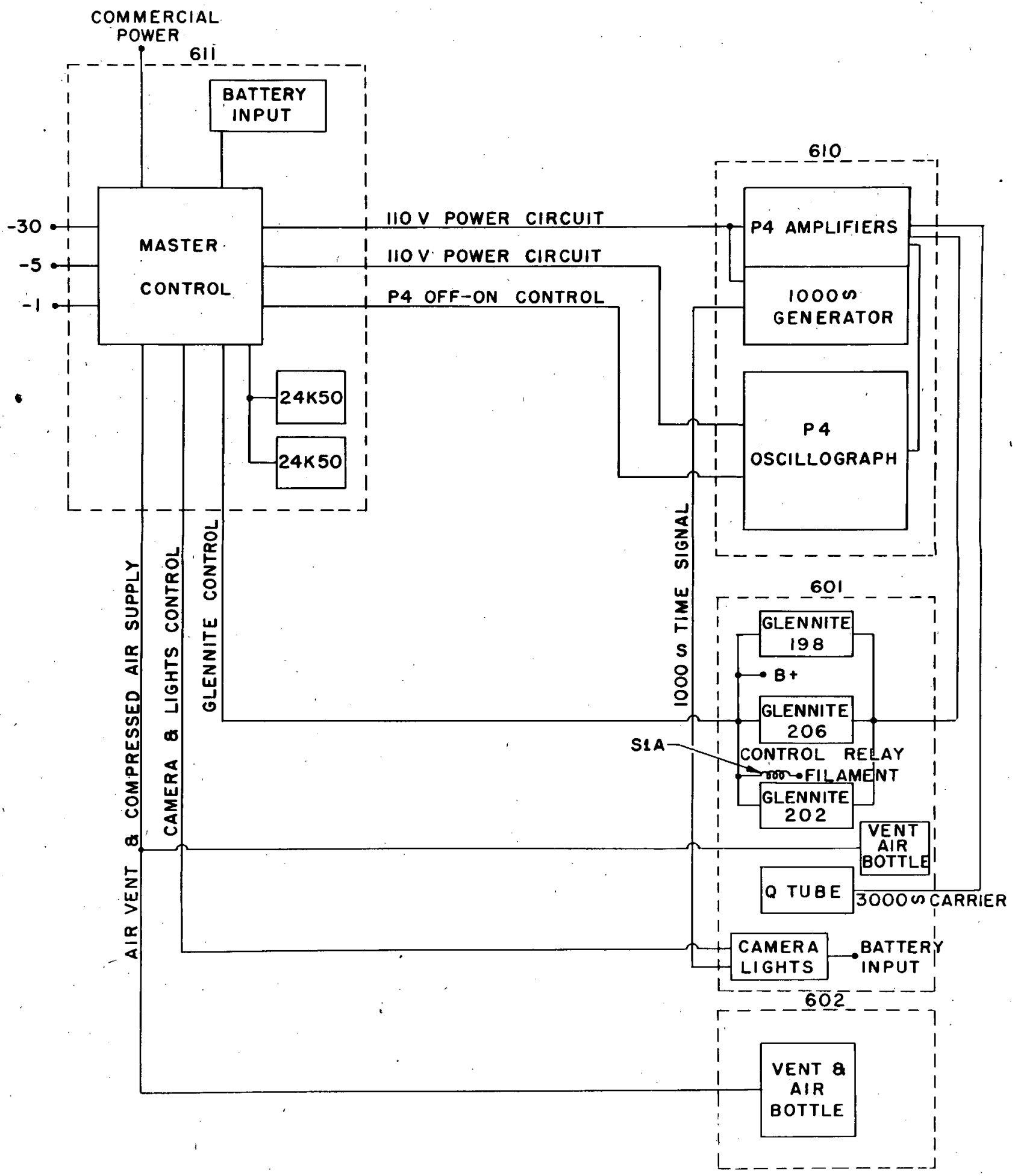

Fig. 2.2-Block wiring diagram, Shot 1 . 
A second drag gauge was employed for determination of $Q^{\prime}$ in Shelter 602 at the location indicated in Fig. 1.5. This gauge was the same type described in Sec. 2.1.2.

A medium-speed camera was used in Structure 602 to study displacements of animals (Sec. 2.5). Lighting for this photography was obtained from two banks of eight 150-watt 120-volt lamps. These lamps received power through a relay circuit from 20 automobile type storage batteries located in an auxiliary shelter adjoining the test shelter. A flash bulb was placed in the camera field which received a signal from an EG\&G Blue Box and hence afforded a zero time indicator for the photography. This system was also used in Structure 601 photography during Shot 8 .

Electrocardiograms were taken on four dogs, two located in Shelter 601 and two in Shelter 602. These electrocardiograms were obtained with the recording equipment located remotely from the animals, the pickup leads being from 100 to $300 \mathrm{ft}$ in length. Four Sanborn type 67-300 ECG d-c amplifiers and their respective preamplifiers and mixing panel, Sanborn type 67200/1000, were located together with a Consolidated P4 oscillograph in the instrument shelter. ECG signals received from the animals were fed into the amplifiers and recorded by means of Consolidated type 7-238 galvanometers on the oscillograph at a paper speed of approximately 2.5 in./sec.

\subsubsection{General Operation of the System During Shot 8}

The operation of equipment during Shot 8 was similar to that of Shot 1, and additional instrumentation was incorporated insofar as possible into the Shot 1 control system. The $Q$ tube and camera installed in Shelter 602 were afforded circuit control voltages by paralleling similar control units of Shelter 601 (Fig. 2.3).

The electrocardiographic facilities used in Shot 8 required a supplemental timing and control panel (Fig. 2.3) but depended upon initial starting from the -30 min time signal initiating all other circuits in the master control panel. Recording began at -1 sec and continued for $5 \mathrm{~min}$, at which time recording was halted and a 1-hr timer started. After $1 \mathrm{hr}$ a second 5 -min record was obtained, and the equipment was turned off permanently.

\subsection{ANIMAL POSITIONING AND RESTRAINING TECHNIQUES}

As previously mentioned, dogs were so stationed within the shelters that various orientations of the animals were maintained, with respect to the direction of blast wave propagation (see Figs. 1.1 and 1.4 to 1.6). All animals attained a standing posture except 2, 12, 7, 8, 1, and 6 in Shot 1; these were secured snugly with their right sides on the floor and belly-on to the pressure wave. Animals in the entrance way and blast trap were snugged securely to the wall, whereas animals in the shelter proper were loosely held near the curved wall of the shelter.

During Shot 1 the animals were restrained in position by means of a heavy canvas sling around the shoulder and pelvic regions and a wire vest of large-mesh rabbit wire fitted snugly to the chest, from which guy ropes were tied to appropriate eyebolts in the structure. This technique gave considerable difficulty because of the long period of restraint required between the times of placement and recovery.

For Shot 8 a special harness was designed and fabricated from $7 / 8$-in. cotton webbing (250 lb tensile test), which is shown in Fig. 2.4. The lattice work was held together by copper rivets and burrs. Slip buckles were used for attaining proper adjustment. Due to the variation in anatomical structure and dimensions of the animals, it was found necessary to fit each harness individually.

The problem of suspension and restraint between harness and structure was accomplished by incorporating spring clips into the harness. Into these clips No. 3 straight-link chain was snapped at the time of placement, and the distal end of the chain was secured to $1 / 4$ - or $3 / 8$-in. eyebolts within the structure.

This restraining system proved very successful (see Fig. 1.3). Before Shot 8 the animals were trained by suspending them in the harnesses for several hours. Dry runs also served to 


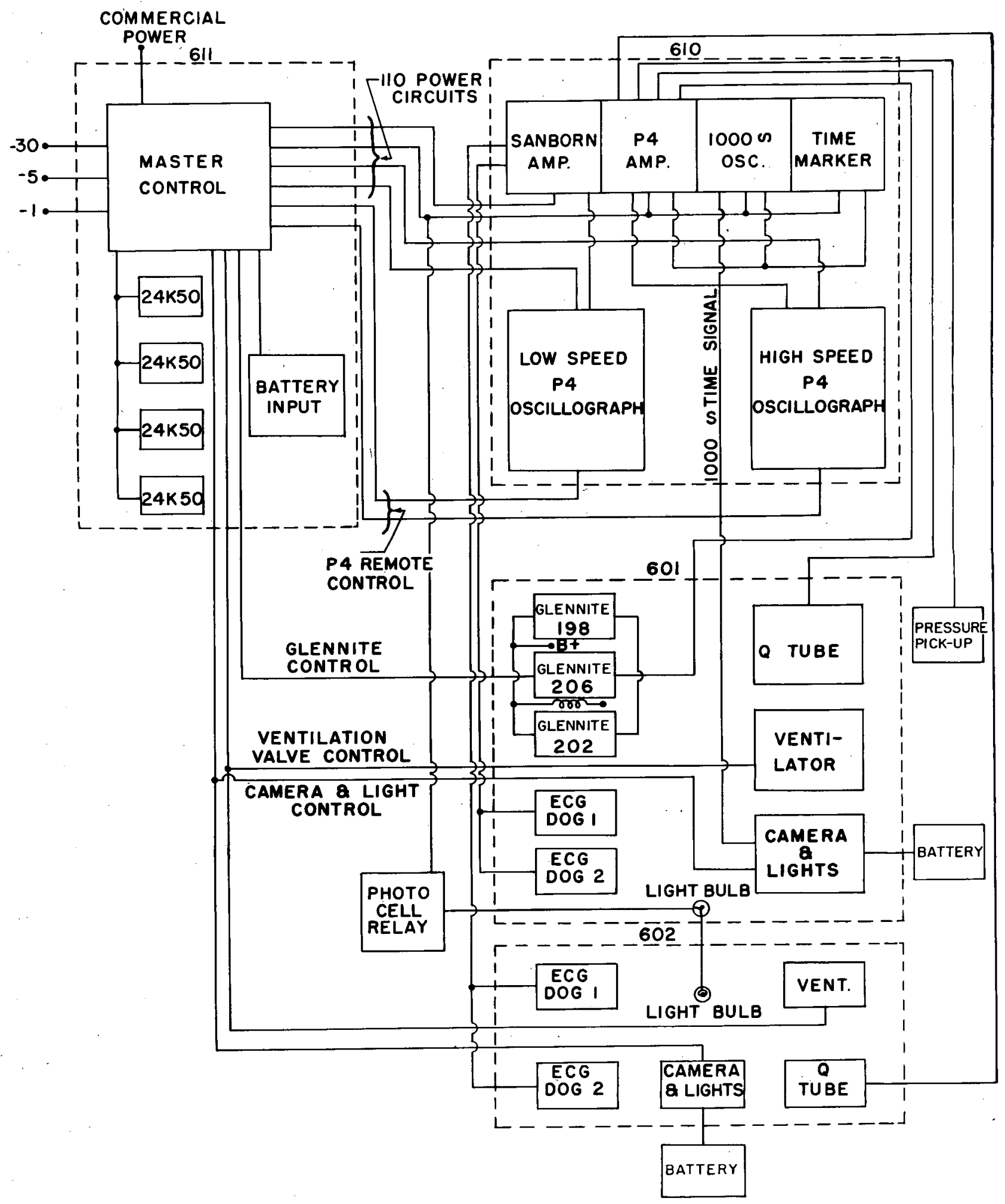

Fig. 2.3-Block wiring diagram, Shot 8 . 


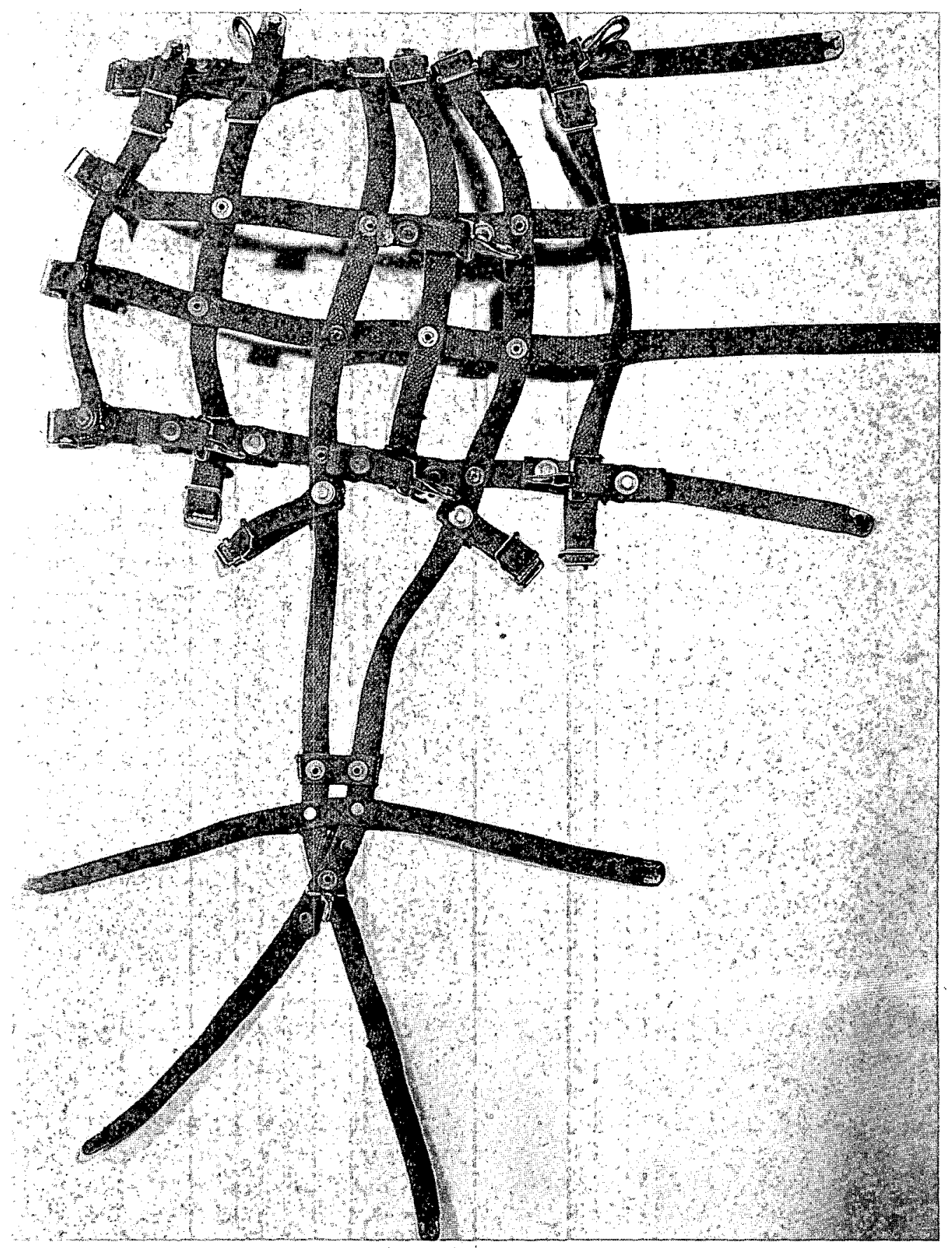

Fig. 2.4-Harness used to restrain dógs, showing general design and construction method. The upper portion fitted the thorax, and in the lower portion four straps were designed for the pelvic region. The central section of the harness was placed ventrally on the animals, and the straps (projecting peripherally in the picture) were buckled snugly on the posterior side. 
train the animals. Physical comfort as well as accurate orientationing and positioning were maintained in the shelters before, during, and after exposure of the animals to blast.

Muzzles were used to prevent the animals from chewing the harness and to avoid possible injury to personnel at the time of recovery.

The animals during Shot 1 were lightly anesthetized several hours prior to detonation but were awake and barking $2 \mathrm{hr}$ prior to zero time. No anesthesia was used during Shot 8.

\subsection{PATHOLOGICAL METHODS AND TECHNIQUES}

\subsubsection{General Remarks}

Examination of gross tissue changes in the control and exposed animals was made by a team of four physicians in the following specialties: a pathologist, a physiologist, an anatomist, and an orthopedic surgeon. The autopsy rooms were,modeled in a temporary building with two divisions, one for dissection and a second room for close assay of gross changes, photography, perfusion, and other fixation processing. In addition to the above team, a second physiologist, a histology technician, and a medical photographer assisted.

\subsubsection{Conduct of Autopsies}

All control animals and three groups of test animals were handled in an identical manner and system except for a slight variation in lung perfusion technique. Upon "recovery" from the test site, animals were transported to the main animal quarters, and autopsies were immediately begun, selecting those animals first which appeared to show the most marked effects of their experience. Examinations were performed on only one animal at a time. An animal was brought to the autopsy room, examined for external damage, and anesthetized intravenously (leg vein) with nembutal solution (60 mg per cc) in dosage of $1 \mathrm{cc}$ for each $5 \mathrm{lb}$ of body weight. This dose was found sufficient to anesthetize without appreciably suppressing central respiratory centers.

As quickly as possible the animals were strapped to the dissecting table and exsanguinated by severing each femoral artery. With cardiac arrest, two members of the team dissected out the carotid artery (avoiding damage to any large venous channels). These vessels were clamped close to the base of the neck, cannulated above with polyethylene tubing, and the head and neck slowly perfused, bilaterally, with buffered formalin (10 per cent) in amounts of approximately 80 to $100 \mathrm{cc}$ to each side. This procedure resulted in excellent and early fixation of the head and upper neck structures.

The team division placed two prosectors dissecting the head, neck, back, and spinal cord and two others examining the thorax, abdomen, and extremities. In this manner the gross examination of all tissues, including photography and fixation, could be uniformly completed in a thorough manner, with the total time of autopsy examination ranging from 60 to 90 min for each animal.

As soon as perfusion of the head was completed, the trachea was clamped tight at the base of the neck and the thoracic cavity opened. This procedure maintained the lungs in an expanded state to more accurately ascertain the sites of pulmonary damage with respect to the more solid structures such as the heart, mediastinal contents, and rib cage. It was found in control animals that failure to close off the trachea before opening the chest wall resulted in massive collapse of all portions of the Iungs to a fraction of their original volume, thereby obscuring anatomical relations and to some extent the histological picture. Since the pulmonary changes were the dominant features, these organs, together with the intact heart and clamped trachea, were removed at once, photographed in color, anteriorly and posteriorly, to demonstrate site and extent of any damage, and perfused with 10 per cent buffered formalin by way of the bronchial tree. During this latter process the lungs, of course, collapsed but were reexpanded to the estimated original volume by the perfusion fluid and maintained in this state until fixation was complete. A slow rate of perfusion was used to minimize dislodging any intrabronchial contents which might be present in the deeper ramifications. In the early 
stages of the experiments, the lungs of the first few animals were perfused through the pulmonary artery and were allowed to collapse. This produced a distorted histological picture in which fine details were somewhat obscured by the irregular atelectasis, lending a peculiar Swiss-cheese effect to the sections. Tests on control animals verified the superiority of the bronchial perfusion method where care was exercised not to overinflate the lungs.

It was found to be quite important in control tests to avoid severing any medium or large venous channel while the heart remained active, since air would immediately be drawn into the general circulation and air emboli would be seen in coronary vessels and frothy blood would be found in cardiac chambers. Although we did not expect to find air emboli in these animals as a result of the long interval between explosive exposure and examination, the possibility of such was looked for.

Throughout the dissection and gross examination, detailed notes were made on check-list forms covering all organs and structures, and sections were placed in 10 per cent buffered formalin and in Helly's fluid for histological study. The list of principle structures which were selected for detailed examination is given in Appendix A.

Colored photographs were made of all lesions or suspected lesions before fixation. The lungs, heart, brain, spleen, kidneys, larynx and trachea, eyes, middle and inner ears, spinal cord, suspected sectors of intestine, and urinary bladder were fixed and preserved, sectioning in buffered formalin for later reexamination at the Central laboratory. Tissue sections of 2- to 4-mm thickness were fixed in 10 per cent buffered formalin and Helly's fluid. The brain was sliced at close intervals ( 3 to $4 \mathrm{~mm}$ ) immediately after removal and stored in buffered formalin. The eyes were fixed only in Zenker-acetic fluid after a small slice was removed from the lateral walls to allow fixative penetration. Certain other fixatives (listed in Sec. 2.3.4) were occasionally used for specific purposes.

\subsubsection{Photography of Pathological Specimens}

The equipment for gross specimen photography consisted of a standard vertical camera mount (B and $J$ type) with ground green plastic base (nonreflecting). Camera: Rolleiflex, with close lens attachments. Film: Ektachrome No. 120, 2- by 2-in. frames. Lighting: Four photofloods, equipositioned about the specimen at an approximate distance of $2 \mathrm{ft}$.

\subsubsection{Processing of Tissues}

(a) Fixatives Employed.

10 per cent buffered formalin (Lillie) ${ }^{2}$

Helly's fluid (Zenker formal, 10 per cent)

Zenker acetic (5 per cent)

Rossman's fluid

Basic lead acetate

Zenker fixed tissues were processed, after a 12-to 18-hr exposure, by washing and storage in 80 per cent alcohol in the usual manner.

(b) Histological Stains Employed in Study.

Hematoxylin-eosin

Masson trichrome

Verhoeff's elastic - Masson trichrome

Modified Lison Prussian blue reaction ${ }^{3}$ (potassium ferrocyanide and hydrochromic acid) for iron.

Periodic-acid-Schiff

(c) Technique for Brain Specimens. Multiple slices of brain were sectioned by the frozen technique and stained with Sudan Black-B in propylene glycol ${ }^{4}$ for study of myelin sheaths and detection of fat emboli. 


\subsubsection{Selection of Tissues and Principal Stains Used}

(a) Lungs. Only buffered formalin was used for fixation. Sample sections were taken from all gross lesions, as well as one or two from uninvolved lobes; selections were made to include a study of bronchial and vascular tree. All sections were stained with hematoxylineosin and Masson trichrome, either with or without the elastic stain.

(b) Heart. Several sections were taken of mitral and aortic valves, anterior and posterior myocardium of left and right ventricle, interventricular septum, papillary muscles, and auricular walls including appendages. Stains used were hematoxylin-eosin and Masson trichrome.

(c) Brain. Since no gross lesions were observed, selected sections were made from the following regions: frontal, occipital, and motor cortex; hippocampus; basal ganglia, including the internal capsule; corpus callosum; pons, medulla, and several sections of spinal cord; and cerebellum, including the dentate nucleus. Several frozen sections, stained with Sudan Black-B in propylene glycol, were made on the brain of each animal exhibiting ataxic signs.

(d) Lymph Nodes. Hematoxylin-eosin stain and Lison's iron method were used.

(e) All Other Tissues. Hematoxylin-eosin stains were used; selected sections were occasionally stained by the Masson trichrome method where indicated.

\subsubsection{Weights of Tissues and Organs}

Except for the animals involved in the first experiment, all major organs were weighed and recorded following excision. In no instance were organ weights increased above the normal range.

\subsubsection{Control Animals}

Thirteen control animals were used. These were similar to the experimentals in size, sex, and breed. These dogs were subjected to the same procedures as were the test animals, including overnight restraint in the shelters. Pathological examinations were identical in detail to those described above. Appropriate microscopic sections and photographs were obtained.

\subsection{CLINICAL METHODS (SHOT 8)}

Because clinical and pathological findings were essentially negative for blast damage during Shot 8, the clinical methods employed will be described very briefly.

The animals were studied prior to the test and at the earliest possible time following recovery. The work-up consisted of complete physical and neurological examinations, electrocardiograms (leads $\mathrm{I}, \mathrm{II}, \mathrm{III}$, and AVF), and chest $\mathrm{x}$ rays. Silver chloride was fused to a silver plate for the ECG electrodes (nonpolarizable), which were held to the clipped leg by gauze saturated in saline solution. The dogs were held in position for P-A chest $x$ rays by means of a V-shaped plastic trough, into which fitted the ventral contours of the animal's chest cage.

Electrocardiograms during the actual test were obtained by equipment described in Sec. 2.1.5. Electrodes consisted of depolarized silver wire threaded through the skin of the leg of the animal. A plaster cast was applied to maintain the electrode and lead in place during the interval from placement to recovery.

\subsection{DISPLACEMENT STUDY METHODS}

Of major concern in the photography of the displacement of the dummies and the suspended dog was the problem of covering an adequately large field of view with the short camera-

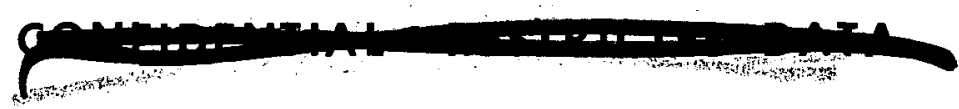


to-subject distance afforded within the shelters. Using 16-mm high-speed motion-picture cameras, wide-angle objectives seemed to be the answer to the problem; one of these lenses (of exceptionally wide coverage) was adapted as closely to our requirements as possible, while its distortion was kept to a minimum. However, the lenses themselves offered only a partial solution, and it was decided to place the instruments outside of their respective shelters, thus obtaining an increased camera-to-subject distance. Although this involved the disadvantage of early camera placement and "digging out" at recovery, it was felt that the 25 per cent increase in camera-to-subject distance justified such a procedure.

In Shelter 601 a port was cut through one wall, and a lead collar containing a 2-in. leadglass window was fitted into this hole. This port was placed, $24 \mathrm{ft}$ from the doorway to the shelter and 39 in. above the floor (Fig. 1.1). The camera lens barrel protruded into the protective collar, seemingly safe from flying debris and/or radiation from within the shelter proper, and the lens axis was maintained perpendicular to the shelter wall. A steel camera mount was rigidly secured to the outer shelter wall, the camera being directly bolted to this mount. Fabricated steel housings were then bolted to the concrete base, but not to the shelter wall, allowing the camera to move with the shelter and independently of the protective housings.

The plan used for mounting the camera outside Shelter 602 was simpler, its primary difference being that the camera could move relative to the shelter. This scheme consisted of a camera port (a rectangular steel conduit welded into the steel wall of the shelter at a $45^{\circ}$ angle), a steel housing fitted with $\mathrm{a} / 1 \mathrm{~s}-\mathrm{in}$. steel floor, a flexible rubber boot connecting the housing and the camera port, and a 2-in. lead wall containing a 2-in. lead-glass window fitted into the front panel of the housing. The camera housing was bolted directly to a concrete slab poured independently of the shelter wall. In this case the camera port was placed $21 \mathrm{ft}$ from the entrance way and 40 in. above the floor (Fig. 1.6). Additional camera-to-subject distance was gained by facing the camera downstream with the lens axis at an angle of $45^{\circ}$ with the shelter wall.

For the purpose of shielding the camera film, calculations of gamma-ray attenuations were made (Appendix B). The camera housing at Shelter 601 was shielded with 5 in. of lead on each surface above the base, and additional 2-in. slabs of lead were placed atop the housing and on the side facing Ground Zero. As discussed in Appendix B, this was more shielding than was minimally required. To shield the 602 housing, two thicknesses of $1 / 8$-in. lead sheet were fitted to the housing, and 2 in. of lead brick were stacked next to this. An additional 2-in. lead slab was placed on top, and another was put against the side facing Ground Zero.

In Shelter 601 the necessary illumination was supplied by four General Electric type 4-4560 24-volt aircraft landing lamp assemblies used in two banks of two lamps each. These were located $10 \mathrm{ft}$ on either side of the camera position and were focused on the dummies. When burned at 30 volts $d-c$ they supplied sufficient light, though their coverage was somewhat spotty. In Shelter 602, sixteen General Electric PAR 150/sp 120-volt lamps were used in two banks of eight lamps each. One bank was located $7 \frac{1}{2} \mathrm{ft}$ downstream from the camera position, and the other bank was $2 \frac{1}{2} \mathrm{ft}$ upstream. These lamps were positioned to illuminate the subject area uniformly.

The camera in Shelter 601 was proposed to operate at a speed of 300 pictures per second, whereas the camera in Shelter 602 (Shot 8) was set up to operate at 200 pictures per second. Complete camera data are given in Appendix $\mathbf{C}$.

Measurements on the 16-mm high-speed films were obtained, using the Bell and Howell Time and Motion Study Projector, model 173 BD. The film was projected at a distance which produced an image of known proportion to the original subject size. Projection size was maintained at a reasonable maximum to assure minimum error in measurement. The pictures taken in Shelter 601 were read in $\mathrm{a} / 2$ to 1 relation to original subject size. Those taken in Shelter 602 were read as follows: the paper tag at 1 to 1 and the suspended dog at $5 / 8$ to 1 . In the latter case it was necessary to correct the readings obtained from the film because the camera was situated at a $45^{\circ}$ angle to the path of motion. For the Shot 8 operations, markers $1 \mathrm{ft}$ apart were painted on the wall opposite each camera installation to facilitate measurement and reference on the film. 

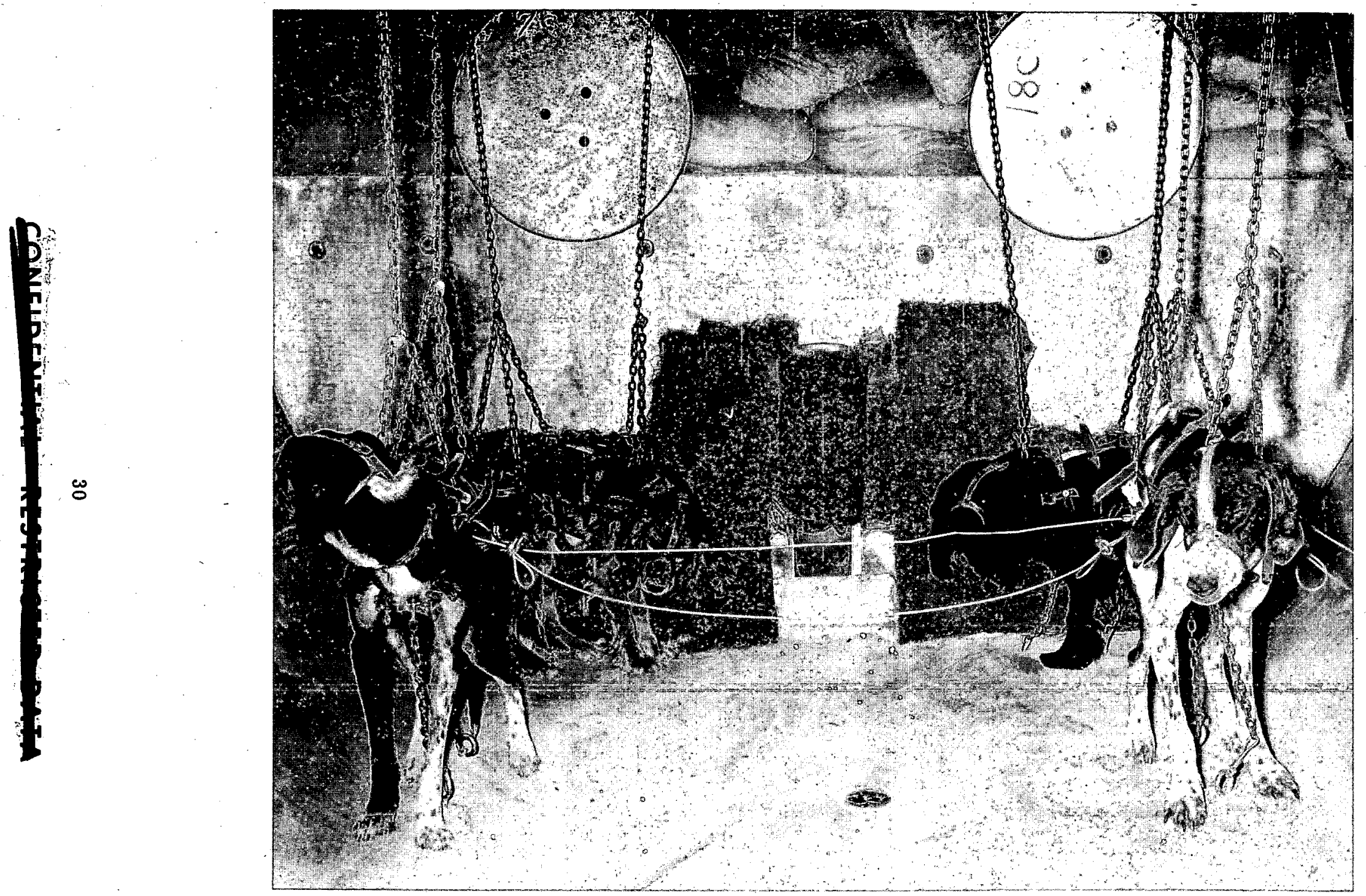

Fig. 2.5-Animals shown in position prior to Shot 11 (C-1, C-2, C-3, and C-4 from left to right). The large metal disks in the background are (BRL) mechanical P-T gauges. A peak-pressure gauge is noted in the floor. 


\subsection{PLAN AND METHODS FOR SUPPLEMENTARY EXPERIMENT (SHOT 11)}

In addition to the operations of primary concern; Shots 1 and 8 , an opportunity was afforded during Shot 11 to obtain data on overpressure effects upon four animals. The structure in which the dogs were exposed was a previously tested shelter, ${ }^{5}$ with one double ramp similar to Structure 602 but entirely open from above. The shelter proper opened directly at right angles to the ramp. Reinforced-concrete culvert sections, 90 in. I.D., had been used in the first half of the shelter proper. Prior to detonation the second 8-ft section was closed in its entire length with sandbags, leaving the first culvert section open to the ramp in its entire cross-sectional area.

Animals were restrained in the manner previously described (Sec. 2.2), within the first "open" culvert section as illustrated in Fig. 2.5. Mechanical pressure vs time gauges were mounted in the bulkhead and at the bottom of the ramp, and peak-pressure gauges were flush mounted in the dirt floor (see Fig. 2.5) by Mervin Clark of the Ballistic Research Laboratories.

\section{REFERENCES}

1. E. W. Ruhl, AEC Shelter Instrumentation, Upshot-Knothole Project 24.3 Report, WT-790, 1953.

2. R. D. Lillie, "Histopathological Technique," The Blakiston Co., Philadelphia, Pa., 1948, p. 28.

3. L. Lǐson, Histochinie Animale: Méthodes et Problèmes, Ganthier-Villars, Paris, 1936.

4. T. L. Chiffelle and F. A. Putt, Stain Technol., 26: 51 (1951).

5. R. L. Corsbie, AEC Communal Shelter Evaluation, Buster Project 9.1b Report, WT-360, 1951. 


\section{CHAPTER 3}

\section{RESULTS}

\subsection{PHYSICAL DATA}

\subsubsection{Pressure Vs Time Data}

Overpressures incident at the shelters during Shot 1 were not obtained. Data from the Sandia Corporation blast line, ${ }^{1}$ however, indicate a maximum pressure of approximately 13.5 psi at the same distance from Ground Zero. This line was essentially at right angles to Shelters 601 and 602 , with respect to Ground Zero. It seemed reasonable to assume symmetry of the advancing overpressure wave.

Pressure vs time traces from gauges $\mathrm{P}-3$ and $\mathrm{P}-11$ (note gauge positions in Figs. 1.1 and 1.4) for Shots 1 and 8 are given in Figs. 3.1 and 3.2, respectively. The upper curves in these figures are plotted with abscissa units such that the general contour and duration of the entire wave can be observed. The lower curves in each figure have an expanded abscissa scale, allowing appraisal of the rise times and early pressure characteristics of the curves. A complete set of pressure-time curves of the data obtained may be found in the report of Ruhl. ${ }^{2}$

Specific portions of the pressure-time traces which appeared to have the greatest immediate biological importance have been derived from the original data, ${ }^{2}$ and analyses of these graphs are presented in Tables 3.1 and 3.2. In these tables values specified under initial rise were obtained in the following manner: the pressure was, in general, read at the earliest point on the curve where the slope of the tangent line passed through zero and reversed its sign from a positive to a negative value; the time noted was the time interval between the arrival time of the shock wave and the occurrence of the first pressure peak noted above; the average rate of rise was found by merely dividing the pressure value by the corresponding time. As as example of initial-rise values selected, in Fig. 3.1 a rise of 7 psi was noted after $14 \mathrm{msec}$ of pressure increase following which the pressure decreased to approximately $3 \mathrm{psi}$. The values for initial rise in this case, therefore, were taken as $7 \mathrm{psig}$ at $14 \mathrm{msec}$ and $0.5 \mathrm{psig} / \mathrm{msec}$. The early maximum rise noted in the tables was chosen by noting the peak pressure attained within approximately the first $30 \mathrm{msec}$ after arrival time. The time and the average rate correspond to the values noted above. In addition to the above characteristics of pressure increase, there usually appeared a rather marked secondary pressure rise as indicated in Fig. 3.1, Shot 1 (lower curve). These second rises frequently occurred within the first $30 \mathrm{msec}$ but were occasionally delayed as noted in Tables 3.1 and 3.2. Peak-pressure values and the duration of the positive phase are given in the last two columns of Tables 3.1 and 3.2 .

To facilitate comparison of pressure-time values occurring in Shots 1 and 8 , the reader may find it helpful to utilize the last two rows in Tables 3.1 and 3.2 which designate the ranges for the values noted above.

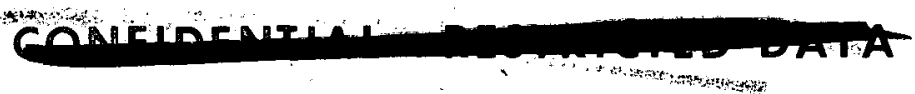



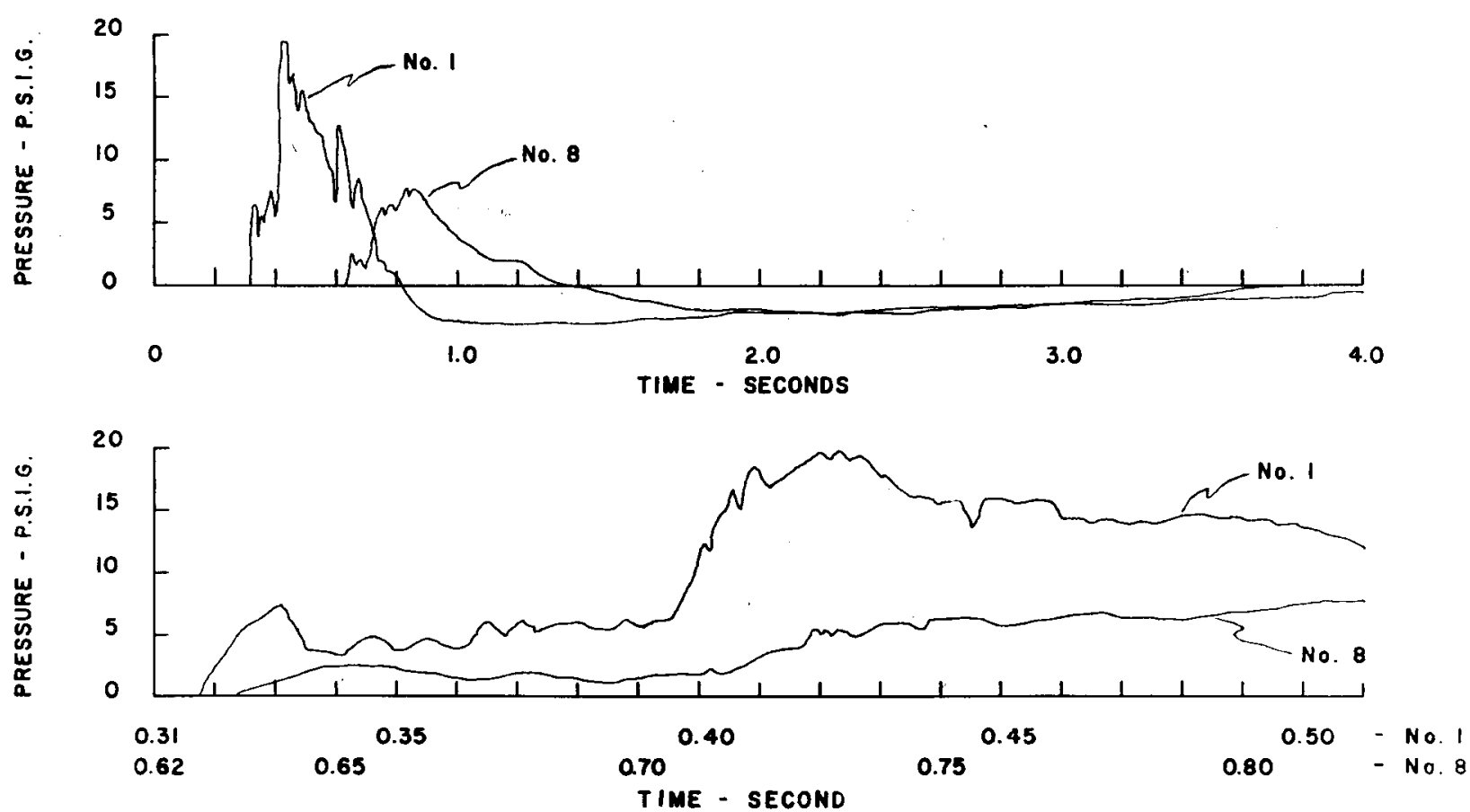

Fig. 3.1-Pressure vs time curves, Shots 1 and 8, gauge P-3, entrance 601 shelter proper. Upper graphs illustrate static-pressure wave form at gauge P-3 during Shots 1 and 8 (curves 1 and 8). Lower graphs have expanded abscissa units so that the rise characteristics may be noted (data by Vitro Corporation of America).
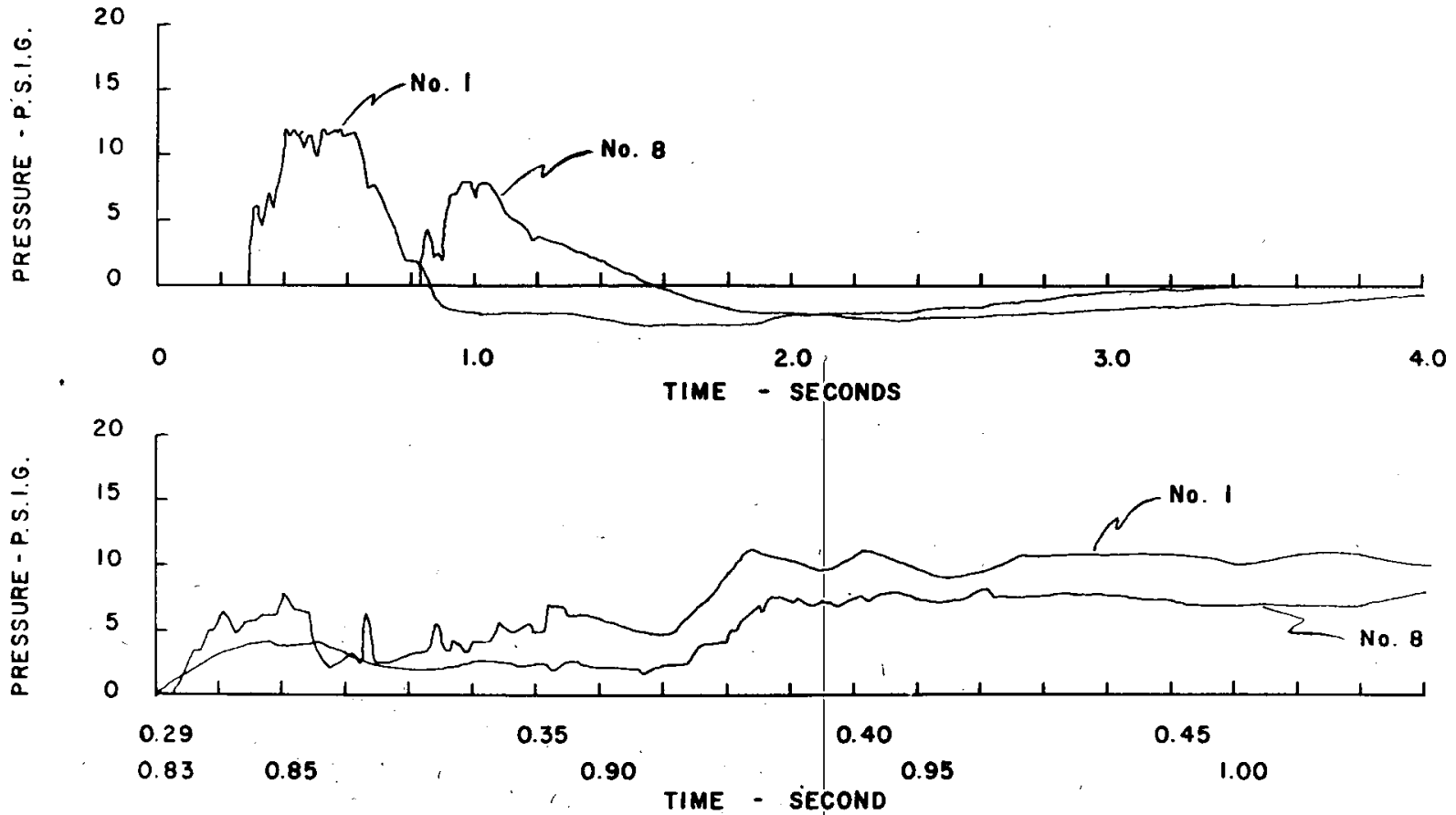

No. 1

No. 8

Fig. 3.2-Pressure vs time curves, Shots 1 and 8 , gauge P-11, entrance 602 shelter proper. Upper graphs illustrate general static-pressure wave form at gauge P-11 during Shots 1 and 8 (curves 1 and 8 ). Lower graphs have expanded abscissa units so that the rise characteristics may be noted (data by Vitro Corporation of America). 
Table 3.1-ANALYSIS OF PRESSURE VS TIME DATA FOR SHOT 1*

\begin{tabular}{|c|c|c|c|c|c|c|c|c|c|}
\hline \multirow[b]{2}{*}{ Gauge No. } & \multicolumn{3}{|c|}{ Initial rise } & \multicolumn{3}{|c|}{ Early maximum rise } & \multirow{2}{*}{$\begin{array}{l}\text { Second } \\
\text { rise, } \\
\text { psig }\end{array}$} & \multirow{2}{*}{$\begin{array}{c}\text { Peak } \\
\text { pressure, } \\
\text { psig }\end{array}$} & \multirow{2}{*}{$\begin{array}{c}\text { Duration } \\
\text { positive } \\
\text { phase, } \\
\text { msec } \dagger\end{array}$} \\
\hline & $\begin{array}{c}\text { Pressure, } \\
\text { psig }\end{array}$ & $\begin{array}{l}\text { Time, } \\
\text { msec }\end{array}$ & $\begin{array}{c}\text { Av. rate, } \\
\text { psig/msec }\end{array}$ & $\begin{array}{c}\text { Pressure, } \\
\text { psig }\end{array}$ & $\begin{array}{l}\text { Time, } \\
\text { msec }\end{array}$ & $\begin{array}{l}\text { Av. rate, } \\
\mathrm{psig} / \mathrm{sec}\end{array}$ & & & \\
\hline 1 & 11.5 & 10 & 1.15 & 19.0 & 22 & 0.86 & 7.5 & 19.0 & 430 \\
\hline 3 & 7.0 & 14 & 0.50 & 7.0 & 14 & 0.50 & $12.5 \ddagger$ & 20.0 & 492 \\
\hline 4 & 9.0 & $<1$. & Inst. $\S$ & 20.0 & 14 & 1.43 & 12.0 & 24.0 & -496 \\
\hline 5 & $5.0^{\prime}$ & 1 & 5.0 & 18.0 & 19 & 0.95 & 12.0 & 21.0 & 443 \\
\hline 6 & 8.0 & 5 & 1.60 & 19.0 & 17 & 1.11 & 11.5 & 25.0 & 485 \\
\hline 10 & 7.0 & 16.0 & 0.44 & 7.0 & 16 & 0.44 & $7.5+$ & 14.0 & 538 \\
\hline 11 & 6.5 & 8 & 0.81 & 8.0 & 17 & 0.47 & $6.0+$ & 12.5 & 557 \\
\hline 13 & 6.5 & $<1$ & Inst. & 16.0 & 13 & 1.23 & 11.0 & 16.0 & 570 \\
\hline \multicolumn{10}{|l|}{ Range: } \\
\hline From & 5.0 & 16.0 & 0.44 & 7.0 & 13 & 0.44 & 6.0 & 12.5 & 430 \\
\hline To & 9.0 & Inst. & Inst. & 20 & 22 & 1.23 & 12.5 & 25.0 & 570 \\
\hline
\end{tabular}

* No data are given in this table for gauges 2,7 to 9,12 , and 14 to 16 .

$\dagger$ See Sec. 3.1.1 for range of negative-phase pressures and durations.

\$ These secondary pressure rises were delayed in their appearance beyond the first 30 -msec interval. They occurred from 43 to $77 \mathrm{msec}$ after the respective arrival times.

$\S$ Inst. indicates instantaneous values of pressure rise with regard to maximum-rise-time characteristics of the $\mathrm{P}-\mathrm{T}$ recording system (see Sec. 3.1.1). 
Table 3.2-ANALYSIS OF PRESSURE VS TIME DATA FOR SHOT 8*

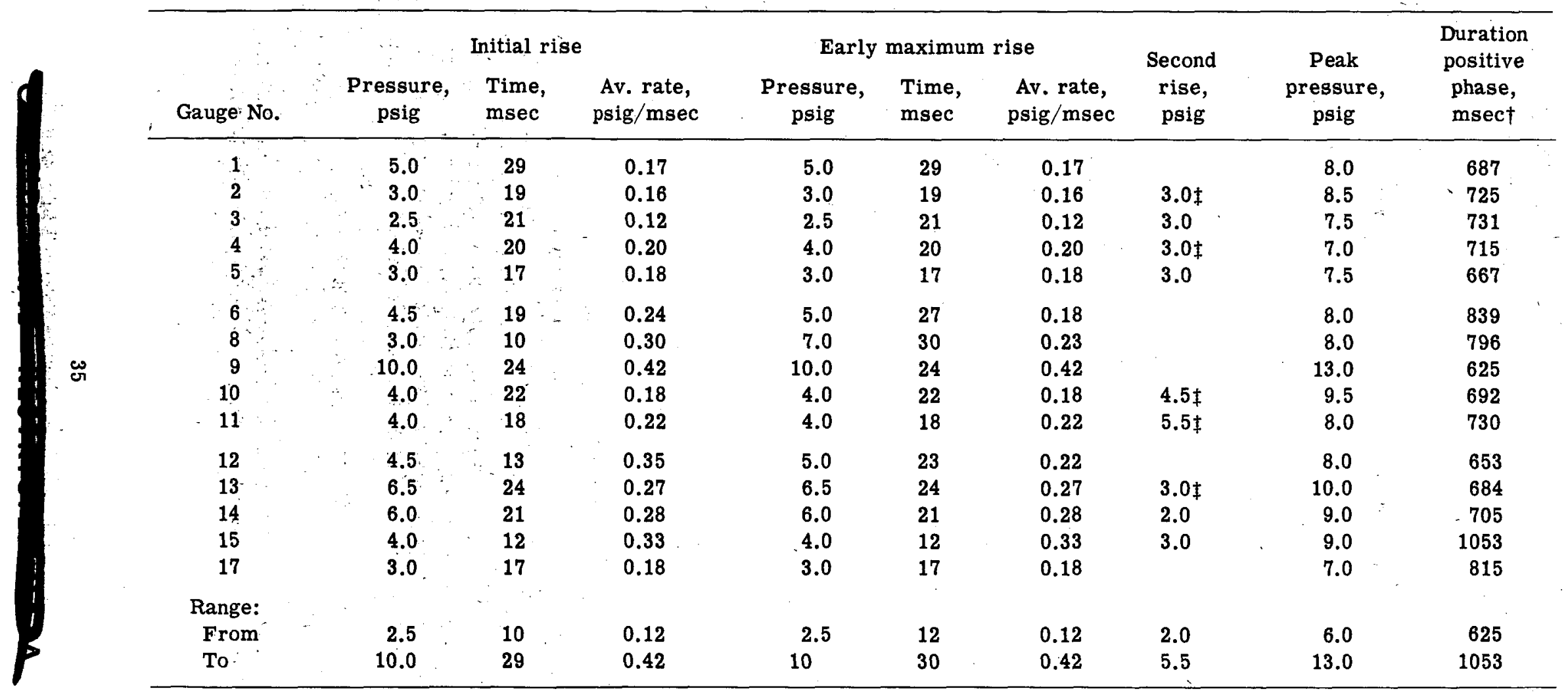

* No data are given in this table for gauges 7,16 , and 18 .

$\dagger$ See Sec. 3.1.1 for range of negative-phase pressures and durations.

$\ddagger$ These secondary pressure rises were delayed in their appearance beyond the first 30 -msec interval. They occurred between 35 and $97 \mathrm{msec}$ after the respective arrival time. 
The response characteristics of the pressure pickup and recording system were tested by shock-tube studies. ${ }^{2}$ The shock front resulted in a rise time of less than 1 msec in the time sensitive system. ${ }^{2}$ Thus pressure vs time responses obtained'in the field, which showed rise times of $<1 \mathrm{msec}$, were considered herein as instantaneous and were so indicated in Tables 3.1 and 3.2. Whether these are true shock fronts appears at this time to be an academic question.

The negative phases of the pressure waves vary from 2.0 to 3.5 psi in Shot 1 and ranged in duration from 2.1 to $2.8 \mathrm{sec}$. For Shot 8 the ranges were 1 to $3 \mathrm{psi}$, with durations from 1.1 to $2.6 \mathrm{sec}$.

\subsubsection{Air-drag Data}

Graphs from the drag-gauge recordings for Shots 1 and 8 are given in Fig. 3.3.

Calibration data as obtained from wind-tunnel studies ${ }^{3}$ with this gauge allow the readings to be represented in pounds per square inch.

\subsubsection{Peak Pressures and Pressure Vs Time for Shot 11}

The peak pressure only was obtained from the gauge at the bottom of the ramps, which was recorded as 40 psi. A doubtful peak of 100 psi is given for gauge $7 \mathrm{C}$ in the bulkhead (note Fig. 2.5). The pressure-time trace for gauge $18 \mathrm{C}$ in the bulkhead was noted as poor. ${ }^{4}$ Both $7 \mathrm{C}$ and $18 \mathrm{C}$ were blown out during the blast. In spite of this misfortune it seems of interest to note the rise pressures of gauge $18 \mathrm{C}$ during the first few milliseconds. This has been done, and data are given in Table 3.3, so that this approximate rate of pressure increase may be compared with those from Shots 1 and 8.

Table 3.3 - ANALYSIS OF PRESSURE VS TIME DATA FOR SHOT 11

\begin{tabular}{lccc}
\hline & \multicolumn{3}{c}{ Gauge No. } \\
& $18 \mathrm{C}^{*}$ & $14 \mathrm{~B} \dagger$ & $3 \mathrm{~B} \dagger$ \\
\hline Initial rise: & & \\
Pressure, psig & 15 & \\
Time, msec & 12 & \\
Av. rate, psig/msec & 1.25 \\
Early maximum rise: & & \\
Pressure, psig & 30 & \\
Time, msec & 26 & \\
Av. rate, psig/sec & 1.15 & 38 \\
Peak pressure, psig & & 37 \\
\hline
\end{tabular}

* These data are from BRL gauge $18 \mathrm{C}-15-100$, which was mounted to record a reflected pressure and was blown out of its original position. Values given, therefore, should be considered accordingly but may add biologically pertinent data, particularly in terms of the rise within the first 12 msec.

$\dagger$ This gauge recorded only peak static pressures.

Peak-pressure gauges in the shelter floor recorded values of 37.0 and $38.0 \mathrm{psi}$. Blast-line data ${ }^{1}$ indicated an outside pressure of approximately 35 psi at a comparable distance from Ground Zero. 


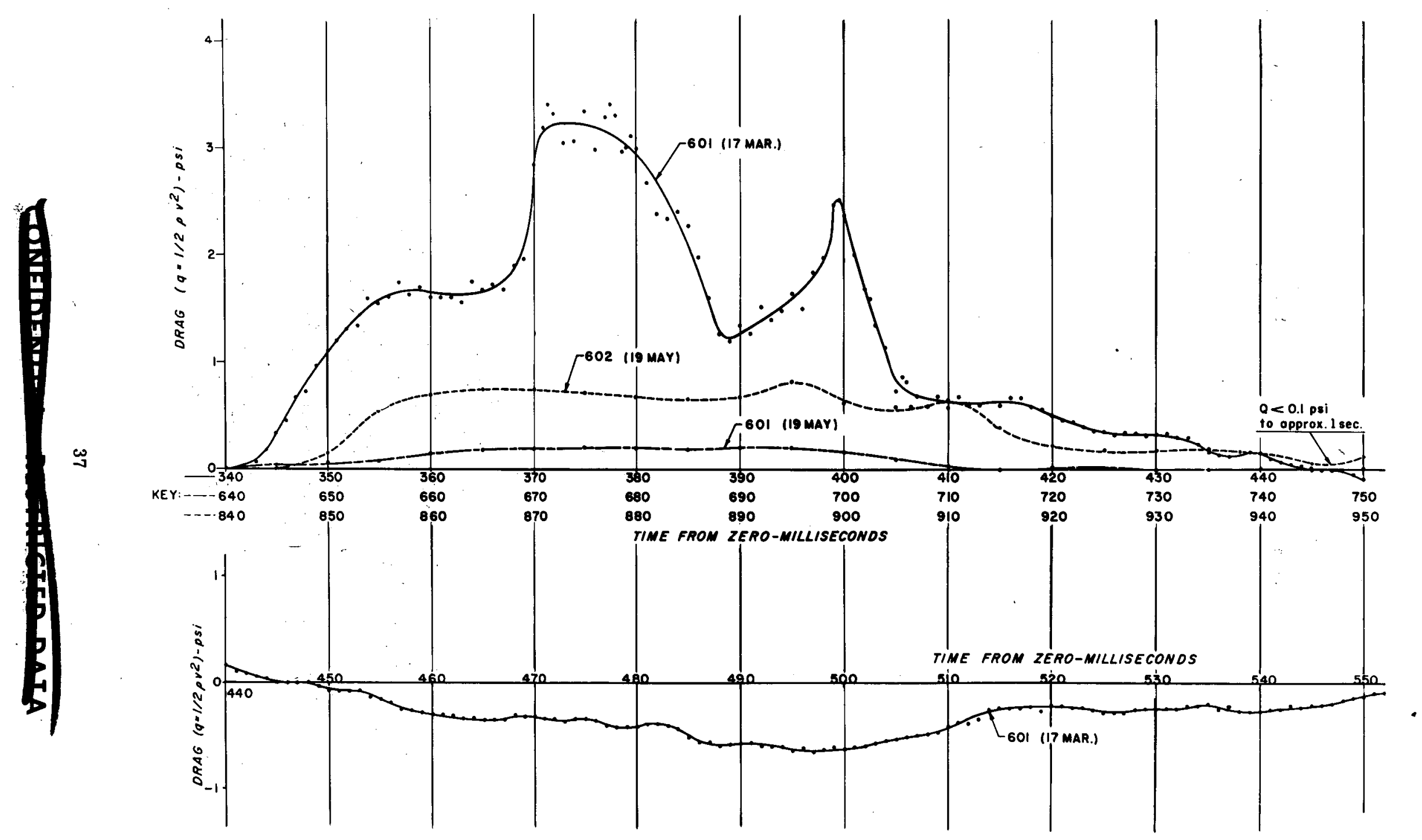

Fig. 3.3-Air drag vs time curves for Shelter 601, Shot 1 (Mar. 17, 1953), and for Shelters 601 and 602 , Shot 8 (May 19, 1953). 


\subsection{CLINICAL DATA}

\subsubsection{Clinical Data from Shot 1 Animals}

The time between detonation and recovery was $4.5 \mathrm{hr}$. One animal (D-15) was dead, having been chloroformed by an advance party. This animal whined and presumably was in pain. The dog against the baffle in Shelter 602 (D-14) displayed labored respirations and appeared to be in shock. A large hematoma was noted, at once, on the tongue of D-14; pulling the tongue forward allowed a patent airway, and the animal recovered. Only one animal showed significant thermal damage, namely, D-9 located at the end of the 601 blast trap. The fur in this case was singed to a moderate degree on both sides of the animal.

The remaining dogs appeared generally little affected by the experience, although nearly all were considerably subdued in responses. All animals ate and drank readily following return to their quarters, and all seemed friendly and generally in good spirits.

Because of the previous respiratory difficulties, D-14 was auscultated at the animal quarters on several occasions. On one observation moist rhonchi were heard; otherwise the lungs sounded essentially clear.

One-third of the animals (D-3, D-7, D-14; D-8, and D-1) exhibited some degree of ataxia. In three dogs (D-7, D-8, and D-1) the ataxia persisted for more than $24 \mathrm{hr}$ (until autopsied, Table 3.4). The disorder seemed to be cerebellar in type since it was characterized by sudden staggering or loss of coordination while walking.

Table 3.4 - TIME AND ORDER OF AUTOPSIES FOLLOWING SHOT 1

\begin{tabular}{|c|c|c|c|c|c|}
\hline \multirow[b]{2}{*}{ Animal } & \multicolumn{2}{|c|}{ Time after explosion, hr } & \multirow[b]{2}{*}{ Animal } & \multicolumn{2}{|c|}{ Time after explosion, hr } \\
\hline & Shelter 601 & Shelter 602 & & Shelter 601 & Shelter 602 \\
\hline$D-15$ & & $12^{\circ}$ & $D-1$ & & 36 \\
\hline D-9 & 14 & & $D-13$ & & 37 \\
\hline$D-3$ & 16 & & $\mathrm{D}-12$ & 40 & \\
\hline $\mathrm{D}-14$ & & 17 & $D-8$ & & 41 \\
\hline$D-4$ & 30 & & D-2 & 53 & \\
\hline$D-7$ & 32 & & $D-5$ & & 54 \\
\hline$D-11$ & 34 & & D-6 & & 55 \\
\hline$D-10$ & & 35 & & & \\
\hline
\end{tabular}

\subsubsection{Clinical Data from Shot 8}

The initial recovery party found one animal, 602-3 (dog in position No. 3 in Shelter 602), dearranged in the harness and bleeding from the nose and mouth. At the time of later examination, however, the bleeding had ceased and no source could be determined clinically or at autopsy. One animal, 601-2, was slightly singed.

The animals, other than 602-3, were all lively and displayed normal reaction patterns, and no clinical evidences referable to blast damage were found. Electrocardiograms taken in the shelters were also normal.

\subsubsection{Clinical Data from Shot 11}

Recovery was delayed following this test until $11 \mathrm{hr}$ after detonation. The animals were found to have suffered marked displacement, as noted in Fig. 3.4, contrasted to original positions (left of Fig. 2.5). 


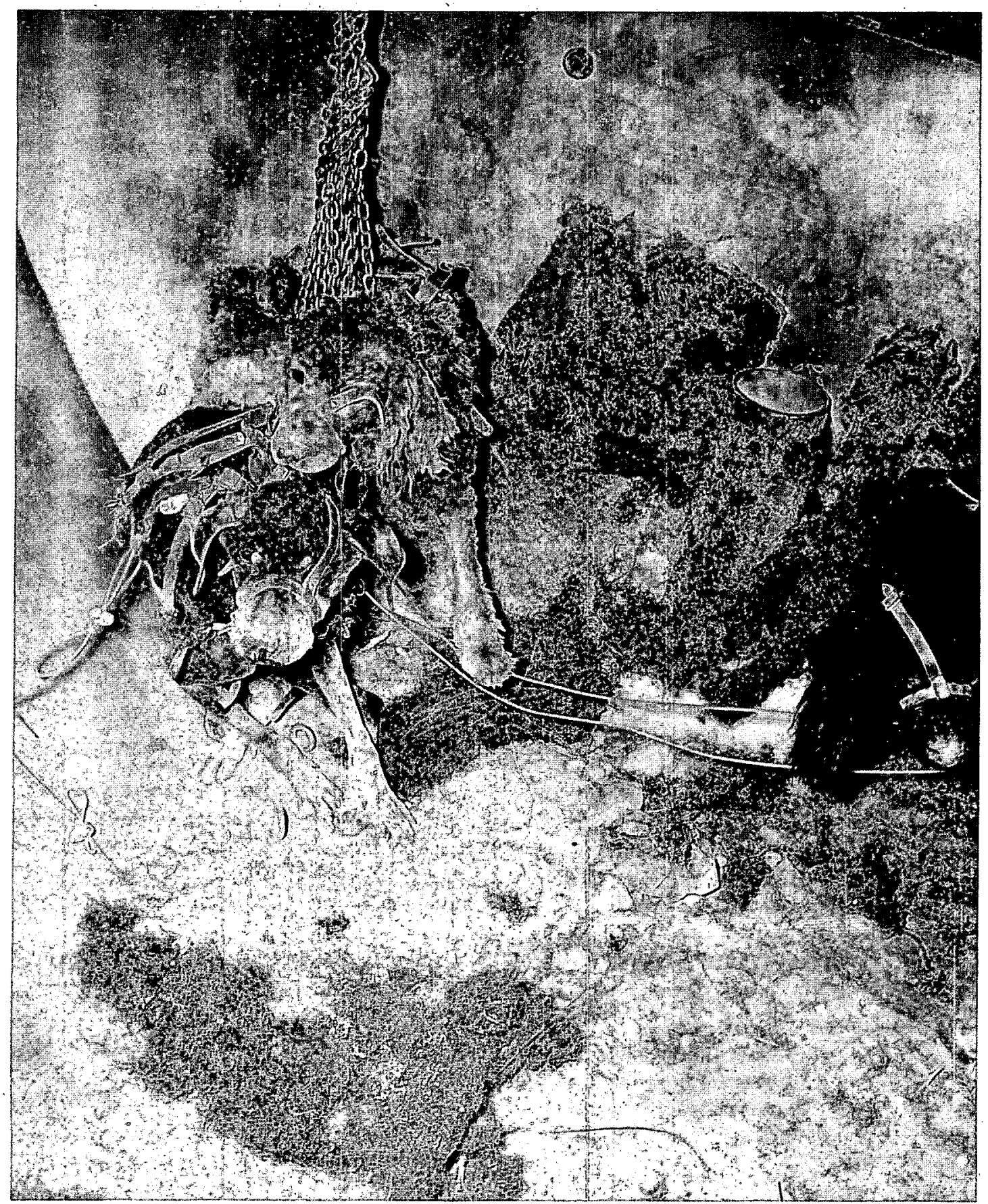

Fig. 3.4-Animals $\mathrm{C}-1$ and $\mathrm{C}-2$ following Shot 11 . Note evidence of marked displacement (twisted chains) and burning of the dogs (see Fig. 2.5).

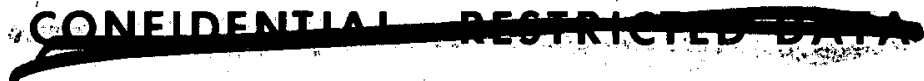


All four animals were lethargic and displayed rather stupified responses. Every animal was burned - three of the four (C-1, C-2, and C-4) severely (animals were numbered C-1, $\mathrm{C}-2, \mathrm{C}-3$, and C-4 from left to right in Fig. 2.5). The extent of singeing may be noted by comparing the two animals on the left of Fig. 2.5 with the illustration of the same two dogs shown in Fig. 3.4. The harness and muzzle straps afforded protection from thermal injury to the underlying surfaces.

Two animals (C-2 and $\mathrm{C}-4)$ vomited several times after eating and drinking, whereas the remaining two refused food and water.

No response could be elicited in dog C-1 to intense auditory stimuli. Animals C-3 and C-4 had markedly reduced auditory acuity.

The eyes of C-1 were injured; the lids were held in a squint, a mucoid discharge was profuse, and the pupils were nearly "pinpoint" and did not react to light.

General physical examinations revealed no evidence of blast injuries per se.

The neurological examinations were essentially negative except for the extreme lethargy of the animals.

\subsection{PATHOLOGICAL DATA}

\subsubsection{Control Animals, Findings}

One singular feature noted in the control animals was the common occurrence of small fresh petechiae, most frequently observed in the substance of cardiac valves (especially the mitral valve), the abdominal and thoracic lymph nodes, the lungs, and the brain. Except in the lymph nodes, these tiny hemorrhages embraced no more than the immediate perivascular zone and were devoid of leucocytic infiltration or reaction. In the sinuses of the lymph nodes were found not only fresh petechiae but also deposits of phagocytized hemosiderin pigment, indicating previous focal red cell extravasation.

Other gross findings, incidental to the experiment, were presence of tapeworms in the ileum, rare chronic cholecystitis, old pyelonephritis, and focal pulmonary parasitic granuloma.

\subsubsection{Experimental Animals from Shot 1}

The animals used in the first experimental exposure were of a mixed-breed type, obtained at random, and were not conditioned to experimental work. They all appeared in good health and were unusually vigorous. Weight range extended between 35 and $42 \mathrm{lb}$. None were known to have immunization inoculations. All but one were found to be infested with tapeworms.

The injuries, in this experiment, were manifest almost entirely by local hemorrhages, scattered in distribution, and varying considerably in degree and number from one animal to another. Only one organ, the urinary bladder, showed gross disruption or tearing of tissue as a result of the blast.

(a) Skeletal-Muscular System. Gross evidence of muscular, skeletal, and soft-tissue injury was noted in only three dogs. No bone fractures were found. Animal D-14 showed multiple moderate-size hemorrhages in the intercostal muscles of the right and left chest wall, especially prominent in the paravertebral region. It is interesting to note that the right chest wall rested against the concrete wall, separated only by a felt padding, whereas the left chest faced the oncoming shock front. A small focal hemorrhage was present in the soft tissues of the esophagus and trachea of D-2 and D-8.

(b) Lungs and Upper Respiratory Passages. No gross or microscopic injury was found in the upper respiratory passages. The tonsils of many animals were hyperemic but not greater than the degree found frequently in the control series. Dust accumulation was not found in any bronchus, although sufficient time had elapsed for its reflex removal. Pulmonary lesions appeared in two forms, the first and most distinctive being areas of frank hemorrhage varying from small red spots a few millimeters in diameter to larger blotches two or more centimeters 
in diameter. The second form consisted of small areas of contusion characterized by local vascular hyperemia, in which actual hemorrhage could not be demonstrated microscopically. This latter form was much less frequently seen. Although the lesions were scattered, a definite pattern of distribution was noted. The hemorrhagic lesions were most commonly seen on the lung surfaces which were wedged between more solid structures, namely, along the fringes of the lower lobes in the costophrenic recess; in the conical apex of the upper lobes; the anterior segments of both cardiac lobes, especially the left, where lung tissue is sandwiched between the anterior chest wall and the heart; and the two finger-like segments and apical portion of the lobus intermedius which lies over the dome of the diaphragm and beneath the heart in such a manner that combined abdominal and thoracic pressure could readily impinge the tissue between the heart and diaphragm. Sometimes the shape of the hemorrhagic marks conformed to rib contours or vertebral and vena-caval contours. This was especially true of D-14.

The size of the individual hemorrhages varied considerably, but none were of massive proportions or of such degree as to obviously interfere appreciably with total alveolar respiratory function. Although some of the subpleural zones appeared of considerable width, they proved to be of shallow depth. In most instances the parenchymal lesions were of small size often seen only microscopically with certainty. Large areas of hemorrhagic consolidation were absent. The pattern of deeper hemorrhages could not be readily correlated with anatomical features such as broncho-vascular walls.

One of the most distinctive gross features was the frequent occurrence of large and small blood clots in the major bronchi of almost half (seven) of the exposed animals. In one animal (D-14) the intraluminal clotted blood formed a virtual cast of the entire right lower lobe bronchus. The presence or absence of bronchial blood and the amount of clots corresponded readily to the severity of pulmonary damage. The bronchi of animals D-14, D-5, D-15, D-6, D-13, D-9, and D-2 contained gross blood clots (note Table 3.5).

Table 3.5 - DISTRIBUTION OF LESIONS IN VARIOUS ORGANS (GROSS AND MICROSCOPIC)*

\begin{tabular}{|c|c|c|c|c|c|c|c|}
\hline $\begin{array}{c}\text { Dog† } \\
\text { No. }\end{array}$ & $\begin{array}{c}\text { Middle } \\
\text { ears }\end{array}$ & $\begin{array}{l}\text { Frontal } \\
\text { sinuses }\end{array}$ & Heart & Lungs & $\begin{array}{l}\text { Omentum, } \\
\text { mesentery }\end{array}$ & Spleen & $\begin{array}{l}\text { Urinary } \\
\text { bladder }\end{array}$ \\
\hline
\end{tabular}

Shelter 601

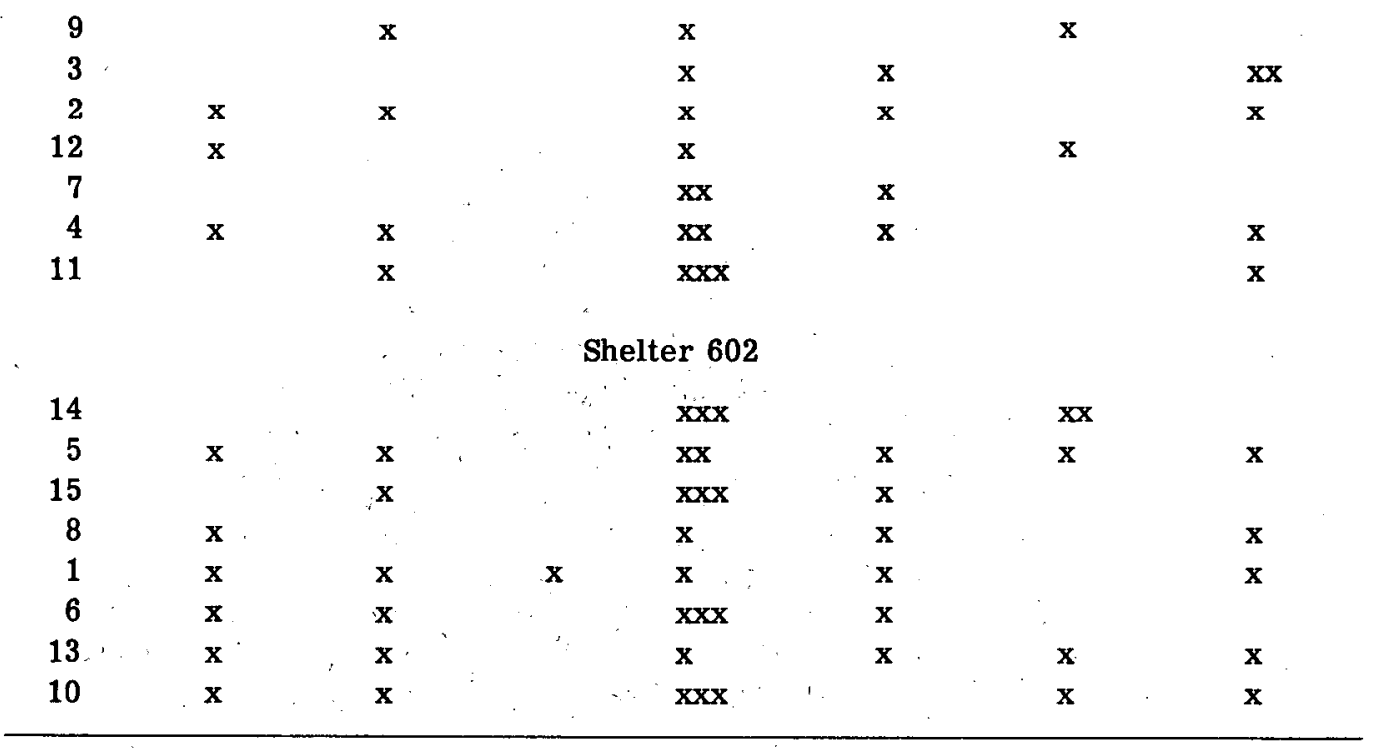

* Degree of damage: $\mathrm{x}$, minimal; $\mathrm{xx}$, moderate; and xxx, marked.

$\dagger$ Arranged in descending order, front to rear of respective shelters.

41

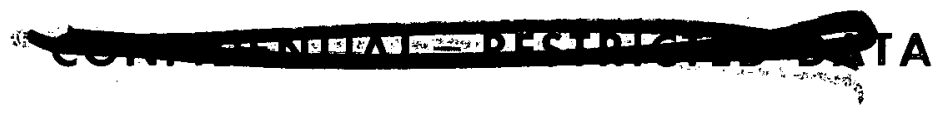


The severity of pulmonary lesions was not the same for each shelter. Surprisingly, Shelter 602, with the additional entry baffle, sustained the most severe total animal damage. Five out of eight animals were judged as having moderate to marked pulmonary hemorrhages, the first three animals in the front end of the shelter and last two animals in the rear, excepting D-13, which was shielded by a large metal cube. In Shelter 601 two animals were judged to have a moderate number of hemorrhages and one marked. All three of these animals were in the extreme distal end of the shelter.

There was no good correlation between estimates of damage in the right or left lung and the side presenting to deformity by the approaching shock front. In only four instances the major damage to one lung corresponds to the side presenting. In three animals the opposite lung to the side presenting suffered the worst damage. In most instances the lesions were bilateral and appeared to be localized where the pulmonary tissue could be compressed between more solid structures, as indicated in a foregoing paragraph.

None of the lungs of the animals were appreciably increased in weight. No evidence of pulmonary edema was seen. In two animals a single small recently formed thrombus was found in branches of the pulmonary artery. Early leucocytic response to the focal hemorrhages and within the bronchial wall (when intraluminal clotted blood was found) was seen in animals examined after many hours had elapsed. No evidence of interstitial or mediastinal emphysema was found. There was no instance of pneumothorax, hemothorax, atalectasis, or emphysema.

In all lungs evidence was sought to demonstrate traumatic disruption of pulmonary parenchyma or shearing away of alveolar tissue from bronchial walls, but none could be found. The collapsible nature of elastic arterial walls produced a frequent artefact of separation from the surrounding tissue. This was not apparent around muscular bronchial walls.

Considerable dust was noted in the lungs of all animals but was seen only as fine pigmented particles containing anisotropic needle-like crystals of silica characteristics. The particles and crystals were never found free but always phagocytized by histiocytes in the walls of terminal bronchioles or bronchi. There was no associated inflammatory reaction. Since the animals had been exposed to numerous dust storms prevalent in the Southwest, it is difficult to interpret the role of dust in this experiment. The dust content; microscopically, appeared no greater than that seen in control animals.

(c) Heart. As noted in Sec. 3.3.1, concerning control animals, tiny fresh petechiae were a frequent occurrence. With Masson trichrome stain dilated and very thin walled blood vessels embedded in a loost reticular fibrous matrix could be readily demonstrated in the cardiac valve leaves. The small red cell extravasation appeared to be the result of terminal capillary fragility. Such lesions were found in the same frequency in the test animals. Only one test animal (D-1) showed evidence of possible cardiac contusion, and in this instance much of the left ventricular wall contained flame-shaped subendocardial hemorrhages. No evidences of air emboli were found.

(d) Omentum and Mesentery. These soft structures were frequently the site of many scattered hemorrhages which were found in 10 out of 15 test animals. They were seldom greater than $1 \mathrm{~cm}$ in size and never were found in control animals.

(e) Spleen. The spleen showed evidence of contusion and subcapsular hemorrhage in 6 of the 15 animals and occasionally attained a size of $3 \times 2.5 \mathrm{~cm}$. The capsule was never torn but was found to be separated or sheared from the soft pulp resulting in a pooling of blood in an area beneath the capsule, after lifting the latter to form a bleb-like mound.

(f) Urinary Bladder. Punctate hemorrhages and actual disruption of the bladder wall (mucosa, submucosa, and part of the muscularis) were frequent findings and occurred in nine animals, four of which (D-5, D-3, D-11, and D-10) had large mural tears, resulting in an irregular stellate ulceration with dark hemorrhagic base and edges formed by the rolled edematous mucosa. No instance of perforation was seen. The presence or absence of such damage did not conform to the extent of pulmonary damage and was presumably dependent upon the existing degree of bladder distension at the time of blast. 
(g) Eyes. No corneal or retinal lesions were seen in any animal.

(h) Ears. Small hemorrhagic lesions in the form of fresh petechiae, or slightly larger, were found in the middle ear cavity of nine animals, the majority (six) occurring in Shelter 602. The tympanic membranes were found to be intact except for one animal (D-4 and D-5) in each shelter; in each case one membrane was perforated.

(i) Frontal Sinuses. The lining membrane of the frontal sinuses was frequently hyperemic and occasionally studded with tiny petechiae. In most of these there was no associated evidence of chronic inflammation.

(j) Gastrointestinal Tract. Occasional small scattered areas of superficial mucosal hyperemia were found in the stomach wall, duodenum, and ileum of a few animals. Microscopic sections showed only mucosal vascular dilatation without hemorrhagic phenomena. These lesions were absent in other animals which were tapeworm infested.

(k) Brain. No gross changes were seen in any brain or spinal cord in the test animals. Numerous sections from many areas of the central nervous system were studied for the appearance of small foci of degeneration, hemorrhage, or fat emboli, but all results were negative.

In Table 3.5 the distribution of pathological changes in all animals has been listed according to frequency of occurrence. The degree of damage has been noted only under columnheading "lungs" and graded $\mathrm{x}, \mathrm{xx}$, or $\mathrm{xxx}$, denoting minimal, moderate, or marked, respectively. The most constant hemorrhages were found in lungs, omentum and mesentery, frontal sinuses, middle ears, urinary bladder, and spleen. It should be noted that the term "marked," as used here, is only a comparative one embracing the extreme of the scope of lesions found herein. In no animal were the hemorrhages of such extensive nature as found with sudden high pressures (obtained with conventional high explosives at close range) nor of such magnitude as to obviously impair pulmonary function. The possible secondary effects, had the animals been allowed to survive, cannot be estimated since survivorship studies were not included in this first test.

Figures 3.5 to 3.12 illustrate gross and microscopic lesions which were typical findings for animals in Shot 1.

For purposes of reference the times at which animals were posted, following the detonation, have been given in Table 3.4 .

\subsubsection{Experimental Animals from Shot 8}

Rare tiny petechiae were found in the soft tissues of the back and neck, most of which could be attributed to the effects of harness restraint. Internal signs of injury were extremely meager and consisted only of rare tiny petechiae scattered over the surface of the lungs of five animals $(601-3,602-10,602-9,601-8$, and 601-2). Corresponding positions may be noted in Figs. 1.5 and 1.6. Otherwise the lungs appeared perfectly normal. No blood was seen in any bronchus. The middle ears of nine animals were hyperemic with an occasional tiny hemorrhage. The left eardrum of 601-3 was ruptured. No other pertinent lesions were found in these animals.

\subsubsection{Experimental Animals from Shot 11}

No significant evidences of blast damage were found in the dogs exposed during Shot 11, with the exception of middle ear lesions. The drums of C-4 were ruptured bilaterally, whereas the remaining three dogs showed right drum perforations and a large middle ear hematoma was found in $\mathrm{C}-3$.

Dog C-1 showed edema of the left front leg, as a result of burns. This animal also had small mucosal hemorrhages in the bladder and bilateral intercostal muscle hemorrhages at the $2 \mathrm{~d}, 3 \mathrm{~d}$, and 4 th levels.

The thoracic and abdominal viscera of all four dogs were remarkably free of lesions.

(Text continues on page 52.)

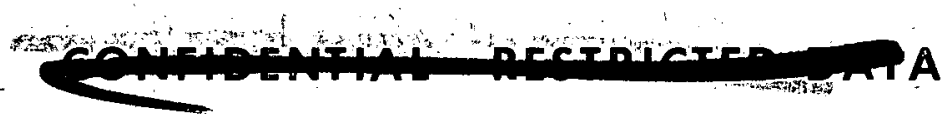




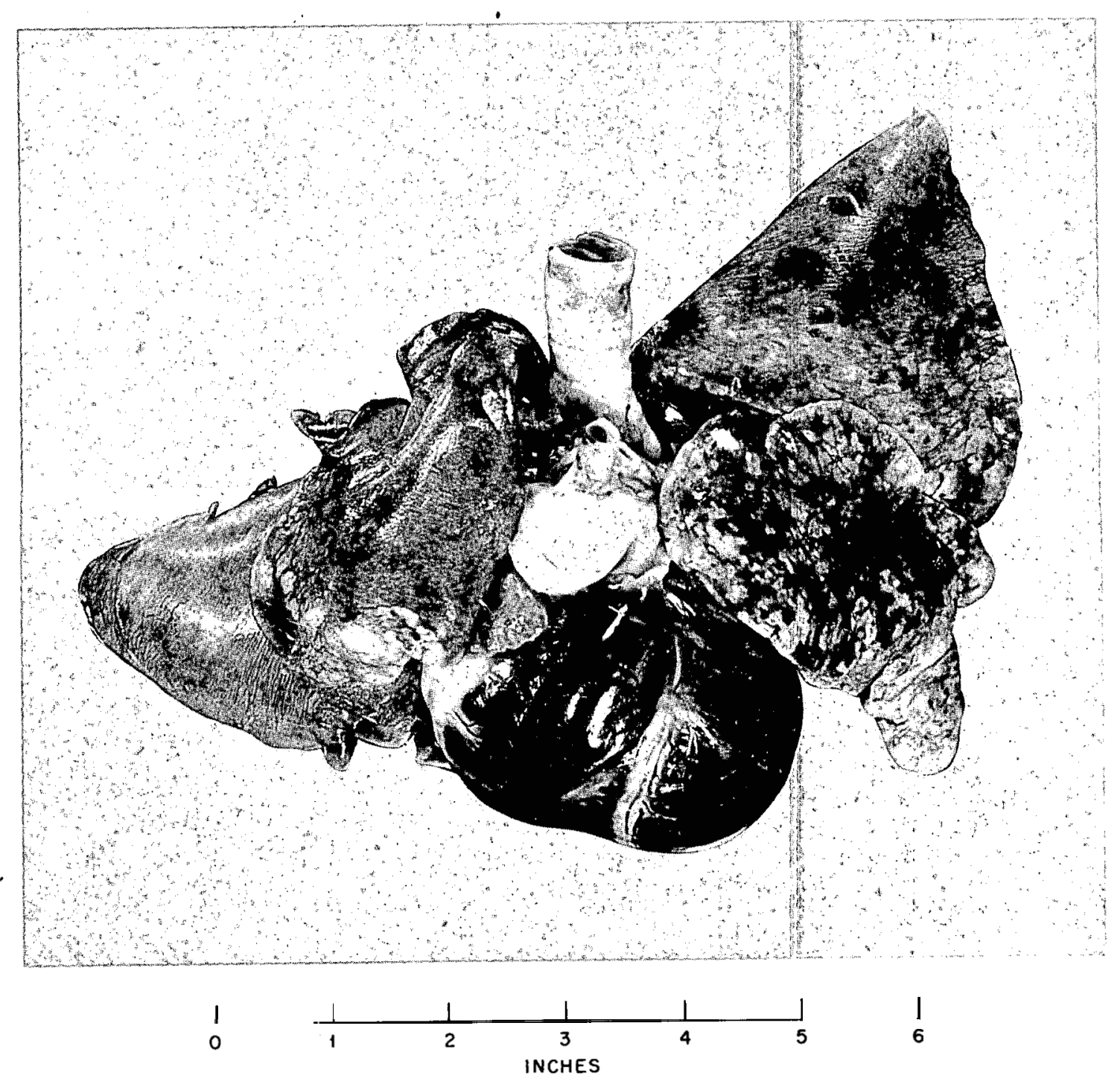

Fig. 3.5-Anterior view of lungs and heart of animal D-10 (position 602-7). Largest group of hemorrhages is present in left cardiac lobe, a large portion of which overlies the heart, in situ. Smaller hemorrhages are visible in the left diaphragmatic lobe. 


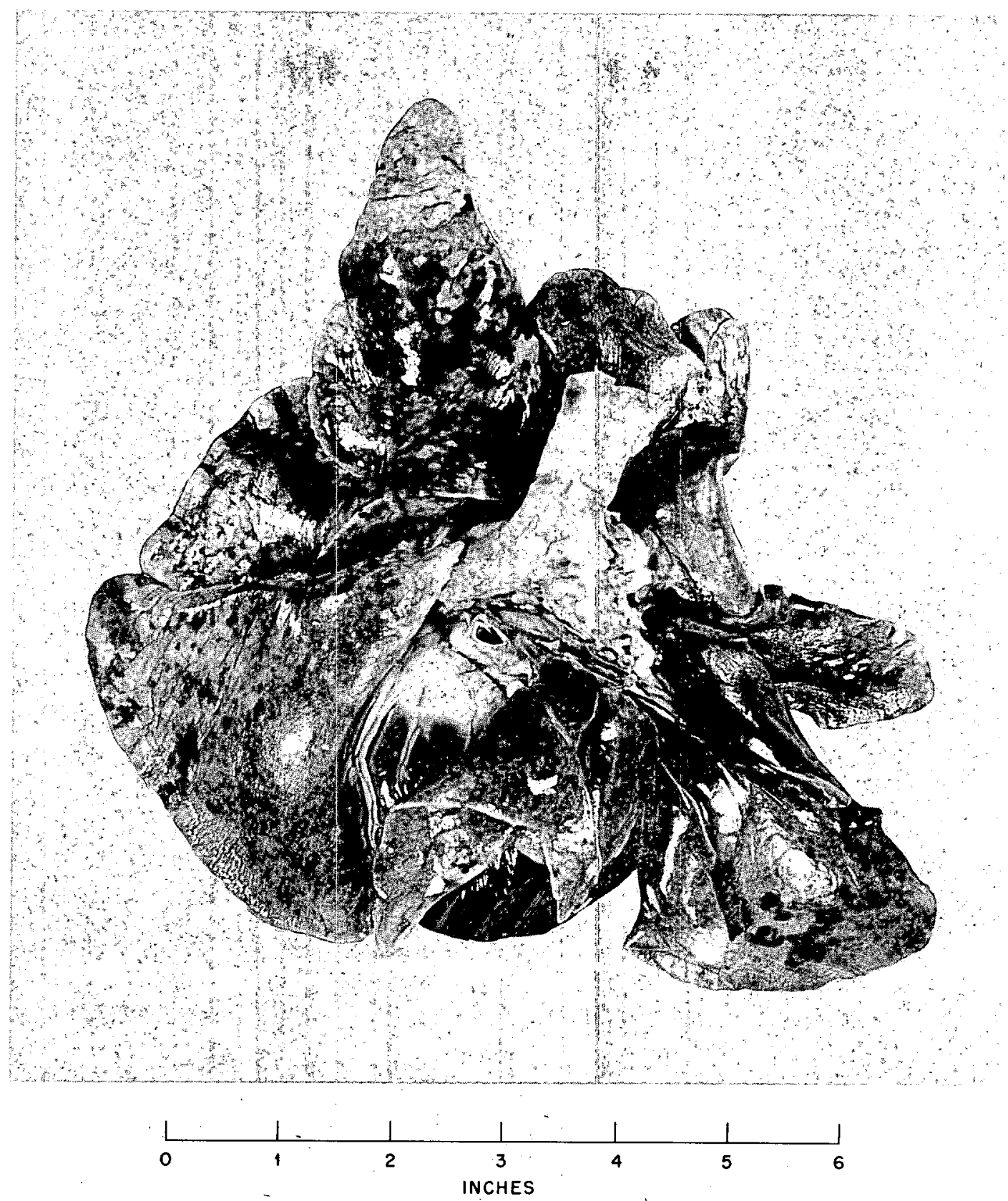

Fig. 3.6- Posterior view of lungs and heart of Animal D-10 (position 602-7). Large hemorrhages are visible in the apical and cardiac lobes. Smaller hemorrhages are seen in tongues and apex of intermediate lobe and in the right diaphragmatic lobe. The left side of this animal was presented to the shock.

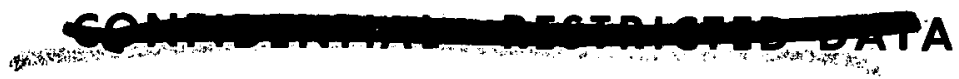




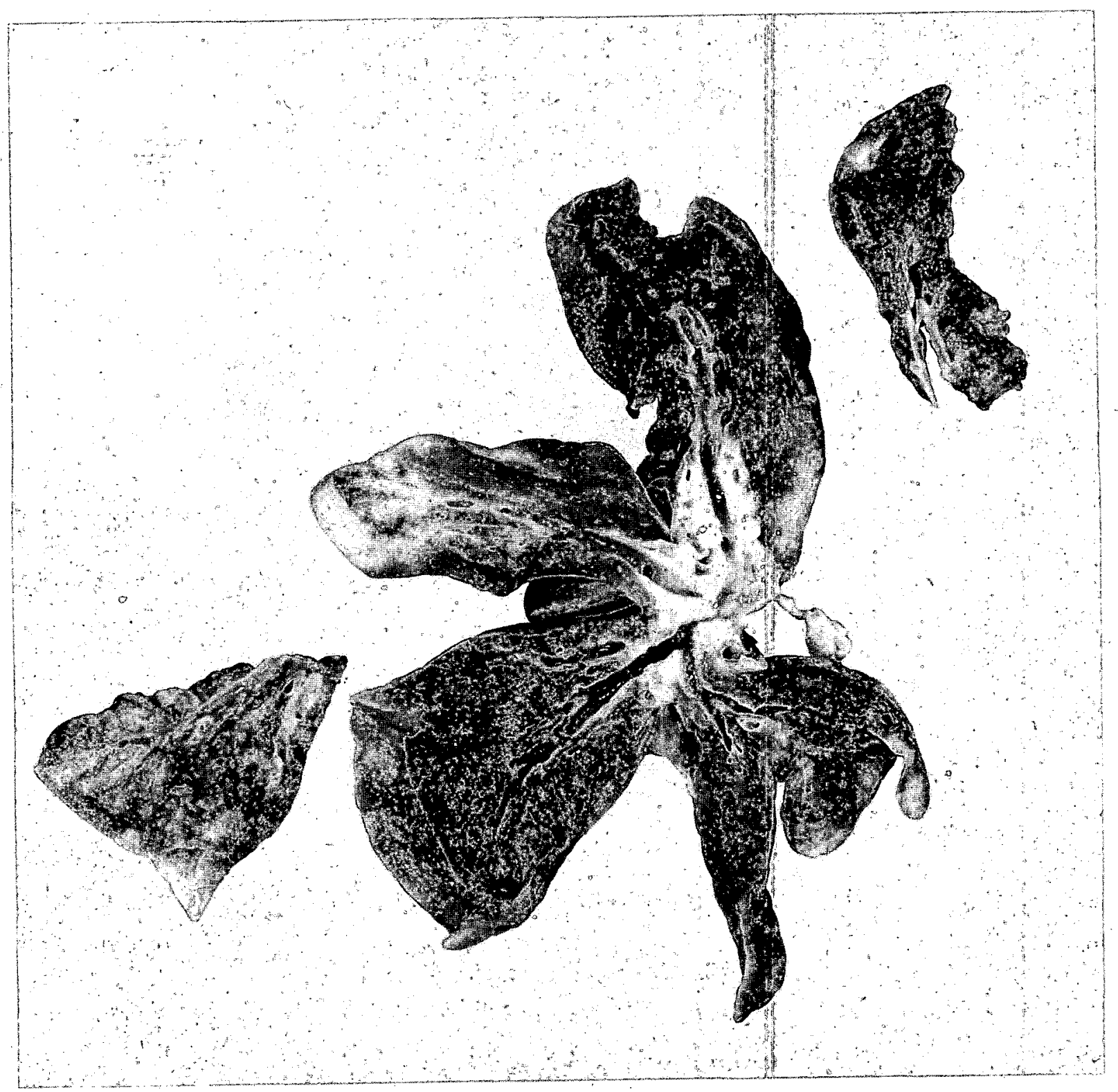

Fig. 3.7-Cross section of fixed right lung of animal D-14. The intraluminal clotted blood is readily visible in the major bronchi supplying the right diaphragmatic lobe and intermediate lobe. 

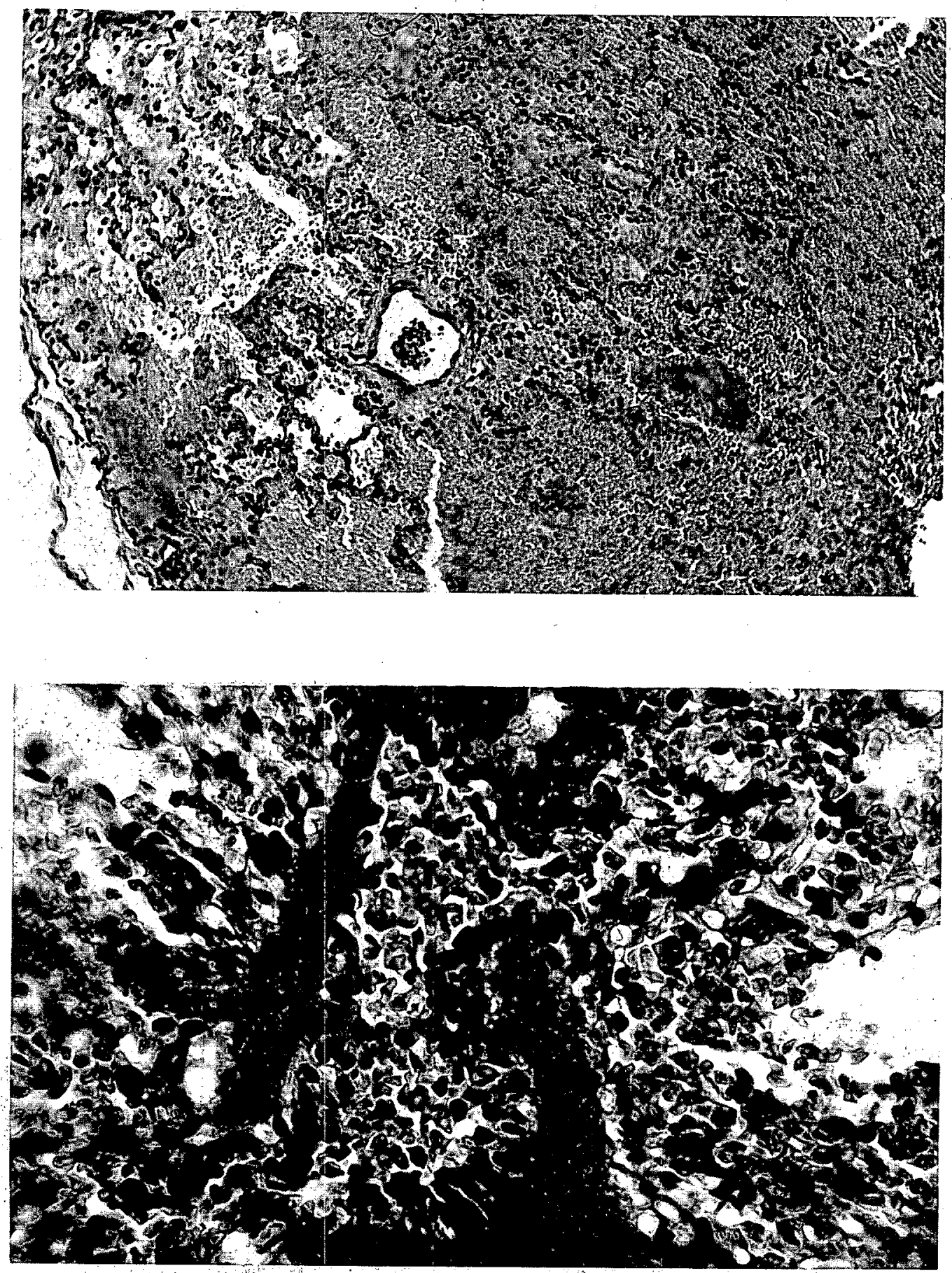

Fig. 3.8-Lung (microscopic), hemorrhagic areas. Upper illustration: typical histological appearance of a larger hemorrhagic area. Some hyperdistension of alveoli is also apparent. Lower illustration: smaller area of hemorrhage, more frequently seen, embracing a muscular alveolar duct and filling the lumen. 

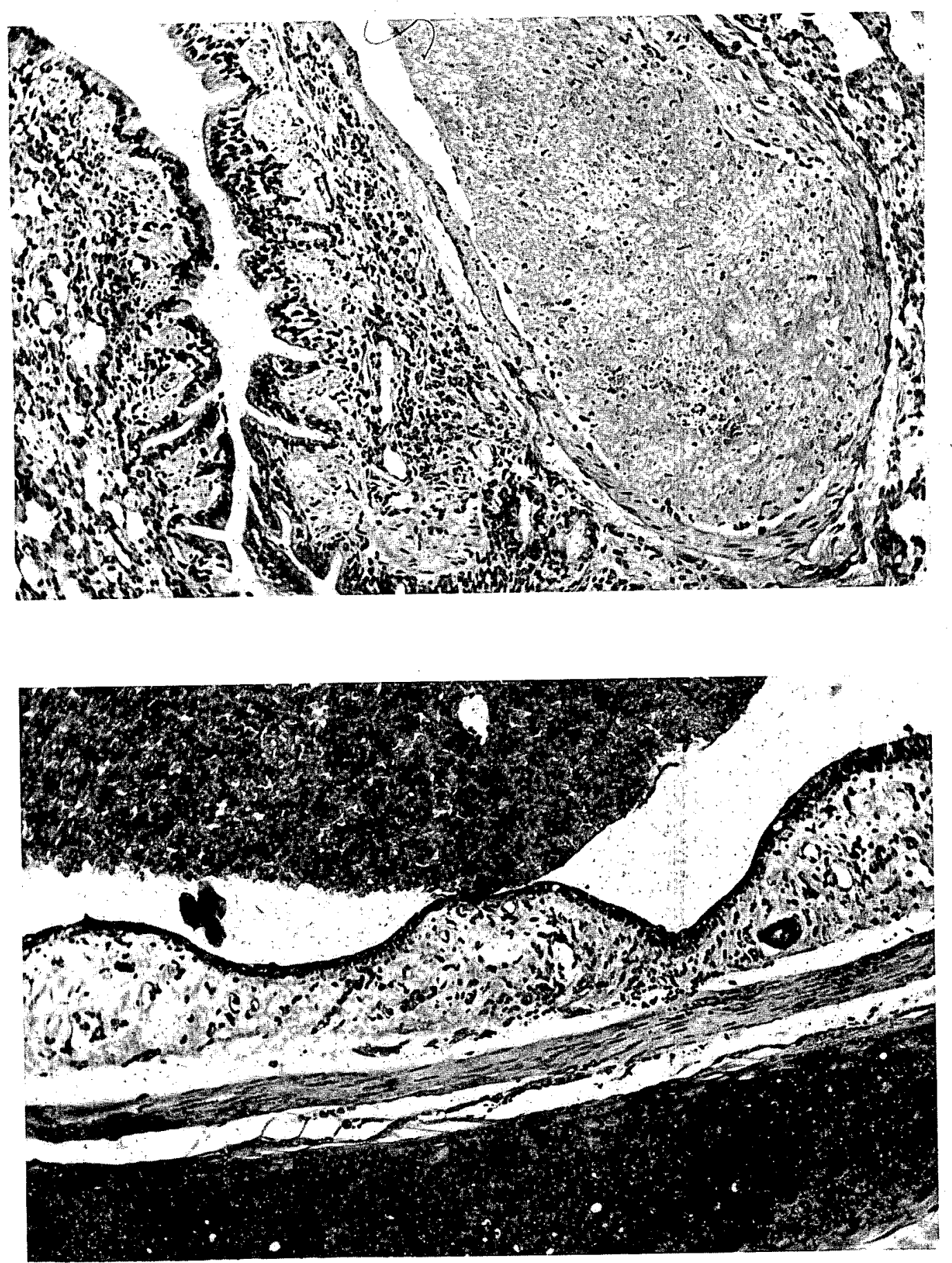

Fig. 3.9-Lung (microscopic), bronchial blood. Upper illustration: a recently formed thrombus partially fills a pulmonary vessel. This phenomena was found in only two of the animals. Lower illustration: large bronchus containing clotted blood in lumen. A mild inflammatory cell infiltrate is seen in the submucosa. 


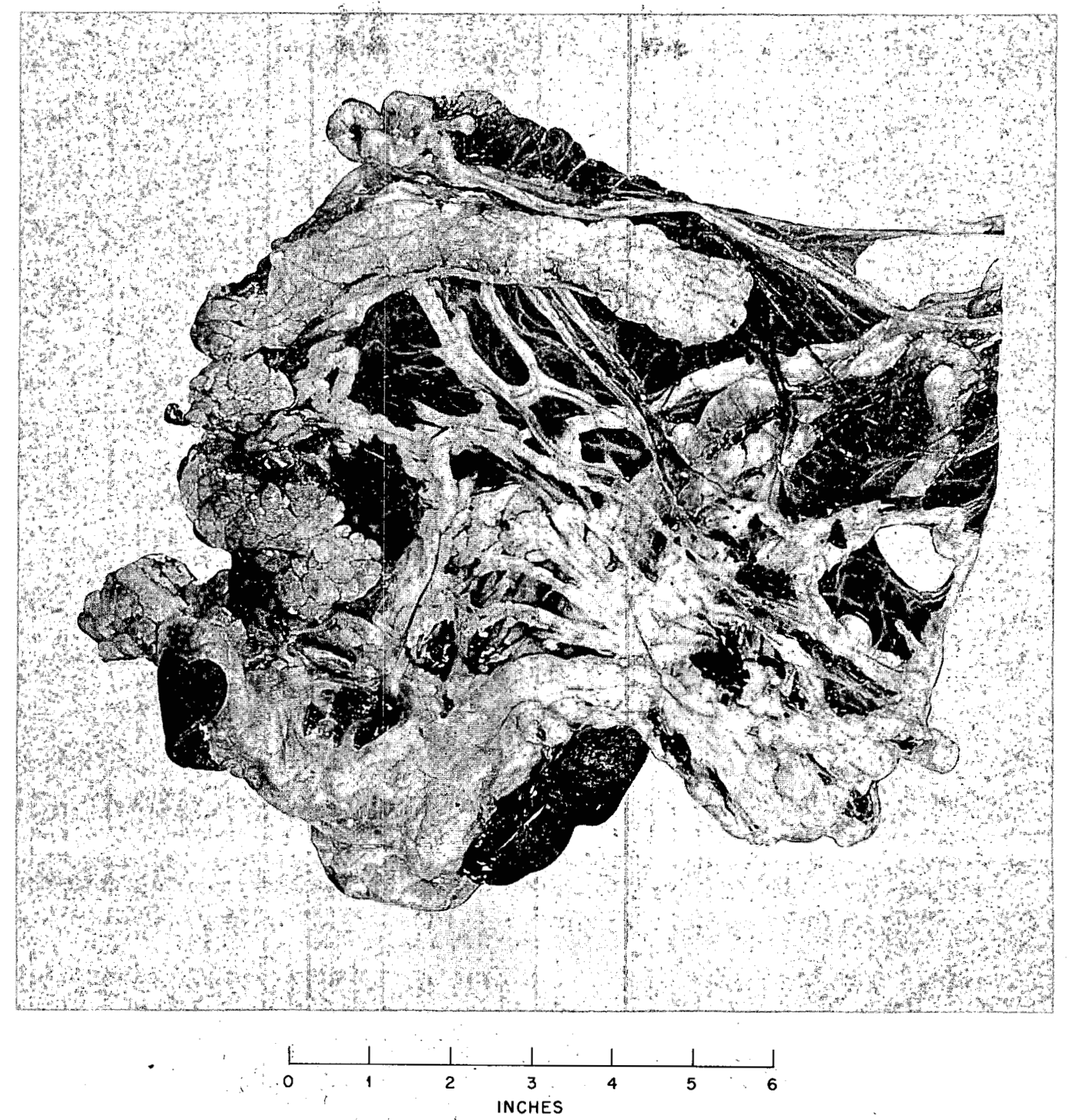

Fig. 3.10-Mesentery (gross), showing hemorrhages (animal D-4, position 601-7). 

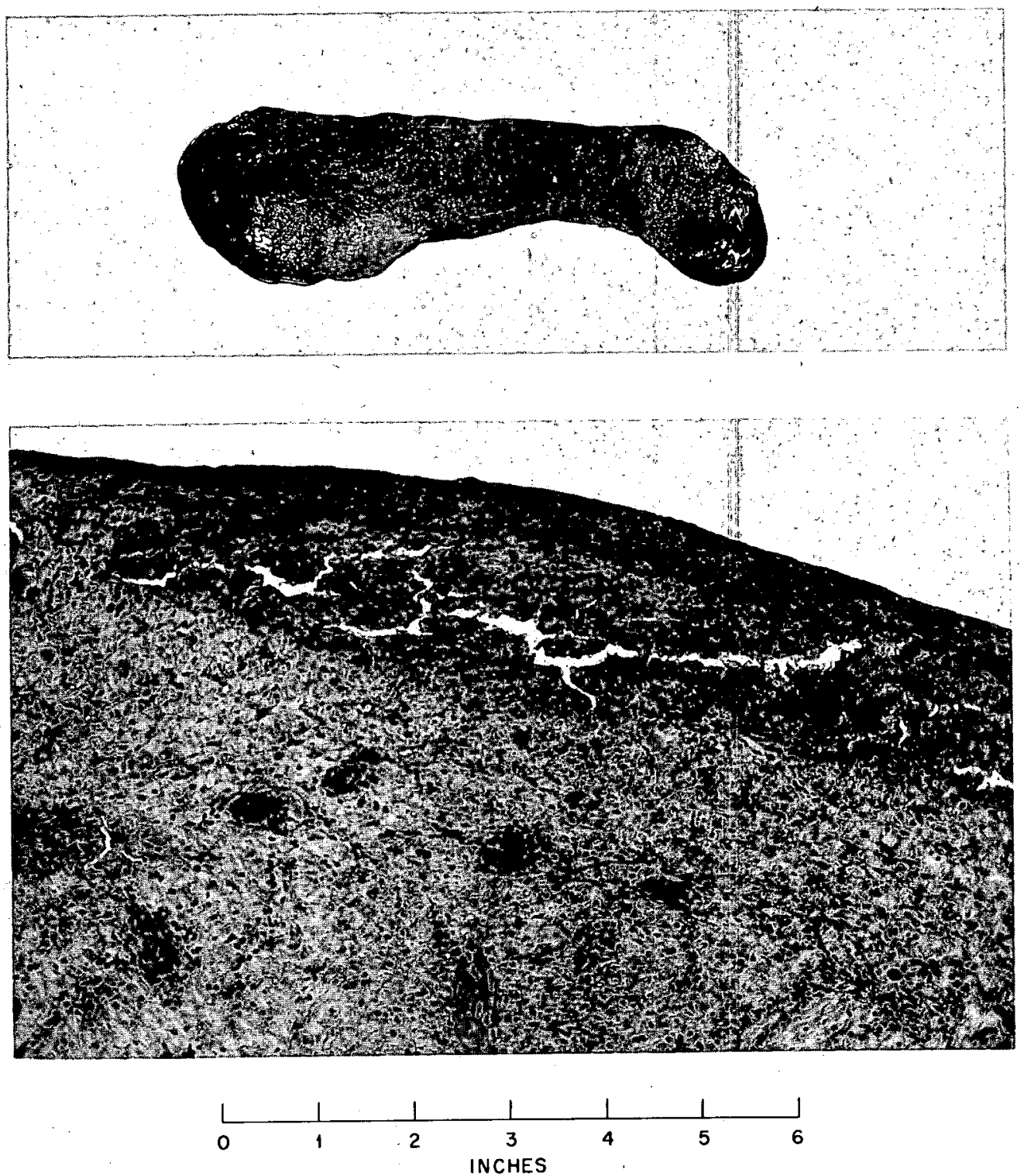

Fig. 3.11-Spleen (gross and microscopic), hemorrhages at poles (animal D-5, position 602-2). Upper illustration: spleen with dark-red hemorrhagic blebs at the poles. The capsule is mtact. Lower illustration: section through one of the contused areas of spleen. There is subcapsular tearing and almost all the illustrated pulp is a large pool of blood.

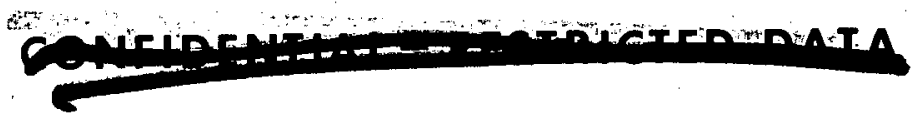



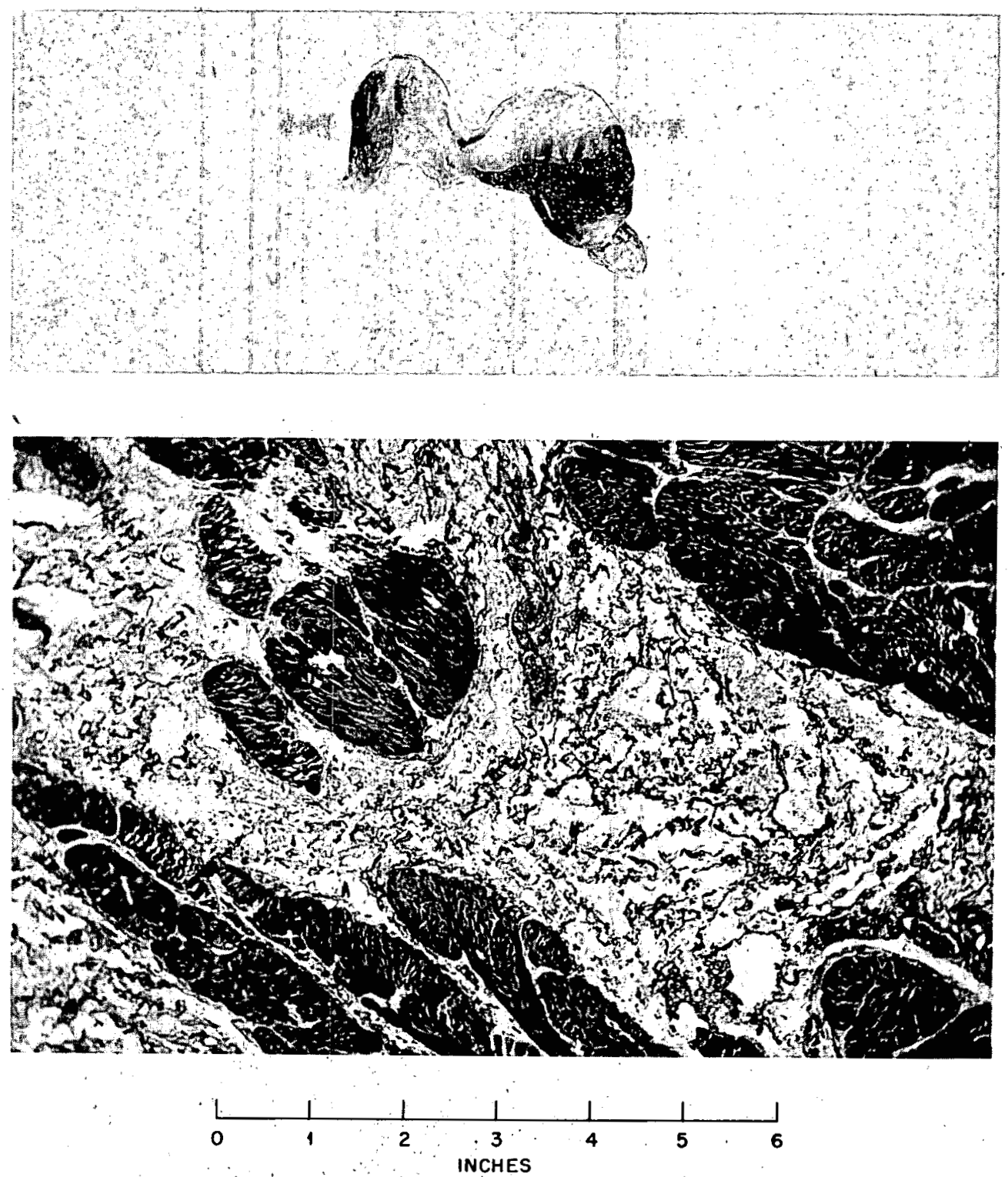

Fig. 3.12-Bladder lesion (gross and microscopic) (animal D-11, position 601-6). Upper illustration: urinary bladder opened. The large tear of the mucosa and wall extends across the specimen. The mucosal edges are separated and edematous clotted blood covers the base of the submucosa and muscularis. Lower illustration: cross section of muscularis showing separation of muscle bundles and interstitial edema. This section was made from margin of the laceration illustrated above.

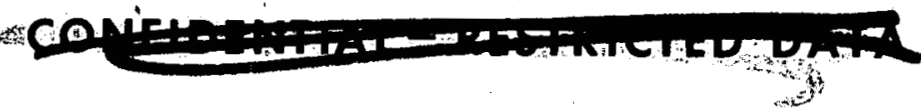




\subsection{DISPLACEMENT DATA}

\subsubsection{Displacement Data for Dummies, Shot 1}

Figure 3.13 is a graphic representation of the movement of the standing dummy in Shelter 601. It was not possible to measure relative motion beyond these ten readings (the first 38 msec of motion) because the entire field was obscured by thick dust. Although slight motion can be discerned in the sitting dummy, its position was hazy due to dust, and no reading could be considered accurate. The running speed of the Fastax camera was 263 pictures per second; $3.8 \mathrm{msec}$ elapsed between the beginning frame edges of any two consecutive frames, during the period in which data were obtained.

Physical evidence within the shelter indicated a rather violent displacement of the standing dummy: One of the quarter-inch eyebolts to which a restraining cable was attached (see Fig.

1.2) was bent open to the shape of an $S$.

The sitting dummy was found to have undergone a 4-ft displacement along the bench.

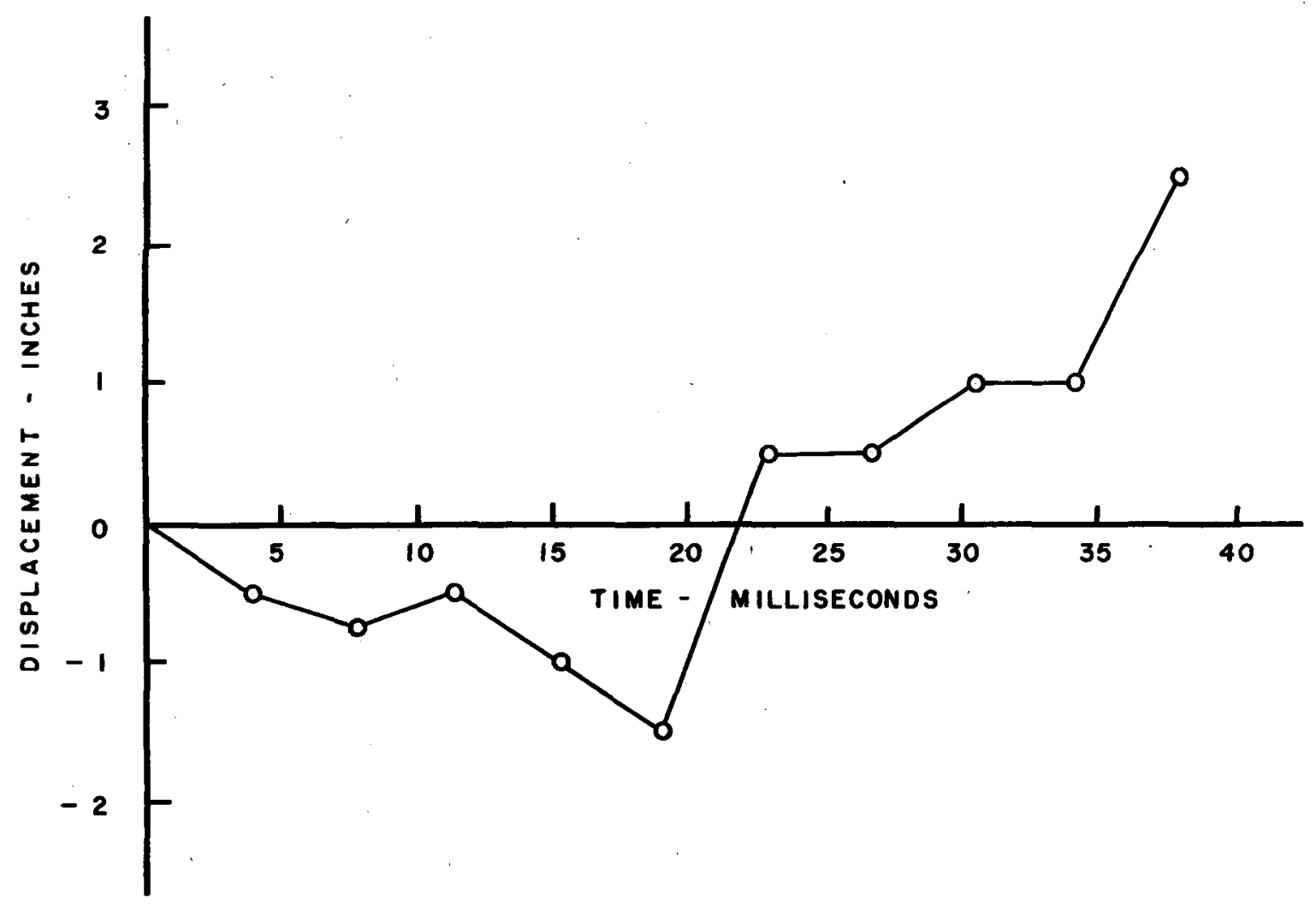

Fig. 3.13-Displacement vs time graph of standing dummy (Structure 601, Shot 1). This graph depicts the motion of the pelvic region of the standing dummy. Negative values appeared to be related to brief hip extension. Beyond $38 \mathrm{msec}$ the pictures were obscured by dust.

\subsubsection{Displacement Data for Dummies, Shot 8}

In Shelter 601 the standing dummy, although jarred off balance, appeared to merely topple over by the force of gravity. Dust did not appreciably obscure the photography in this instance, and the dummy remained in the camera field for $1.25 \mathrm{sec}$.

No final linear displacement was observed for the sitting dummy. The high-speed pictures indicated a swaying "downstream" of $4.8 \mathrm{in}$. in $0.19 \mathrm{sec}$ and a swaying "upstream" of $7.2 \mathrm{in}$. in

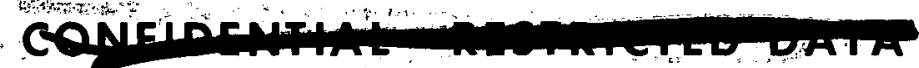


the next $0.36 \mathrm{sec}$ and return to original position. A total time for this motion was $0.62 \mathrm{sec}$. Some corrections of origtinal readings were necessary because of unavoidable spherical aberration in the lens.

Measurements of the suspended tag (used as an indicator of shock-wave arrival time and negative phase) were inconclusive since the tag was either in a shadow or obscured by dust during its initial period of travèl.

The running speed of the Fastax camera, during the time of motion, was 270 pictures per second.

\subsubsection{Displacement of Suspended Dog (Shelter 602, Shot 8)}

Figure 3.14 is a graphic representation of the movements of the suspended animal and of the paper tag in Shelter 602. The entrance of dust for a short interval after the shock-front

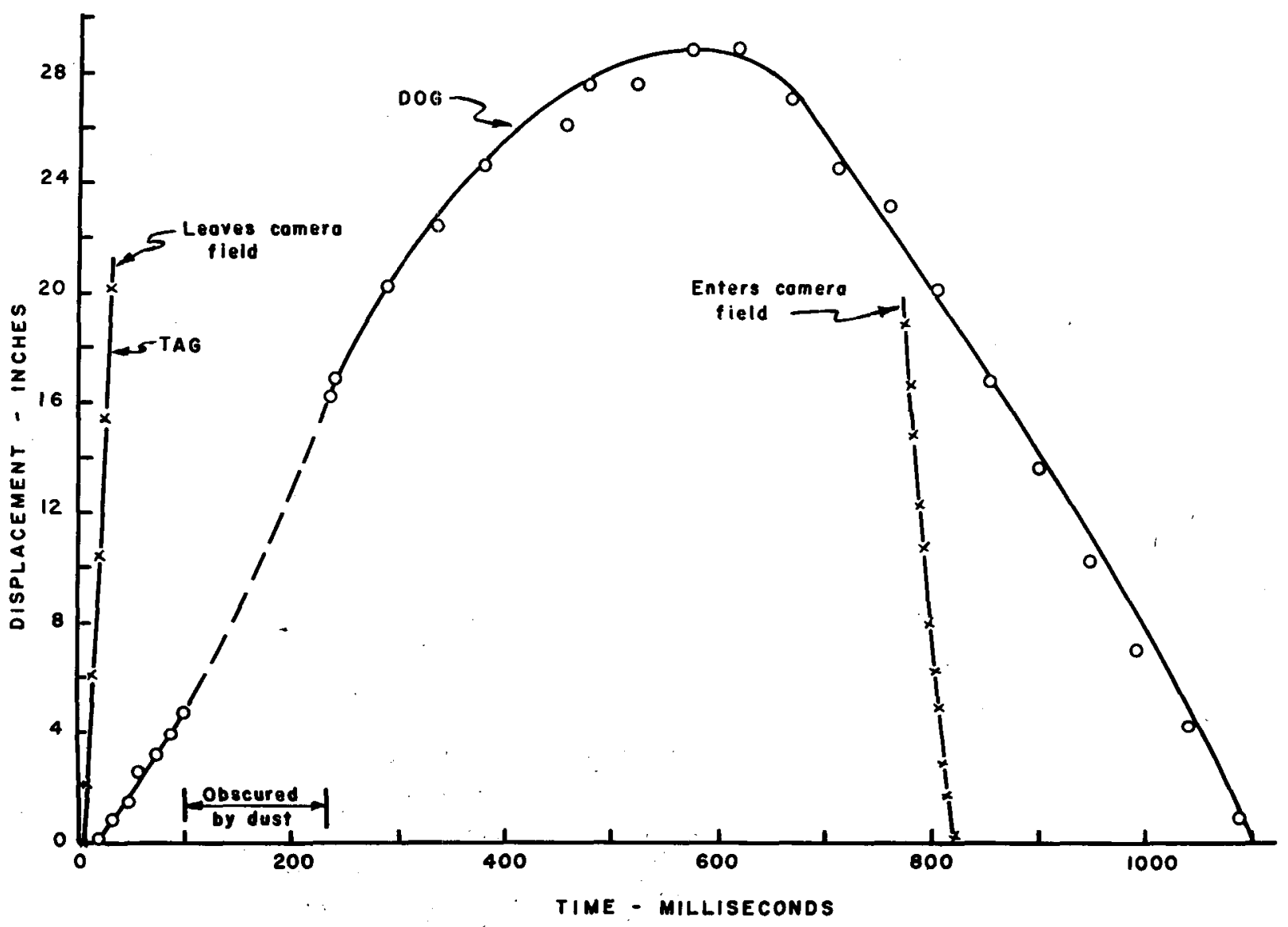

Fig. 3.14-Displacement vs time graph of suspended dog and tag (Structure 602, Shot 8). The relative motions of the suspended paper tag and dog illustrate the inertia characteristics of the animal mass. The air-drag forces were small in this instance (see Fig. 3.3).

arrival is responsible for a period of $32 \mathrm{msec}$ during which no data were obtained. Though the objects studied exhibited a slight pendulum motion, the vertical displacement was slight and would not appreciably change the horizontal displacement which was used as a basis of measurement.

The running speed of the Bell \& Howell camera was a constant 213 pictures per second, and the elapsed time between beginning consecutive frame edges was $4.7 \mathrm{msec}$. 


\subsubsection{Accelerometer Data}

The accelerometer records showed erratic fluctuations during Shots 1 and 8 , and the data were hence considered unreliable.

\section{REFERENCES}

1. B. F. Murphey, Outside Measurements for Upshot-Knothole Nos. 1, 8, 9, 10, and 11, Sandia Corporation Ref. Sym.: 5111 (88), July 1953.

2. E. W. Ruhl, AEC Shelter Instrumentation, Upshot-Knothole Project 24.3 Report, WT-790, 1953.

3. B. F. Murphey, Sandia Corporation, personal communication, 1953.

4. M. F. Clark and C. N. Kingery, Civil Effects Test Group Shelter Data, Upshot-Knothole 11, Ballistic Research Laboratories, Aberdeen, Md., 1953. 


\section{CHAPTER 4}

\section{ANALYSIS AND DISCUSSION OF RESULTS}

\subsection{REMARKS CONCERNING PHYSICAL DATA}

\subsubsection{Pressure Vs Time Phenomena}

During Shot 1 the shelters were in the precursor region, and hence "clean" shock fronts were not imposed upon the open ramps. The same situation existed in Shot 8 (see Table 3.2, gauges 8 and 17) and also in Shot 11. Consideration should be given to this fact in analyzing related pressure phenomena within the shelters and in comparing the field data with model studies.

In spite of the fact that gauges within the shelter proper (gauges 1 to 3 and 9 to 11) did not record rise times indicative of shock fronts, the blast waves appear to have traveled at essentially sonic velocity $(1 \mathrm{ft} / \mathrm{msec})$. For example, the distance between gauges 1 and 3 was $40 \mathrm{ft}$, and the difference in arrival times of the shock wave was $38 \mathrm{msec}$. The appearance of secondary static-pressure increases correlates, with respect to their time of occurrence, with a slightly greater velocity of travel for reflected waves. The most prominent secondary rises in Figs. 3.1 and 3.2, for example, begin in the neighborhood of 75 to $85 \mathrm{msec}$ after respective arrival times. One would assume that this principal secondary increase in pressure represented a reflection from the end of the shelter, and the distance of travel, namely about $96 \mathrm{ft}$ for a round trip, supports this contention. The occurrence times of these reflected waves are given further consideration in Sec. 4.1.2).

In addition to the reflected wave pattern noted above, a second general property exhibited by these blast waves within the shelters is of importance. As the waves entered the doorways considerable turbulence was probably present, but, in general, as the waves proceeded down the shelters a more sharply rising wave became evident. This may be noted from the initial rise rates in Tables 3.1 and 3.2 , for gauges 1 to 3 and 9 to 11 . Gauge 10, Shot 1 , seems an exception according to values in the table; however, in the actual trace the primary portion of the initial rise is considerably more rapid than that of gauge 11, Shot 1. Hence the waves behaved as would be expected from shock-tube studies, namely, to progressively present a more sharply rising front in traveling down the tube (the shelter).

It is important to note that gauges 4,12 , and 14 (in Shelters 601 and 602 , Shots 1 and 8 ) and gauge 18-C (in Shelter 7.1b, Shot 11) were directly facing the oncoming blast wave. Data from these gauges, therefore, must be considered as representing a reflected type of pressure phenomena. In contrast the remaining gauges in 601 and 602 were flush mounted parallel to the direction of blast-wave propagation and thus recorded static-pressure phenomena.

\subsubsection{Remarks Concerning Drag Data}

Arrival times for the material velocity (see Fig. 3.3) corresponded within a few milliseconds to respective arrival times of the blast. wave, as would be expected.

The striking fluctuations in the drag record of 601, Shot 1 (17 March 1953), undoubtedly bear relations to reflected wave effects. The sharp decrease noted at $400 \mathrm{msec}$ seems clearly

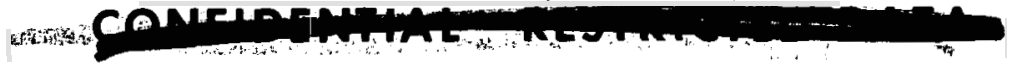


to be due to the reflection of the original wave from the end of the shelter and corresponds to the proper transit time for this reflected wave. The earlier portions of the curve do not seem to be as immediately related to reflection phenomena in the entrance way and blast trap.

\subsection{CORRELATION OF BIOLOGICAL FINDINGS WITH PHYSICAL DATA}

Several characteristics of the overpressures imposed upon the animals appear to be important. Variations in these physical characteristics, therefore, were considered in terms of respective variations in the degree of biological blast damage. Although the correlation of physical and biological data does not allow very precise critical values to be assigned to the physical parameters, either alone or in combination, several correlative aspects of the data afford important information relative to blast damage.

The following properties of the overpressure waves were considered with reference to their importance in producing the injuries found:

1. Presence or absence of a shock front.

2. Variations of pressure rises with respect to time.

3. The magnitudes of the overpressures.

4. The durations of the overpressures.

5. The material velocity or air drag.

6. The magnitude and duration of the underpressures.

During Shot 1 , gauges 4 and 13 recorded pressure rises in less than $1 \mathrm{msec}$, and theserises may represent shock fronts (see Sec. 3.1.1). Hence dogs D-5 and D-9 may indeed have been exposed to shock fronts. These animals, however, were slightly and moderately injured, whereas several other dogs were severely damaged at locations where shock fronts did not exist (Tables 3.1 and 3.5). Thus it may be concluded that with waves of this type shock fronts are not essential for biological blast damage.

As regards the magnitude of the static overpressure, it is significant to consider the relation between maximum or peak values and blast injuries. Since no damage occurred in Shot 8 , in which peak overpressures varied from 6 to $13 \mathrm{psi}$, it appears that pressures below perhaps 12 to 13 psi will not be associated with damage. This value, say 12 psi, is not to be regarded as an implicit minimum value, because an associated drag of high magnitude, for example, might incur damage at a somewhat lower static overpressure.

Because some animals (Shot 11) were exposed to static overpressures of 38 psi (Table 3.3) and suffered no damage, whereas others showed marked damage at 20 psi, it follows that maximum values of static pressure alone were not critical in causing these blast lesions.

In the data from the present tests, the duration of the positive pressure phase did not seem related to the extent of trauma. Durations in Shot 8 were considerably longer in most instances than were corresponding durations in Shot 1 (Tables 3.1 and 3.2), whereas in Shot 8 no pathological lesions were significant as contrasted to marked lesions in Shot 1 dogs. It should be pointed out, however, that for blast waves of very short duration (i.e., high explosive waves of a few milliseconds duration) much higher overpressures than 20 psi appear to be required for severe damage to larger animals. ${ }^{1,2}$

The magnitudes and durations of the underpressures in Shots 1 and 8 did not seem to be important variables in terms of the damage observed. Furthermore, the pathological character of many of the lesions would suggest a traumatic etiology; in other words, a rapid positive pressure loading of the animals rather than one of negative loading seems more conceivable as the primary etiological factor in these experiments.

Blast-wave characteristics discussed thus far have not yielded an adequate concept of parameters explicitly related to degrees of biological damage. The rate at which the animal is loaded, or the dynamic loading, appears to be a critical factor.

The phenomena exhibited by the blast wave within the shelter proper tended to produce a gradient of the rate of pressure increase. This was due to two properties of the waves discussed in Sec. 4.1.1: first the original wave tended to display a more rapidly rising front as it progressed down the shelter, and second the reflected wave (which essentially doubled the 
pressure) appeared very soon near the end of the shelter and progressively later as it traveled back toward the entrance. Hence the general rate of pressure increase became progressively greater from the entrance to the rear of the shelter. This generalization correlates with the definite trend in the pathological data which indicates more severe damage (especially in the lungs) for animals positioned closer to the rear of the shelter (note Table 3.5). This trend was obvious in both shelters during Shot 1. The data given in Tables 3.1 and 3.2 for rates of rise also support, in general, the relation of this loading rate to biological injuries.

In attempting to correlate the data from specific gauges and specific animals it is very important to consider the geometry of exposure of the particular gauge and animal combination. Animals for which the geometry of exposure seems to afford reliable data, for example, are D-11 near gauge 1 in Shot 1 and 601-11 and 602-17 near gauges 1 and 9 in Shot 8. Dog D-11 suffered severe damage following exposure to $11.5 \mathrm{psi}$ at a rate of $1.15 \mathrm{psi} / \mathrm{msec}$ and also to $19 \mathrm{psi}$ at a rate of $0.86 \mathrm{psi} / \mathrm{msec}$. Dog $601-11$, on the other hand, suffered no damage following exposure to $5 \mathrm{psi}$ at a rate of $0.17 \mathrm{psi} / \mathrm{msec}$. Likewise, dog $602-17$ suffered no damage following exposure to $10 \mathrm{psi}$ at the rate of $0.42 \mathrm{psi} / \mathrm{msec}$. It should be noted that these gauges recorded local static pressures.

Animal 9 in Shot 1 near gauge 4 presented an interesting exposure situation. Though he suffered grade 1 lung damage, it can be noted in Table 3.1 that he was exposed to 9 psi at a rate of at least $9 \mathrm{psi} / \mathrm{msec}$ (rise time $<1 \mathrm{msec}$ ) and to $20 \mathrm{psi}$ at a rate of $1.43 \mathrm{psi} / \mathrm{msec}$. Gauge 4, however, recorded a reflected type of pressure rise, and one may thus infer that the initial local static pressure was considerably lower and probably about half that of gauge 4 values (as indicated by gauge 5). The pressure rapidly increases, nevertheless, in the region of the animal, to a value near $20 \mathrm{psi}$ at a rate perhaps slightly less than $1.4 \mathrm{psi} / \mathrm{msec}$.

Animals in Shot 11 were exposed to initial pressure rises of about 15 psi at rates of about $1.2 \mathrm{psi} / \mathrm{msec}$ (or slightly less), according to the best available data. Judging from the Shots 1 and 8 data, the reason these animals suffered no significant blast damage is not apparent.

The work of Stapp ${ }^{3}$ on human deceleration showed a definite relation between the rate of deceleration and sign or symptoms. If the acceleration is considered from the viewpoint of forces imposed upon the body and parts of the body the following must in general apply:

$$
\mathbf{F}=\mathbf{m a}
$$

Thus, if $\mathrm{da} / \mathrm{dt}$ is considered, with $\mathrm{m}$ a constant, then

$$
\frac{d F}{d t}=m \frac{d a}{d t}
$$

Provided one defines proper surfaces, resulting in an assigned direction (or directions) to the pressures of the present experiments, the following must in general apply:

$$
\mathbf{F}=\mathbf{P A}
$$

where $A$ is a suitable reference area. Hence, if $\mathrm{dP} / \mathrm{dt}$ is considered, $A$ remaining constant,

$$
\frac{d F}{d t}=A \frac{d P}{d t}
$$

It therefore seems realistic to assume that biological damage resulting from applied forces is related to the rate of application of the forces as well as the total force in these, and undoubtedly other circumstances.

The drag is considered an important factor, in combination with the overpressure, for the production injuries: As indicated in Fig. 3.3, values were probably considerably greater in Shot 1 than in Shot 8. Since pressure rises were also of greater magnitude and rate in Shot 1 , it was not feasible to segregate the relative etiological importance of these factors in the present experiments. It may be significant to note here that the eyebolts to which animal D-15 was attached were bent in the direction of the entrance (note Fig. 1.4). The reflected pressure

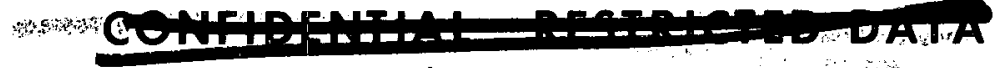


and material velocity from the first radiation cube were thus undoubtedly of considerable magnitude. This animal sustained severe lung damage (near the front of the shelter). By contrast, D-13 (Fig. 1.4) sustained only mild lung damage at the rear of the shelter, where the pressure was undoubtedly high and increased rapidly, but where the animal was exposed to a drag which was probably lower in magnitude and of shorter duration.

\subsection{ANALYSIS OF DISPLACEMENT DATA}

In Fig. 3.13 the velocity of travel (for the standing dummy during Shot 1), which is indicated in the final time-displacement interval, was considered a more reasonable value than an average of previous intervals. One supporting reason for this contention is the fact that the motion of the dummy lags behind the drag which reaches a maximum at about this time. (Note, for example, the relation of dog and tag motion in Fig. 4.1.) The velocity during this last interval of reliable measurement is about $125 \mathrm{ft} / \mathrm{sec}$. This velocity would be attained at the end of a free fall from a height of approximately $17 \mathrm{ft}$. Although these values are crude, they do allow some appreciation of the effective magnitude of the drag forces involved and the chances of traumatic injury.

Likewise the drag forces imposed upon a man in this situation may be estimated by reference to the relation

$$
\mathbf{F}=\mathbf{q A c _ { d }}
$$

where $F=$ the force imposed on the body

$q=$ the drag $\left(1 / 2 \rho V^{2}\right)$

$A=a$ suitable area of reference for the body

$c_{d}=$ the coefficient of the force (drag coefficient)

Two factors, namely $A$ and $c_{d}$, are not explicitly known for man. The mean projected area of the body, however, has been determined by Zuckerman, ${ }^{4}$ and the effective vulnerable area is estimated as $2.38 \mathrm{sq} \mathrm{ft}$. This may serve as a suitable area in the present force estimation. Considering, now, a drag of 3 psi (Fig. 3.3), the aerodynamic force becomes

$$
\begin{aligned}
F & =3(2.83 \times 144) c_{d} \\
& =1222 c_{d} \text { pounds }
\end{aligned}
$$

Hence the force imposed upon a man from a drag of 3 psi is remarkably high, even if the drag coefficient were given a value appreciably less than 1 .

The displacement characteristics of the suspended dog (Fig. 3.14) were not analyzed in detail. An important aspect of the relative motion of tag and dog, however, is the inertia exhibited by the dog. This factor, relative to force and motion, implies that the drag may contribute significantly toward deformation of an animal (and hence primary damage), as well as causing violent displacements (and thus secondary damage). No deformation could be discerned from the pictures of the animal studied, which was being exposed to a drag of $0.7 \mathrm{psi}$.

\section{REFERENCES,}

1. R. B. Fisher, P. L. Krohn, and S. Zuckerman, The Relationship Between Body Size and the Lethal Effects of Blast, Ministry of Home Security of Great Britain, Report R.C. 284.

2. H. De Saga, Blast Injuries, Chapter XIV-D, German Aviation Medicine, World War II, Department of the Air Force, U. S. Government Printing Office, Washington, 1950.

3. J. P. Stapp, Human Exposures to Linear Deceleration, U. S. Air Force Technical Report 5915, Part 2, 1951.

4. B. D. Burns and S. Zuckerman, The Wounding Power of Small Bomb and Shell Fragments, Ministry of Home Security of Great Britain, Report R.C. 350. 


\section{CONCLUSIONS}

\subsection{CONCLUSIONS REGARDING PRIMARY BLAST INJURIES}

The orientations of the shelters with respect to the direction of blast-wave propagation and the outside overpressures imposed upon the ramps were the two obvious principal aspects of the gross problem of determining overpressure conditions within the structures.

Blast damage of considerable severity was sustained by dogs in Shelters 601 and 602 during Shot 1. No significant damage was found in animals exposed in these shelters during Shot 8, and no blast lesions of major importance were found in the animals exposed in Shelter 9.1b during Shot 11.

It was not possible to determine, from the data of the present experiments, precise physical values which are critical to the etiology of blast injuries. Several important general conclusions, however, can be stated, namely:

1. Biological blast damage, of the primary type, may occur in dogs from overpressures of relatively low magnitude (in the neighborhood of 12 to $20 \mathrm{psi}$ ); when the durations of these overpressures are relatively long (several hundred milliseconds, as contrasted to durations of high explosive waves); whether or not shock fronts are present; when the rate of pressure increase is above some critical value (perhaps in the neighborhood of $0.4 \mathrm{psi} / \mathrm{msec}$ ); and the drag associated with the overpressures may be an important contributing factor.

2. Damage may fail to result from overpressures of higher magnitude (38 psi) and long duration even though the rate of pressure increase may be relatively rapid (perhaps 1 psi) msec). Precise reasons for the inconsistency have not been apparent.

- One might conclude from the present data that overpressure conditions with values below those given in item 1 might afford dogs safety from blast injury. (Such lower values were indeed associated with no damage during Shot B.) Further research is deemed advisable, however, to confirm or extend the validity of this conclusion.

Extrapolation of the present data from dog to man is not explicitly possible. The data might roughly hold, in a general way, for adult man; but if infants and children were considered the values might be grossly in error.

\subsection{CONCLUSIONS REGARDING BODILY DISPLACEMENT}

Rather violent displacements resulting in significant secondary traumatic injuries may be anticipated in Shelter 601 occupants under conditions similar to those of Shot 1 . The maximum drag value in this shelter during Shot 1 was about 3 psi. Air drag in 602 was unfortunately not determined during Shot 1 . A maximum safe drag value allowable cannot be assigned with certainty, but values of $q$ at least below $0.5 \mathrm{psi}$ would seem highly desirable.

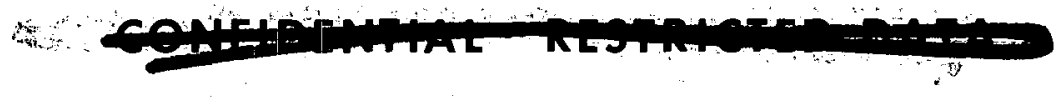


The general problem of the safety afforded by the 601 and 602 type shelters from the effects of overpressures involves consideration of present and anticipated future weapon yields and the location and orientation of the shelters with respect to probable burst sites. Such considerations greatly extend the complexity of the problem and may indeed prompt the contention that the safety of the present structures, with respect to primary blast and displacement injuries, is in considerable doubt. 


\section{CHAPTER 6}

\section{RECOMMENDATIONS}

Consideration should be given to the problem of improving the design of the 601 and/or 602 type shelters, such that a higher degree of safety is afforded with respect to primary-blast and displacement hazards.

Further research is necessary to better define the relations between the physical characteristics of blast waves and biological damage. 


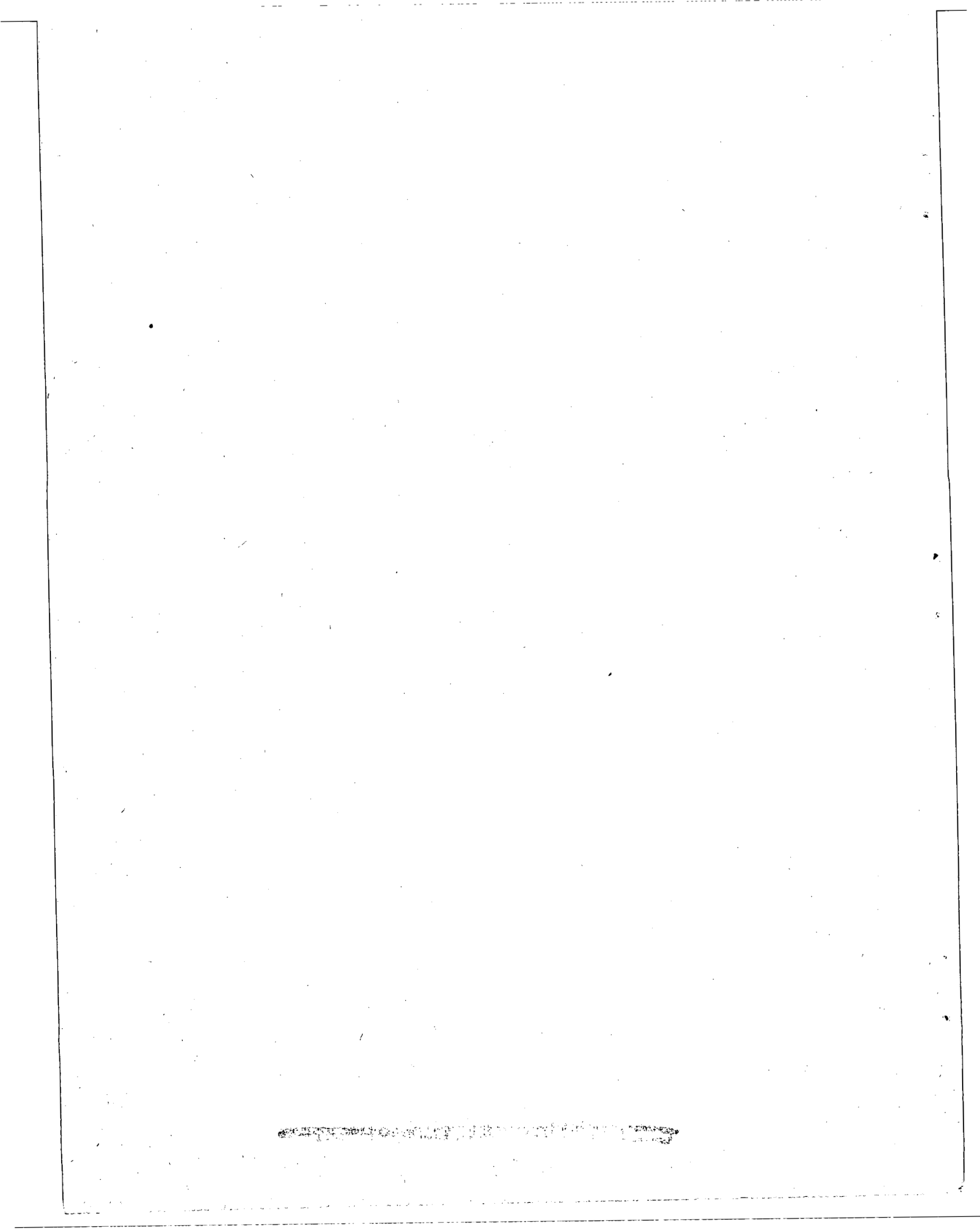




\section{APPENDIX A}

\section{LIST OF STRUCTURES EXAMINED AT AUTOPSY}

Skin and subcutaneous tissue

\section{Muscle}

Skeletal system

Head: scalp, brain, pituitary, sinus (including nasal), nasal structures, pharynx and tonsils, tongue, eyes, ears (middle and inner), salivary glands

Back: vertebrae (including bone marrow), spinal cord

Neck: trachea and esophagus, larynx and epiglottis, soft tissues, thyroid and parathyroids, lymph nodes

Extremities

Blood vessels

Chest: lungs, heart, mediastinal structures, intercostal muscles, ribs (including marrow), diaphragm

Abdomen: abdominal wall, liver and gall bladder, spleen, pancreas, lymph nodes, mesentery, omentum, gastrointestinal tract, adrenals, kidneys, ureters, urinary bladder, genital organs, back musculature, lumbar plexus 


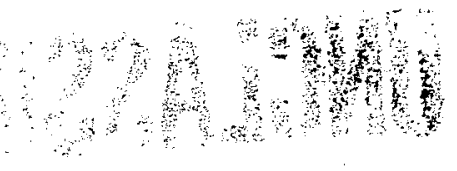

APPENDIX B

\section{CALCULATION SCHEME FOR GAMMA ATTENUATION}

Calculations for gamma-ray intensities, incident upon the camera region, were made for purposes of shielding the film. Conventionally employed absorption coefficients for earth and concrete were applied to the first order linear differential equation

$$
\frac{\mathrm{dI}}{\mathrm{dx}}=-\mu \mathrm{I}
$$

In addition, essentially complete scatter was considered after approximately $1 \mathrm{ft}$ of earth penetration. This gave intensities within the shelter much higher than actually measured by NBS film packs. Thus the minimum of $5 \mathrm{in.} \mathrm{of} \mathrm{lead} \mathrm{estimated} \mathrm{for} \mathrm{use} \mathrm{underground} \mathrm{to} \mathrm{shield} \mathrm{the}$ film on Shot 1 was probably considerably more than was necessary. It appeared that slant range calculations might have given a better approximation to intensity fall-off through earth in this situation.

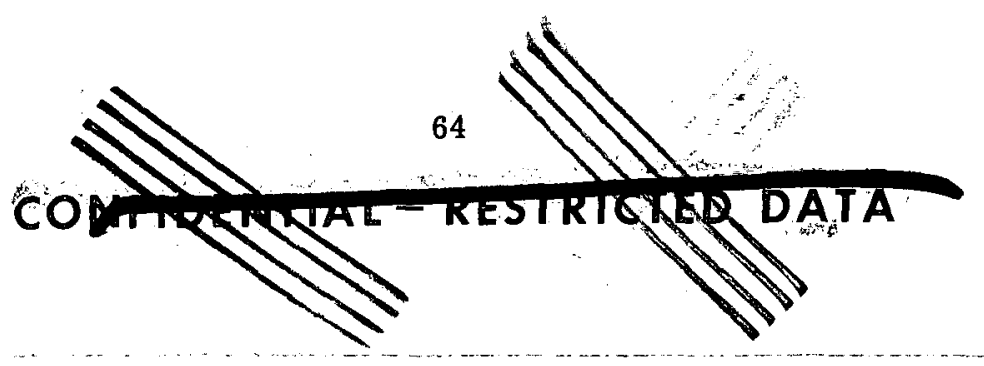




\title{
APPENDLX C
}

\section{CAMERA DATA}

\author{
SHELTER 601 (Shots 1 and 8)
}

Camera: 16-mm Wollensak Fastax

Lens: $6.1-\mathrm{mm}$ Wollensak $\mathrm{f} 1.5$ coated lens covering an angular field $63 \times 84^{\circ}$

Proposed speed: approximately 300 pictures per second

Running voltage: 12 volts d-c (supplied)

Film: Eastman Kodak Super XX Negative

Incident light reading: 960 foot-candles

Lens opening: $f 1.5$

Timing marks: 1000 cycle (supplied)

SHELTER 602 (Shot 8)

Camera: 16-mm Bell \& Howell 70-TA (72 ${ }^{\circ}$ shutter; motor driven)

Lens: $12.5-\mathrm{mm}$ Wollensak $f$ 1.5 coated lens covering an angular field $31.7 \times 41.6^{\circ}$

Proposed speed: approximately 200 pictures per second

Running voltage: 120, volts d-c (supplied)

Film: Eastman Kodak Negative Panchromatic Safety

Incident light reading: 1920 foot-candles

Lens opening: $f \mathbf{1 . 5}$

Timing marks: none 


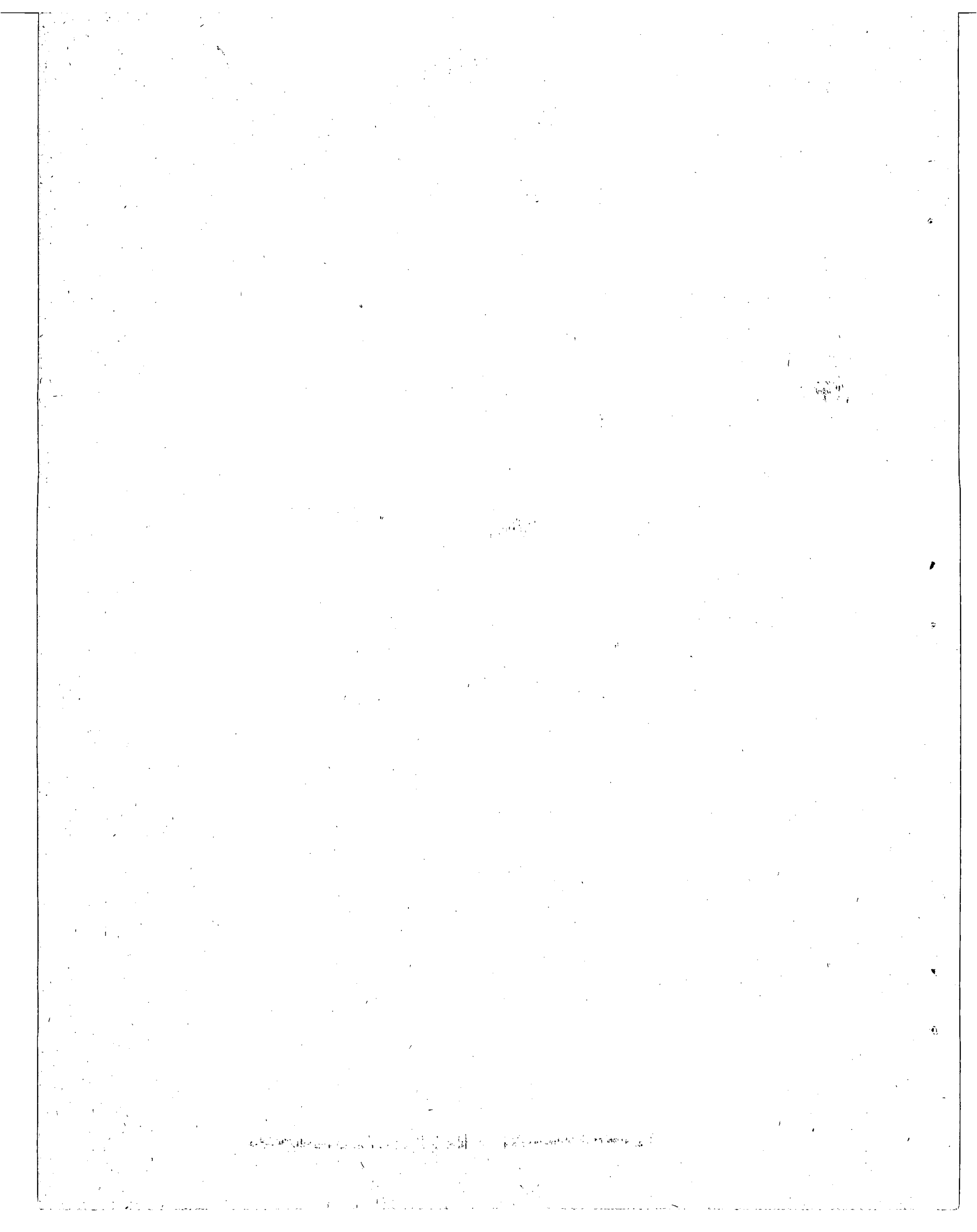

